\title{
THE RELATION OF TORQUE TO TENSION FOR THREAD-LOCKING DEVICES
}

\author{
By H. L. Whittemore, G. W. Nusbaum, and E. O. Seaquist
}

\section{ABSTRACT}

This investigation was made to determine, under static loads, the torsional resistance to unscrewing of nuts, with and without locking devicest and the relationships these torques bear to the stresses in the bolt. The torque required to produce a given stress in the bolt was also determined for each device.

Twenty-four manufacturers of thread-locking devices accepted the invitation to submit samples of their device for test and agreed to publication of the results.

A total of 41 devices were tested, including such devices as standard nuts, jam nuts, and slotted nuts with cotter pins. Only about one-quarter of these devices showed any appreciable difference in the static torque-tension relation from that of the American National coarse-thread standard nut.

\section{CONTENTS}

I. Introduction

II. Scope of the investigation 947

III. Specimens _._.

1. Devices_... 948

2. Bolts

3. Ordinary nuts

4. Vickers numbers

IV. Testing equipment.-1._. 960

1. Torque-tension machine... 960

2. Tuckerman optical strain gage._. 961

V. Preparation of specimens

VI. Measuring specimens

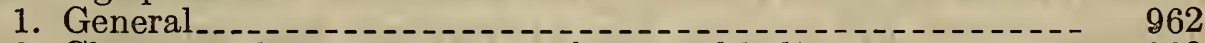

2. Clearances between threads of nut and bolt........ 963

3. Obliquity of face of nuts.

$\begin{aligned} & \text { VII. Method of test } \text { 1. Torque tension } \\ & \text { 2. }\end{aligned}$

1. Torque tension

VIII. Results_._._-_._- 967

1. General $\ldots$

2. Persy's theory

3. Clearance and obliquity of bearing face of nut.... 971

4. Devices....... 971

$\mathrm{X}$. Conclusions

\section{INTRODUCTION}

Screw threads are widely used to fasten parts of machines and structures. Where the parts are not subject to impact and vibration, a screw thread holds securely. However, where they are subject to impact, as in a railroad-track joint, or vibration, as in an automobile engine, ordinary nuts and bolts become loose and must be tightened frequently to prevent failure. For this reason devices are used to 
lock the screw threads. Thousands of patents have been issued for devices of this kind, and there are many now on the market.

The importance of this problem to the industries and the people of this country led the Bureau of Standards to undertake an investigation of methods of locking screw threads, to determine, if possible, the properties of different locking devices under conditions simulating those found in service.

A search through the technical literature gave very little information. In fact, no article bearing specifically on the problem of locking screw threads was found. No complete experimental investigation of the standard theory, developed by Persy ${ }^{1}$ for the effect of friction on the torque-tension relationship of ordinary nuts, was found, although a few authors ${ }^{2-9}$ have determined screwing-on torques for a number of regular nuts.

A few tests of thread-locking devices have been made by commercial organizations and the results used by them. A study of the reports of tests of this kind which were available showed none that could be used as a basis for generally valid conclusions, because in no case was an attempt made to measure the forces acting on the locking device during the test, or to evaluate the significace of the other variables which have an effect on the results. For example, if one locking device is used in an air hammer, then replaced by another device, the fact that one of the devices loosened and the other did not would not prove the superiority of the one which did not loosen unless the forces which acted on each device had been measured and found to be the same. An assumption that the forces were the same on both devices may lead to serious errors. The measurement of forces exerted upon a machine part subjected to impact and vibration is one of the most difficult problems in mechanical testing, and one for which, in many cases, methods and apparatus have not been developed.

A program for the investigation was therefore outlined, planned to analyze the forces acting on screw threads which tend to unscrew them and to study the behavior of different thread-locking devices subjected to the action of these forces under measured conditions. All known manufacturers of devices for preventing the unlocking of screw threads; that is, for preventing the rotation of the nut on a bolt-were invited to cooperate in this investigation by submitting samples of their devices.

Other things being equal, a locking device requiring a high torque to unscrew it would be expected to prove more satisfactory in service than one requiring a low torque. A part of this program, therefore, consisted of a study of the torque required to screw on and screw off each locking device under static conditions. Because the conditions

$1 \mathrm{~J}$. V. Poncelet, Frottement des vis et des écroux, Crelle's Journal, vol. 2, pp. 293-300, 1827. See also F. Grashof, Maschinenlehre (Voss, Leipzig, 1883), vol. 2, pp 265-276.

2 H. Camerer, Beiträge zur Schraubenberechnung, Zeits. des V. D. I., vol. 44, pp. 1063-65, Aug. 11. 1900.

3 Carl Stimson, Test of Track Bolts and Wrenches, Proceedings of the American Railway Association, vol. 17, pp 265-280, 1916.

- Oberhuber and A bele, Bolts for Use in Power Plant Construction, Mechanical Engineering, vol. 48, pp. 500-504, May, 1926.

$\checkmark$ George S. Case, Stresses on Bolts-Nut Dimensions-Wrench Design, Mechanical Engineering, vol. 48 , pp. 919-925, September, 1926.

4. W. Köhler, Anzugspannungen und deren bedeutung bei der arbeit der schraube, Bergmann Mitteilungen, vol. 4, pp. 223-229, November-December, 1926

7 Résistance et pose des vis et des boulons: proportions des écroux et des clés, Pratique des Industries Mecaniques, vol. 12, pp. 105-109, June, 1930.

K. Schimz, Eine neue statische schraubenprüfmaschine, Maschinenbau, vol. 9, pp. 573-575, Sept. 4, 1930.

Albert Kingsburg, Experiments on the Friction of Screws, Trans. Am. Soc. Mechanical Engineers, yol. 17, pp. 96-116; 1896. 
in these tests were more readily controlled and measured, this part of the program has been completed first.

The development of apparatus for determining the behavior of these devices under other measured conditions, particularly conditions more closely simulating those which occur in service, has made considerable progress, and additional reports will be published when data have been obtained which warrant publication.

This report is, then, the first of the reports on this investigation of devices for locking screw threads. It gives a drawing and description of each of the locking devices submitted by the cooperating manufacturers; a description of the apparatus and methods used fordetermining the relation between the screwing-on and screwing-off torques on the nut and the tensile stress in the bolt. The results of the tests are given in a series of curves, and some general conclusions have been drawn. A fuller coordination of the experimental results and theory will be attempted when the investigation has progressed further.

\section{SCOPE OF THE INVESTIGATION}

Forty-one devices were included in the investigation and are described in detail under III, Specimens. Twenty-four manufacturers submitted 33 locking devices from commercial stock. Some of these devices were ordinary ${ }^{10}$ nuts which had been modified, and one was an ordinary bolt which had been modified; that is, they had features not found in ordinary nuts and bolts. These will hereafter be referred to as "modified" nuts and "modified" bolts. Of these 33 locking devices 16 were modified nuts, one was a modified bolt, and two had a special thread for both bolt and nut. Fourteen were separate devices to be used with ordinary nuts, of which 10 were spring or lock washers. With all of these separate devices U. S. standard regular nuts were used.

In addition to the locking devices submitted by the manufacturers, the test program included the following ordinary devices: American National coarse-thread regular nut, American National fine-thread regular nut, each of these nuts with jam nuts, and American National fine-thread castellated nut with cotter pin. American National coarse-thread slotted or castellated nuts with cotter pins would have been included in the program if they could have been obtained commercially.

Because the older U. S. standard nuts are still extensively used there were also included tests on U. S. standard regular nuts, U. S. standard regular nuts with jam nuts, and U.S. standard slotted nuts with cotter pins.

As it was considered desirable to make all of the tests on devices of the same nominal size, all bolts had a nominal diameter of threefourths inch. This size was considered representative of the screw threads widely used in engineering work. For the same reason, all bolts had the American National right-hand coarse thread except those used with American National fine-thread nuts and with the two devices having a special thread.

The dimensions of the American National thread (coarse and fine) nuts and bolts are given in the Report of the National Screw Thread

10 American National and U. S. standard nuts will hereafter be referred to as "ordinary nuts" and American National bolts as "ordinary boits." 
Commission, Bureau of Standards Miscellaneous Publication No. 89, and those of the U. S. standard thread in the Report of the Special Committee on a Uniform System of Screw Threads, Journal of the Franklin Institute, volume 49, pages 53-57, 1865 (adopted March 16, 1865, l. c., p. 280).

The $3 / 4$-inch American National coarse thread has 10 threads per inch. The regular nut is $21 / 32$ inch thick and $1 \frac{1}{8}$ inches across flats of the hexagon. The jam nut is $7 / 16$ inch thick. The American National fine thread has 16 threads per inch. The regular nut and the jam nut are the same sizes as the coarse-thread nuts.

The U. S. standard thread, like the American National coarse thread, has 10 threads per inch, but the regular nut is larger, being $3 / 4$ inch thick and 1\%4 inches across the flats of the hexagon. The U.S. standard does not prescribe the dimensions of jam nuts. The jam nut was, therefore, made $7 / 16$ inch thick, the same as for the American National nut. The differences between the American National coarse thread and the U.S. standard thread are so small that a U.S. standard nut may be used on an American National coarse-thread bolt.

\section{SPECIMENS}

\section{DEVICES}

To each device a symbol was assigned, viz: $I, I I$, .III, etc., for nonproprietary devices; $\mathrm{A}, \mathrm{B}, \mathrm{C}$, etc., and $\mathrm{AA}, \mathrm{BB}, \mathrm{CC}$, etc., for proprietary devices; of these the devices designated by double letters were spring washers.

A description (and for the devices designated by letters a drawing to scale) of each device follows. Unless otherwise noted in the description, the device was made of steel.

Device $I$ was an American National coarse-thread regular nut.

Device $I I$ was a U. S. standard regular nut.

Device III was an American National fine-thread regular nut.

Device $I V$ was an American National coarse-thread regular nut and a jam nut.

Device $V$ was a U. S. standard regular nut and a jam nut.

Device VI was an American National fne-thread regular nut and a jam nut.

Device VII was a U. S. standard slotted nut and a cotter pin, $1 / 8$ inch in diameter. The slots in the nut were $3 / 16$ inch wide and $1 / 4$

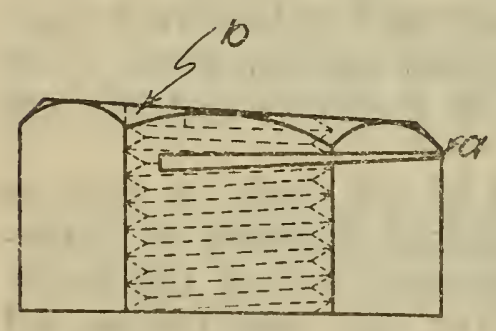

$A$

Figure 1.-Device $A$ inch deep.

Device $V I I I$ was an American National fine-thread castellated nut and a cotter pin, $1 / 8$ inch in diameter. The slots in the nut were $5 / 32$ inch wide and $1 / 4$ inch deep. The width across the flats of the hexagon measured 11116 inches, being less than the standard dimension, which was $1 / 8$ inches.

Device A, Figure 1, was a U. S. standard nut, slotted and then permanently deformed so as to close the slot at $a$. One thread had been removed at $b$ for an arc of approximately $60^{\circ}$. When the device was screwed on a standard bolt, the slot in the nut was forced open at $a$, causing the threads in the nut to exert forces upon the threads of the bolt, which increased the frictional resistance to rotation of the nut. 
Device B, Figure 2, was a bolt and nut having a special thread, eight threads per inch. The sides of the threads were symmetrical and had an included angle of $29^{\circ}$, the same as the Acme thread. The surfaces at the major diameter of the bolt and nut were cylindrical. The surfaces at the minor diameters were tapered, forming a screw helicoid having a small angle with the axis, hereafter referred to, for simplicity, as helical cones. When the nut was screwed on the bolt it had the

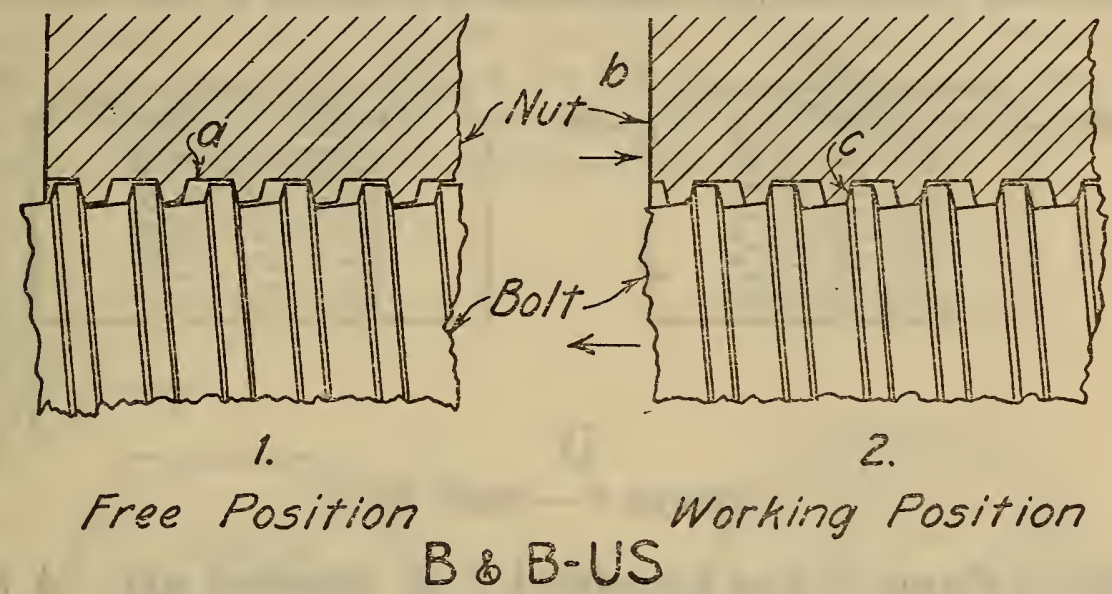

Figure 2.-Devices $B$ and $B-U$. S.

position shown at 1 , there being a space, $a$, between the threads of the bolt and the nut. In this position the nut rotated freely. When the nut was tightened, the force on the bearing face, $b$, of the nut first brought the helical cones together, then increased the elastic compression on these cones until the thrust faces, $c$, came into contact. When the stress in the bolt reached the working value, much of the load was carried by these thrust faces of the threads. The helical cones in the nut exerted compressive forces on the cones on the bolt, increasing the frictional resistance of the nut to rotation.

The nuts were $27 / 32$ inch thick and $1 \frac{1 / 8}{8}$ inches (the same as American National) across the flats of the hexagon.

Device B-U. S., Figure 2, was identical with B except that the nut was $1 \frac{1}{4}$ inches (the same as U. S. standard) across the flats of

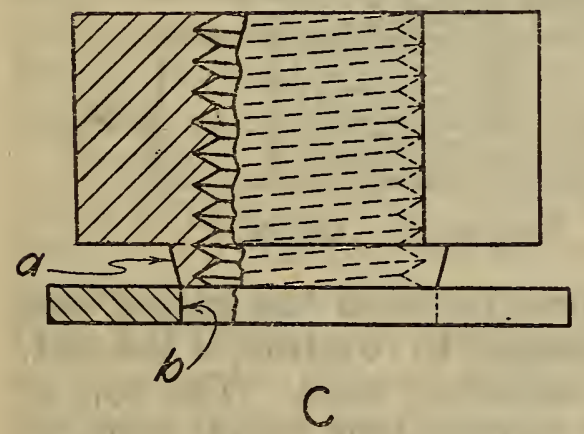

Figure 3.-Device $C$ the hexagon.

Device C, Figure 3, consisted of a malleable iron nut and a punched steel washer. The nut had a conical projection, $a$, extending from its bearing face. The small diameter of this cone fitted in to the bore of the washer, $b$. As the nut was tightened, the conical projection was forced into the washer, thereby compressing the cone and increasing the forces exerted by the threads in this portion of the nut on the threads of the bolt. Thus the frictional resistance of the nut to rotation was increased. Except for the threads, the nut was not machined. The nut was $29 / 32$ inch thick over all and $1 \frac{1}{4}$ inches across the flats of the hexagon. 
Device D, Figure 4, was a modified U. S. standard nut with two diametrically opposite radial slots, $a$. The nut had been permanently deformed by compressive forces having the action lines, $b-b$. When the device was screwed on a standard bolt it rotated freely until the deformed portion of the nut reached the end of the bolt. Continued rotation forced the deformed threads of the nut against the bolt threads. The forces which these deformed threads exerted on the bolt increased the frictional resistance to rotation of the nut.
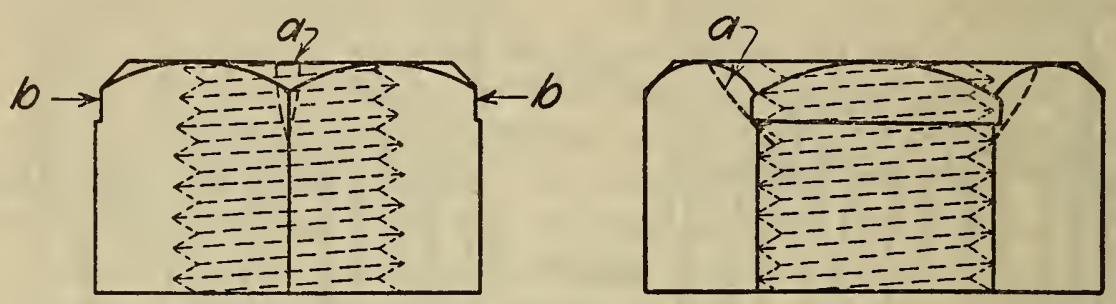

D

Figure 4.-Device D

Device E, Figure 5, was a modified U. S. standard nut. A helical spring, $a$, having about two coils of steel wire 0.081 inch diameter, was placed in a recess in the bearing face of the nut. One end of the spring was bent parallel to the axis of the coil and inserted in a hole, $b$, at the bottom of the recess to prevent rotation of the spring with respect to the nut. When the nut was screwed on a standard bolt, the bolt first engaged the coil spring and then the thread of the nut. The frictional forces between the spring and the bolt increased the diameter of the spring as the nut was screwed on the bolt. If the nut was unscrewed, the frictional forces decreased the diameter of the

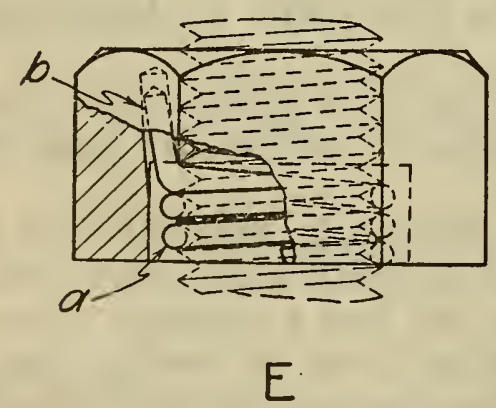

Figure 5.-Device $E$

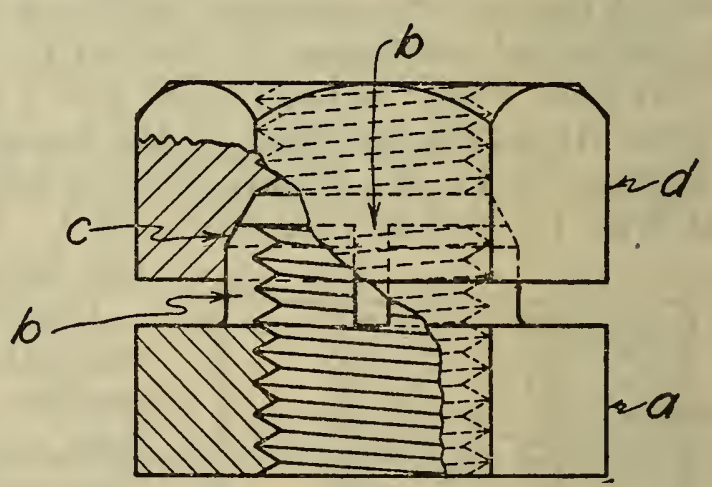

FIgURE 6.-Device $F$

spring, thus increasing the frictional forces between the spring and the bolt and increasing the frictional resistance to rotation of the nut.

Device F, Figure 6, consisted of two separate nuts. The top of the first nut, $a$, consisted of a cylinder having four radial slots, $b$. The top end of the cylinder had a conical surface, $c$. The jam nut, $d$, had a conical recess in its bearing face. Nut $a$ was first screwed on the bolt and tightened. Nut $d$ was then screwed on the bolt and tightened. The forces exerted at $c$ by the tapered recess in nut $d$ on the conical portions of nut $a$ increased the forces exerted by the threads in the cylindrical portion of nut $a$ upon the threads of the 
bolt and increased the frictional resistance to rotation of the nuts. Both nuts were $1 \frac{1}{4}$ inches across the flats of the hexagons. The thickness of the first nut was ${ }^{13} / 16$ inch over all and that of the jam nut $5 / 8$ inch. The recess in the jam nut was $5 / 16$ inch deep. The total thickness of threaded portions of the two nuts was $1 \frac{1}{8}$ inches.

Device G, Figure 7, was a modified U. S. standard nut. The top had a hole, $a$, in which a pin, $b$, was a tight fit. The portion of the pin which projected from the top of the nut was bent toward the axis of the nut until it was parallel to the top. When the nut was screwed on a bolt, the projecting end of the pin was deflected by the threads on the bolt. When the nut was unscrewed, the pin acted as a pawl, increasing the resistance to rotation of the nut.

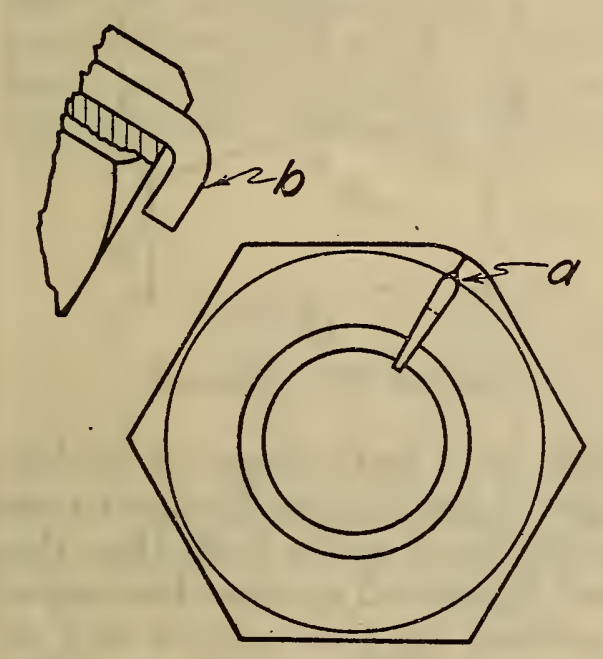

G

Figure 7.-Device $G$

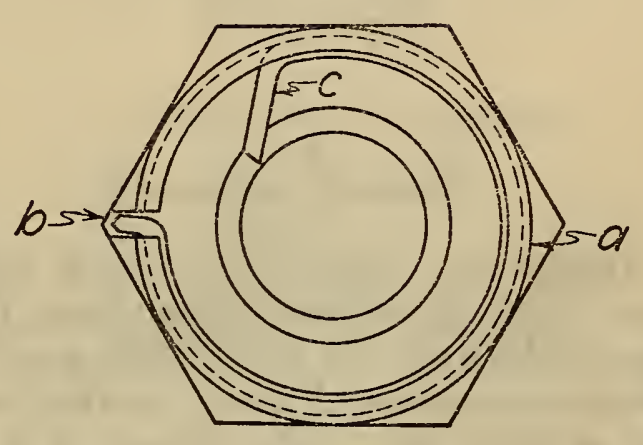

$H$

FIGURE 8.-Device $H$

Device $\mathrm{H}$, Figure 8 , was a nut with an annular groove, $a$, in a recess in the top. The wall of the recess had a radial slot, $b$. A wire spring, $c$, was sprung into the groove, $a$. One end of the spring was bent radially outward and was restrained by the slot, $b$, and the other end was bent inward to engage the bolt thread. When the nut was screwed on the bolt, the inner end of the spring was deflected outward by the threads of the bolt. When the nut was unscrewed, the spring acted as a pawl, increasing the resistance to rotation of the nut.

Device I, Figure 9, was a jam nut made from sheet steel 0.043 in. thick having a conical portion, $a$, the inner edge of which was a single thread, $b$. There were six radial slots, $c$, in the inner edge. After a regular nut was tightened on the bolt this device was screwed on the bolt and tightened against the top of the regular nut. The forces, exerted by the threads of the bolt on the thread of this device, deflected the segments of the thread inward against the roots of the bolt threads, increasing the frictional resistance to rotation of the nut. The distance across the flats of the hexagon was $1 \frac{332}{32}$ inch.

Device J, Figure 10, was a special nut having a shallow $V$-shaped groove, $a$, extending diametrically across the bearing face. A deeper and narrower groove, $b$, parallel to $a$, extended diametrically across 
the top. The nut rotated freely on the bolt until the bearing face came into contact with the part to be clamped. Tightening the nut caused forces to be exerted at $c-c$ in the direction of the arrows. These forces deformed the nut and increased the frictional resistance to rotation of the nut. The nut was $1 \frac{11}{16}$ inch thick and $1 \frac{1 / 4}{4}$ inches across the flats of the hexagon.

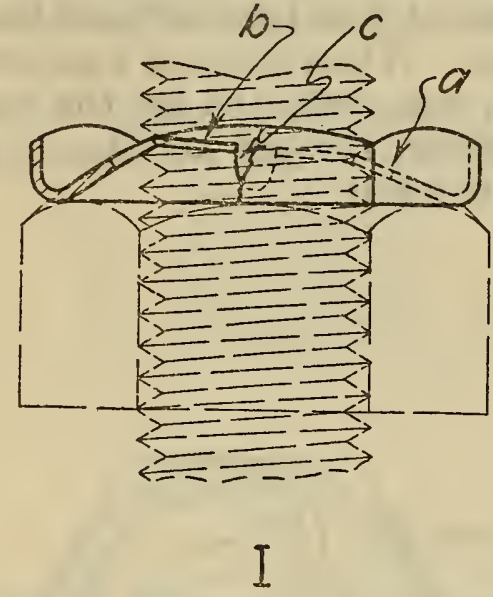

FIGURE 9.-Device I

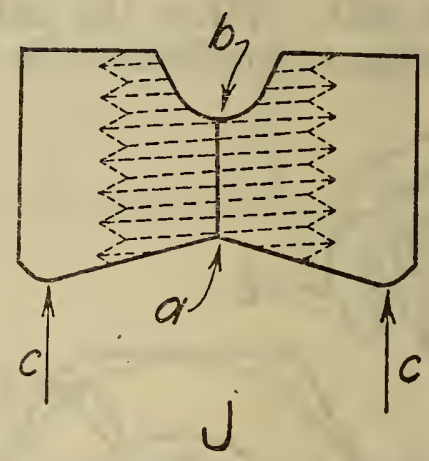

FIGURE 10.-Device $J$

Device K, Figure 11, was a thin jam nut, both faces of which, $a-a$, were cylindrically concave, the axes being perpendicular to the axis of the nut. A regular nut was first tightened on the bolt, then this device was screwed freely on the bolt and tightened against the top of the regular nut. The forces at $b-b$ exerted by the regular nut on this device deformed it, thereby increasing the forces at $c-c$ upon the bolt threads. These latter forces increased the frictional resistance

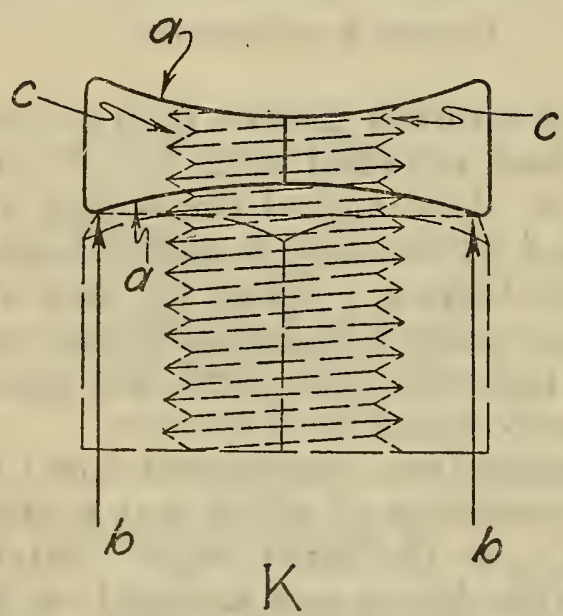

Figure 11.-Device $K$

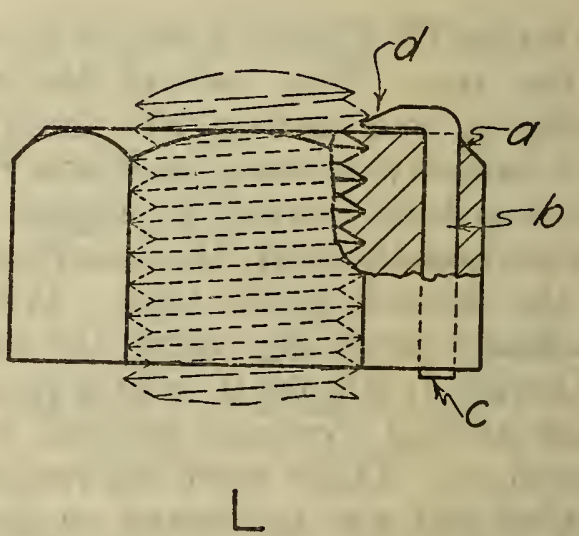

FIgdRE 12.-Device $L$

to rotation of this device. The nut was $1 \frac{1}{4}$ inches across the flats of the hexagon. The thickness at the outer edges was $7 / 16$ inch. The minimum thickness was $3 / 16$ inch.

Device L, Figure 12, was a modified American National coarsethread nut having a hole, $a$, parallel to the axis. A pin, $b$, was a snug fit in this hole. The end, $c$, of this pin projected 0.01 to 0.02 inch from the bearing face of the nut and the other end, $d$, extended inward, 
radially, to the minor diameter of the threads of the nut. When the nut was screwed on the bolt, it rotated freely until the end, $c$, of the pin came into contact with the part to be clamped. As the nut was tightened, the pin was pushed toward the end of the bolt, causing the end, $d$, of the pin to exert forces on a thread of the bolt, which increased the frictional resistance to rotation of the nut.

- Device M, Figure 13, was a modified U. S. standard nut with a hole, $a$, in the bearing face, parallel to the axis. This hole had a counterbore at $b$. A hardened taper pin, $c, 0.122$ inch diameter at the outer edge, was a snug fit in the hole, the end, $d$, extending 0.03 to 0.04 inch beyond the bearing face of the nut. When the nut was screwed on the bolt it rotated freely until the end, $d$, of the pin came into contact with the part to be clamped. Further tightening of the nut deflected the pin until the face of the nut came into bearing. The force exerted by the pin in its deflected position increased the resistance to rotation of the nut.

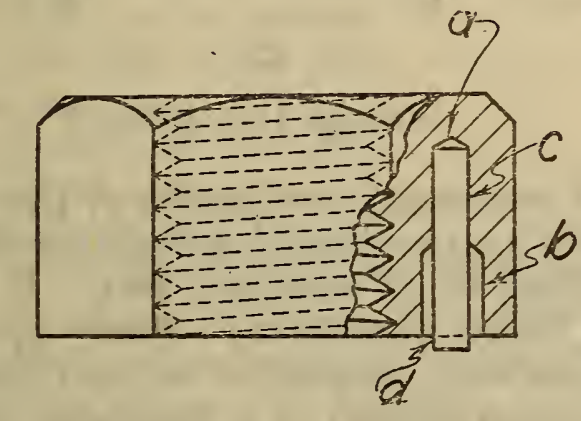

$M$

'FIgURE 13.-Device $M$

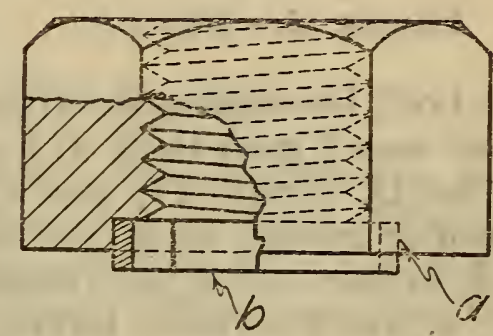

N

Device N, Figure 14, was a modified U. S. standard nut with a cylindrical recess, $a$, in the bearing face. A soft copper ring, $b$, formed from a rectangular strip with butted ends, fitted into the recess and extended beyond the face of the nut. The inner diameter of the ring was slightly larger than the bolt. When the nut was screwed on the bolt it rotated freely until the ring came into bearing with the part to be clamped. Further tightening of the nut deformed the ring, which flowed into the bolt threads. The forces exerted by the ring on the bolt threads and on the recess in the nut increased the frictional resistance to rotation of the nut.

An alternative method of using this device is to screw it on the bolt so that the recess and copper ring are in the outer face. After the nut is tightened, the ring is deformed by a suitable tool and hand hammer. This method was not used in this investigation.

Device O, Figure 15, was a modified U. S. standard nut with a slot, $a$, which extended $1 / 8$ inch beyond the axis. The bearing face was beveled so that the greatest thickness of the nut was along the outer edge of the slot at $b$. As the nut was tightened on the bolt, a force was exerted at $b$ in the direction of the arrow, bending the portion of the nut below the slot, thereby increasing the forces on the threads of the bolt. These forces increased the frictional resistance to rotation of the nut. The thickness of the nut at $b$ was $3 / 4$ inch and at $c$ was $5 / 8$ inch. 
Device P, Figure 16, was a modified U. S. standard nut with two parallel slots, $a-a$, one in each of two opposite sides of the hexagon, extending to the minor diameter of the threads. There was a shallow V-shaped groove diametrically across the bearing face in such a position that the thickest portions, $b-b$, of the nut were along the open edges of the slots. When the nut was tightened on the bolt, forces were exerted at $b-b$ in the direction of the arrows which deformed the nut and increased the forces which the threads in the nut exerted

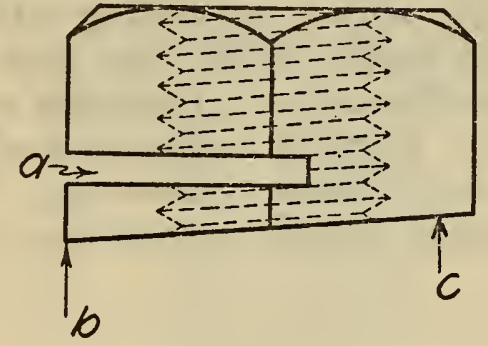

O

FigURE 15.-Device $O$

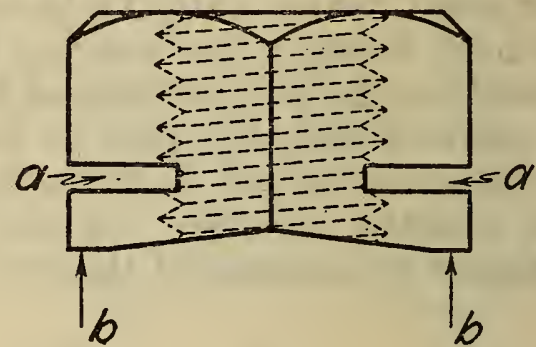

$P$

Figure 16.-Device $P$

on the bolt, increasing the frictional resistance to rotation of the nut. The nut was $3 / 4$ inch thick at $b$ and $11 / 16$ inch midway between the slots.

Device Q, Figure 17, was a modified U. S. standard nut. It had an annular recess, $a$, in the top. There were three equally spaced slots, $b$, in the wall of the recess, which were tangential to the threads. A key, c, was provided, having the cross section of a truncated equilateral triangle whose height was 0.117 inch and whose width of base was 0.131 inch. After the nut was screwed on the bolt and tightened,

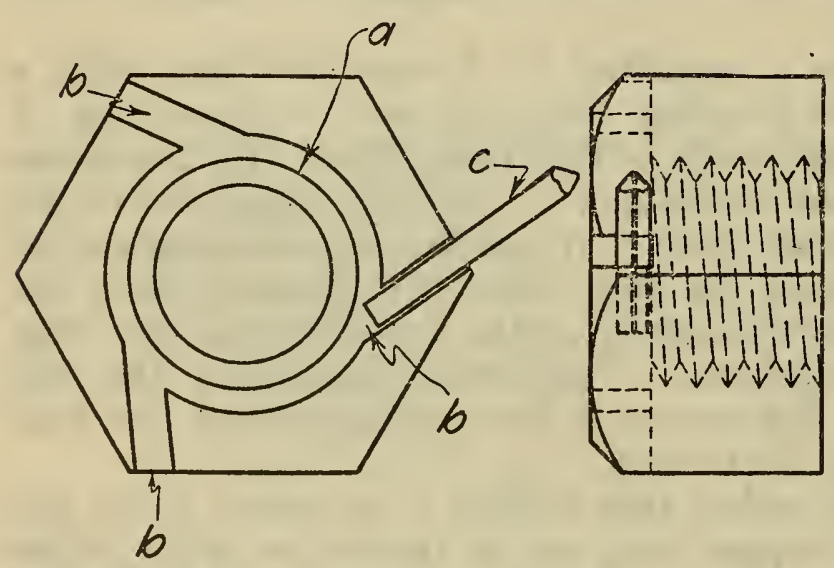

Q

FigURE 17.-Device Q the key was placed in one of the slots and driven between the wall of the recess and the bolt threads, thus bending the key around the bolt threads. The forces exerted by the key upon the nut and upon the threads of the bolt increased the frictional resistance to rotation of the nut.

Device R, Figure 18, was a modified U. S. standard nut. It had a recess, $a$, in the bearing face. A slot, $b$, tangential to the threads, extended from one of the sides of the nut through the wall of the recess. A single coil helical spring, $c$, was provided, having the cross section of a truncated equilateral triangle, whose height was 0.098 inch and width of base was 0.11 inch. One end of this spring extended radially outward. The spring was screwed on the bolt for one thread. The nut was then placed over the spring and the nut and spring were then rotated together. An axial force had to be 
applied to the nut until it engaged the bolt threads, after which the nut and spring acted as a unit. As the nut was screwed on the bolt, the frictional forces between the spring and the bolt caused the diameter of the coil of the spring to increase. When the direction of rotation of the nut was reversed, the diameter of the coil of the spring was decreased,increasing the forces between the spring and the bolt, which increased the frictional resistance to rotation of the nut.

Device S, Figure 19, was a conical soft steel washer having serrations, $a$,in theinner edge. A regular nut was first tightened on the bolt and this device placed
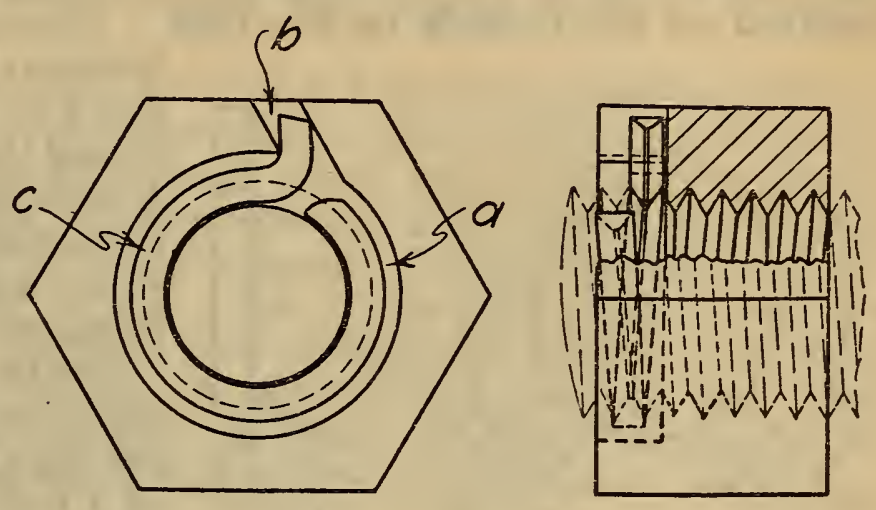
over the bolt with the serrations in contact with the top of the nut. A jam nut was screwed on the bolt and tightened until the device was flattened, causing the serrations to engage the threads on the bolt. The jam nut was then removed. The forces exerted by the serrations upon the threads of the bolt caused frictional resistance to rotation of the device. The thickness of the washer was 0.083 inch.

An alternative method of applying this device is to flatten the device, using a suitable piece of tubing, by blows of a hand hammer. This method was not used in this investigation.

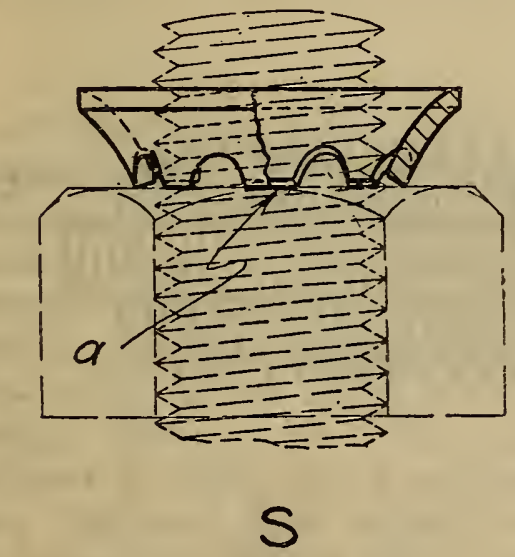

Figure 19.-Device $S$

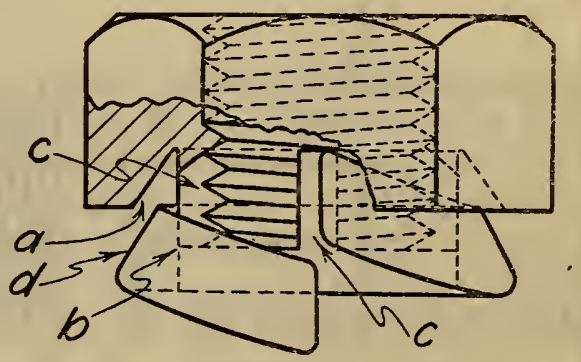

$T$

FIGURE 20.-Device $T$

Device T, Figure 20, consisted of a special nut and a helical steel spring washer. The nut had a conical seat, $a$, in the bearing face and a cylindrical portion, $b$, extending from the bottom of the conical seat outward beyond the face of the nut. This cylindrical portion had two diametral slots, $c$, perpendicular to each other. The outside of the spring washer, $d$, was conical and the inside was cylindrical. The washer was placed in the recess, then the nut was screwed freely 
on the bolt until the washer came into bearing with the part to be clamped. Tightening the nut compressed the washer against the concial seat in the nut. The forces exerted by the conical seat in the nut decreased the diameter of the washer and exerted compressive forces upon the segments of the cylindrical portion, $b$, thus increasing the forces which the threads in the cylindrical portion of the nut exerted on the threads on the bolt. These last forces increased the
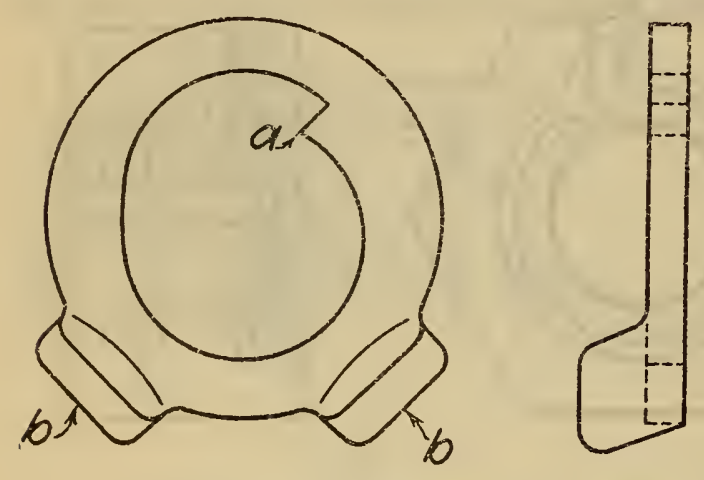

U

Figure 21.-Device $U$

frictional resistance to rotation of the nut. The nut was $1 \% 16$ inches across the flats of the hexagon and $3 / 4$ inch thick. The dimensions of the spring were 0.201 inch parallel to the axis and 0.281 inch in radial thickness.

Device U, Figure 21, was a soft sheet steel washer, 0.138 inch thick, having a sharp prong in the bore at $a$ and two lugs, $b$, on the outer edge making an angle of approximately $80^{\circ}$ with the face of the washer. The washer was placed on the bolt under a regular nut, with the lugs adjacent to the sides of the nut. The nut was then screwed freely on the bolt. When the nut was tightened the washer turned with it until it came into bearing. The prong in the washer was then forced into the threads of the bolt by the forces which the corner of the nut exerted on the lugs. The force exerted by the prong on the threads of the bolt increased the frictional resistance to rotation of the washer. Since only a small rotation of the nut with respect to the washer was permitted by the lugs, the resistance of the nut to rotation was also increased.

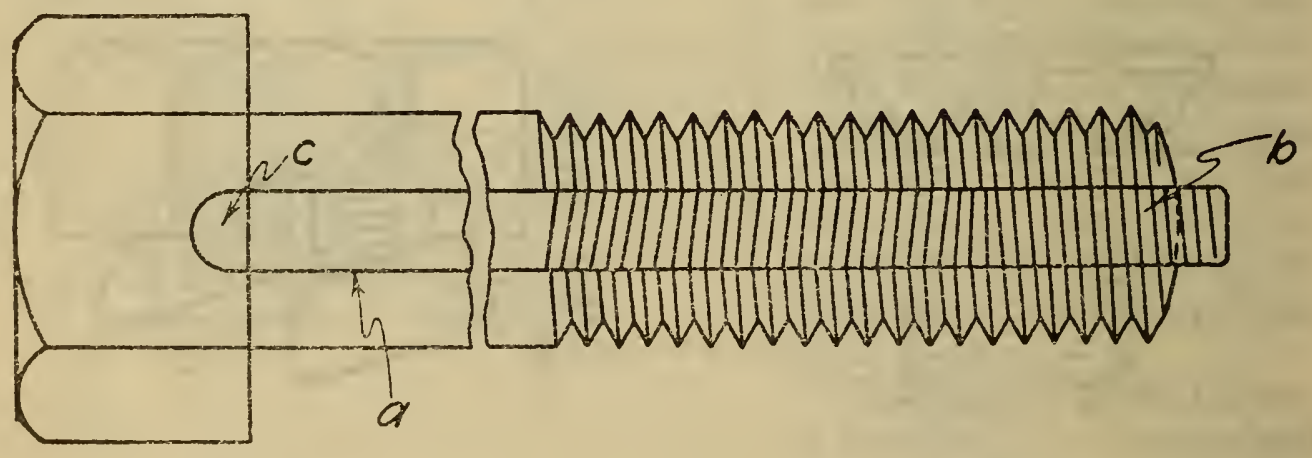

$\bigvee$
Figure 22.-Device $V$

Device V, Figure 22, was a bolt having a keyway extending the full length of the shank and into the head. The bolt was threaded with an American National right-hand thread. A steel key, $a$, fitted snugly in the keyway. This key had notches, $b$, in its outer surface for a length corresponding to the length of the bolt threads. The notches near the end of the bolt matched those on the bolt, but the lead angle changed gradually to that of a left-hand thread. The 
end of the key, $c$, in the head of the bolt was L-shaped, so that, when it came into bearing, axial movement of the key was prevented. A regular nut screwed on the bolt freely for the first few threads. As the nut was tightened, the forces exerted on the key notches increased the frictional resistance to rotation of the nut. Additional resistance to rotation was provided by bending the free end of the key sharply over the top of the nut after the desired stress in the bolt was obtained.

Devices AA to JJ, Figure 23, were what are commercially known as lock or spring washers. These devices, herafter referred to as spring washers, were all steel helical springs, single coil. They were placed on the bolt, then a regular nut was screwed on. The spring washer was compressed as the nut was tightened. When the nut was unscrewed the force exerted by one edge of the spring washer on the bearing face of the nut increased the frictional resistance to rotation of the nut. The force exerted by the clamped part on the other edge of the washer increased the frictional resistance to rotation of the washer. The dimensions of these devices are given in Table 1.

TABLE 1.-Dimensions of spring washers

Devices AA to JJ

\begin{tabular}{|c|c|c|c|}
\hline Device & $\begin{array}{c}\text { Thickness } \\
\text { parallel } \\
\text { to axis }\end{array}$ & $\begin{array}{l}\text { Width at } \\
\text { right angle } \\
\text { to axis }\end{array}$ & Remarks \\
\hline $\begin{array}{l}\text { AA } \\
\text { BB } \\
\text { CC } \\
\text { DD } \\
\text { EE } \\
\text { FF } \\
\text { GG } \\
\text { HH } \\
\text { II } \\
\text { JJ }\end{array}$ & \begin{tabular}{rr|} 
Inch & \\
$1 / 4$ \\
$7 / 32$ \\
$1 / 4$ \\
$5 / 8$ \\
$3 / 16$ \\
$7 / 32$ \\
$1 / 8$ \\
$3 / 16$ \\
$7 / 32$ \\
$3 / 16,9 / 32$
\end{tabular} & $\begin{array}{r}\text { Inch } \\
1 / 4 \\
11 / 32 \\
3 / 8 \\
38 \\
34 \\
34 \\
14 \\
14 \\
14 \\
38 \\
3 / 16 \\
516\end{array}$ & $\begin{array}{l}\text { Outside edge rounded, inside surface knurled. } \\
\text { Inside and outside knurled. } \\
\text { Both faces knurled radially. } \\
\text { Ends of coil wedge-shaped. } \\
\text { Do. } \\
\text { Do. } \\
\text { Wedge-shaped rib adjacent to bore on one side. }\end{array}$ \\
\hline
\end{tabular}

\section{BOLTS}

All the bolts, except device $\mathrm{V}$, Figure 22, were purchased for this investigation. They were made from S. A. E. 1020 steel, were $3 / 4$ inch diameter, 8.0 inches long under the head, and were threaded for $23 / 2$ inches. One of these bolts is shown in Figure 24. The heads were formed cold, and then the bolts were normalized to obtain a uniform structure. The bodies were ground to size on centerless grinders. Ten bolts taken at random were found to be round and straight within 0.001 inch. The American National coarse threads were ordered to meet the specifications for class 2, Free fit. The American National fine threads were ordered to meet the specifications for class 3, Medium fit. Measurements showed that they complied with these requirements. The bolts for devices B and B-U. S. were threaded by the manufacturer of the device.

From three bolts taken at random, American Society for Testing Materials standard tensile specimens were machined, having a diameter of $1 / 2$ inch and a gage length of 2 inches. The Vickers number was determined upon 40 bolts using a diamond pyramid indenting tool and a load of $30 \mathrm{~kg}$. Mechanical properties of the bolt material are given in Table 2. 


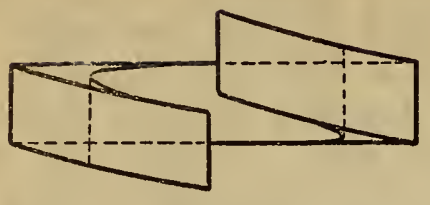

AA

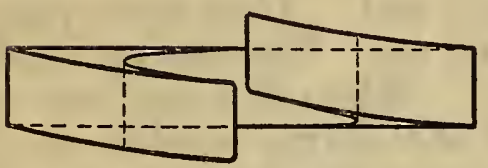

CC

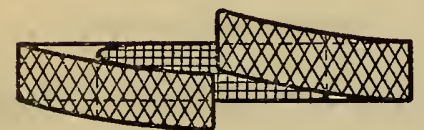

EE

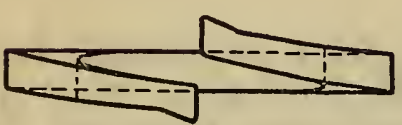

$G G$

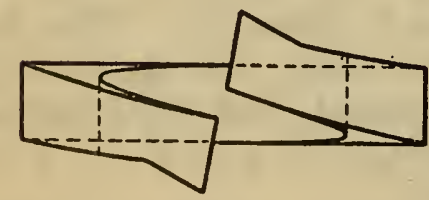

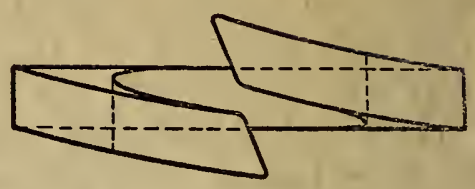

$B B$

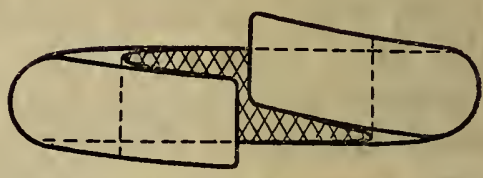

DD
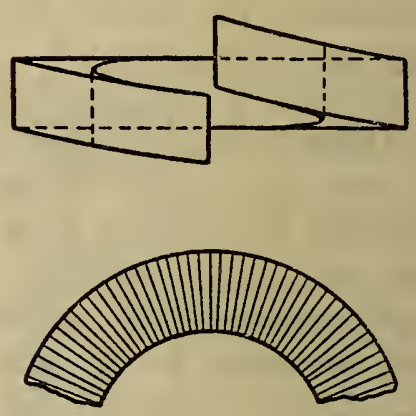

FF

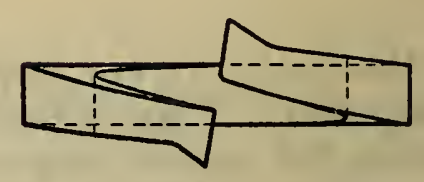

$\mathrm{HH}$

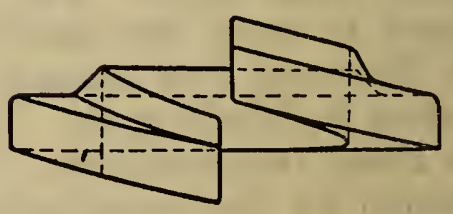

UU

\section{II}

Figure 23.-Devices $A A$ to $J J-S p r i n g$ washers 
B. S. Journal of Research, RP386

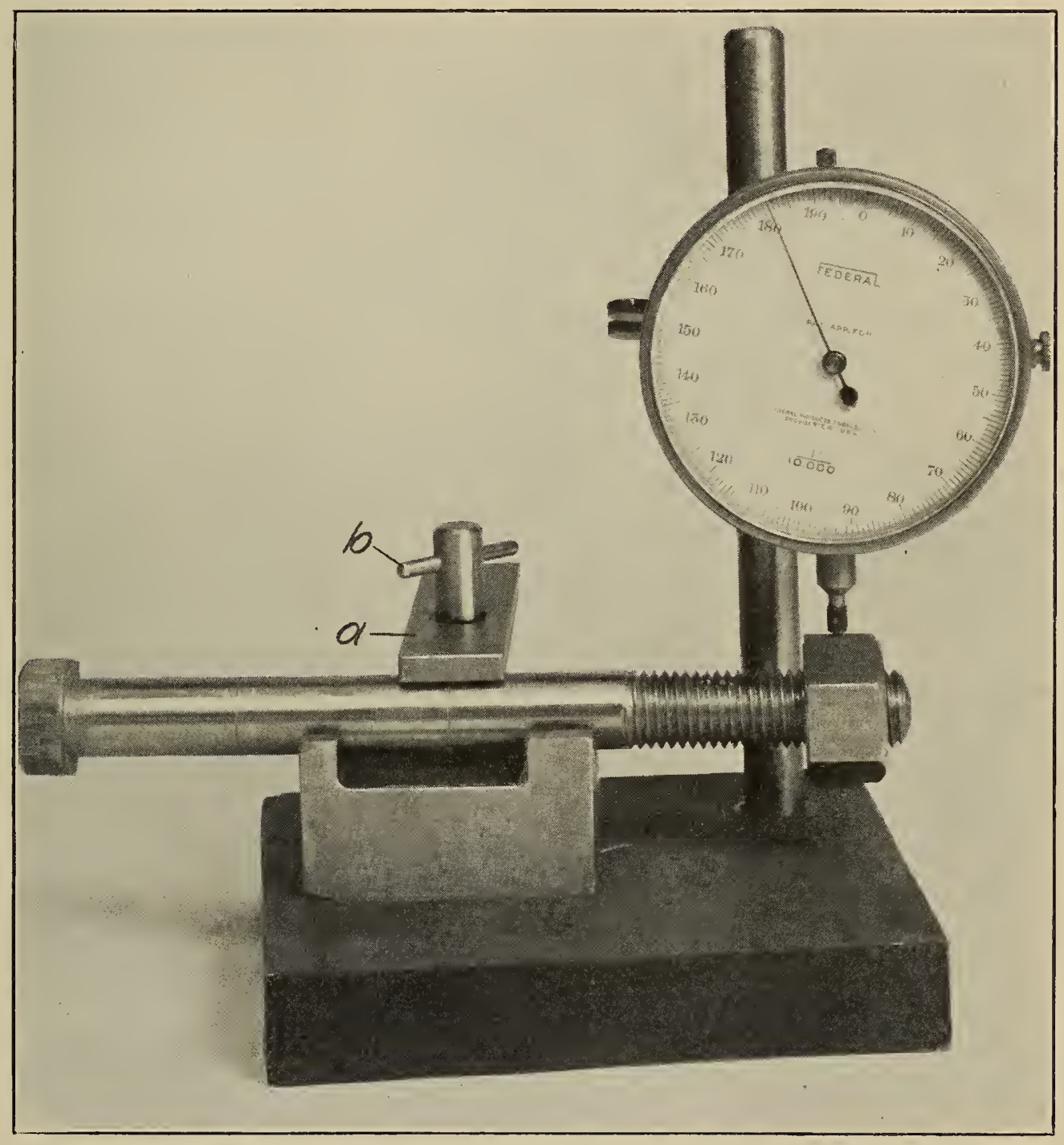

FIGURE 24.-Fixture for measuring the clearance between the threads on the bolt and the threads in the nut 
TABLE 2.-Mechanical properties of bolt material

\begin{tabular}{|c|c|c|c|c|}
\hline Specimen & 1 & 2 & 3 & Average \\
\hline $\begin{array}{l}\text { Limit of proportionality, lb. per sq. in.1 } \\
\text { Yield point, lb. per sq. in. }{ }^{2} \\
\text { Ultimate strength, lb. per sq. in } \\
\text { Young's modulus of elasticity, lb. per sq. in } \\
\text { Elongation in } 2 \text { inches. } \\
\text { Reduction in area } \\
\text { Vickers number }{ }^{8}\end{array}$ & $\begin{array}{r}51,500 \\
60,000 \\
71,000 \\
28,700,000 \\
27 \\
64.7\end{array}$ & $\begin{array}{r}43,100 \\
54,800 \\
66,800 \\
28,500,000 \\
27 \\
64.3\end{array}$ & $\begin{array}{r}51,500 \\
59,200 \\
73,200 \\
29,500,000 \\
27.5 \\
57.3\end{array}$ & $\begin{array}{r}48,700 \\
58,000 \\
70,400 \\
28,900,000 \\
27.2 \\
62.1 \\
167\end{array}$ \\
\hline
\end{tabular}

1 Dotermined as the stress at which the stress-strain curve deviated from a straight line by 0.00001 inch per inch.

2 Determined by drop of beam.

3 Maximum, 191; minimum, 146.

\section{ORDINARY NUTS}

The regular nuts were American National coarse thread, American National fine thread, and U. S. standard. They were all (except those used with device $V$, which were furnished by the manufacturer) made from S. A. E. 1112 cold-rolled hexagon steel and were classed commercially as "semifinished" nuts. The slotted and castellated nuts were purchased from commercial stock. All of the other nuts were supplied by the manufacturer of the device.

\section{VICKERS NUMBERS}

The Vickers number of each locking device is shown in Table 3 , the value given representing the mean of nine indentations, using a diamond pyramid (three indentations on each of three specimens). The load used $(10,30$, or $50 \mathrm{~kg})$ was chosen to give an impression which could be easily measured. The regular nuts showed little variation, the maximum deviation from the mean being 4.2 per cent. The modified nuts were somewhat less uniform, showing deviations from the mean as great as 13 per cent. The spring washers showed deviations as high as 12 per cent. Variations of these magnitudes are to be expected in good commercial practice. There was no indication that these variations had any effect upon the torque tension relationships of any of the devices.

TABLE 3.-Vickers numbers of locking devices

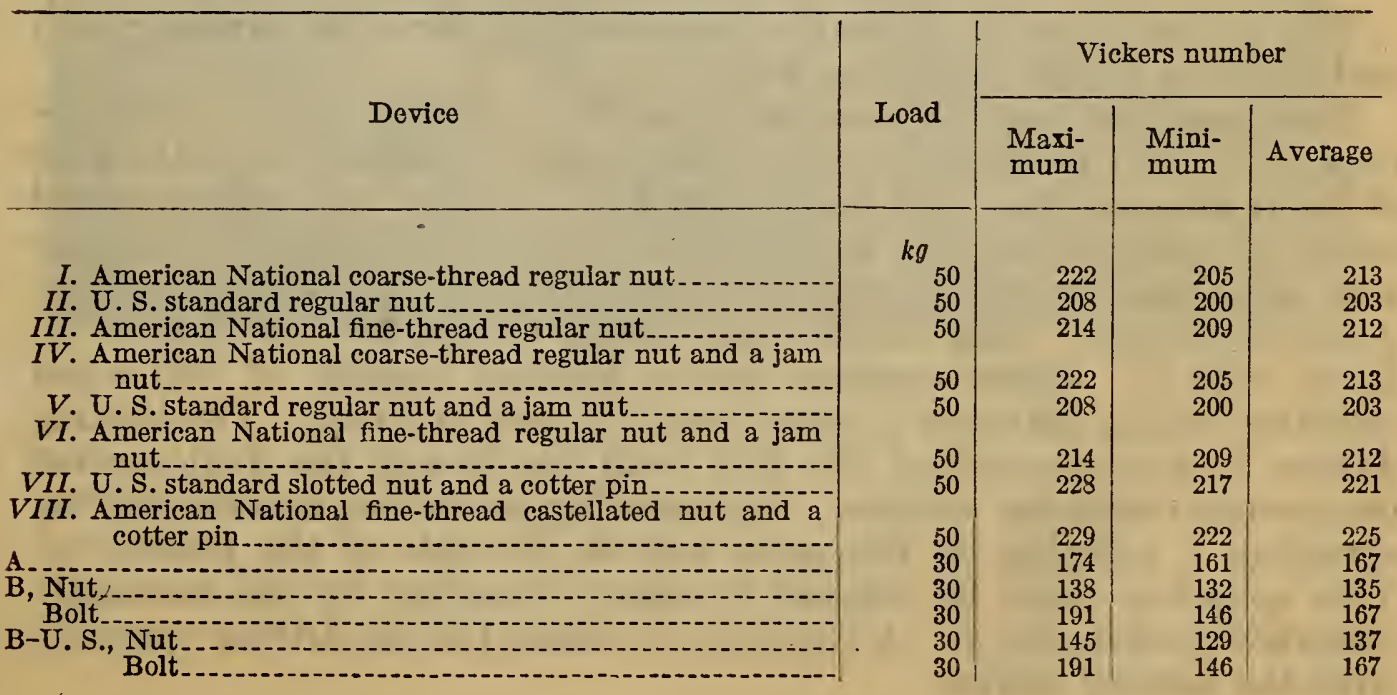


TABLE 3.-Vickers numbers of locking devices-Continued

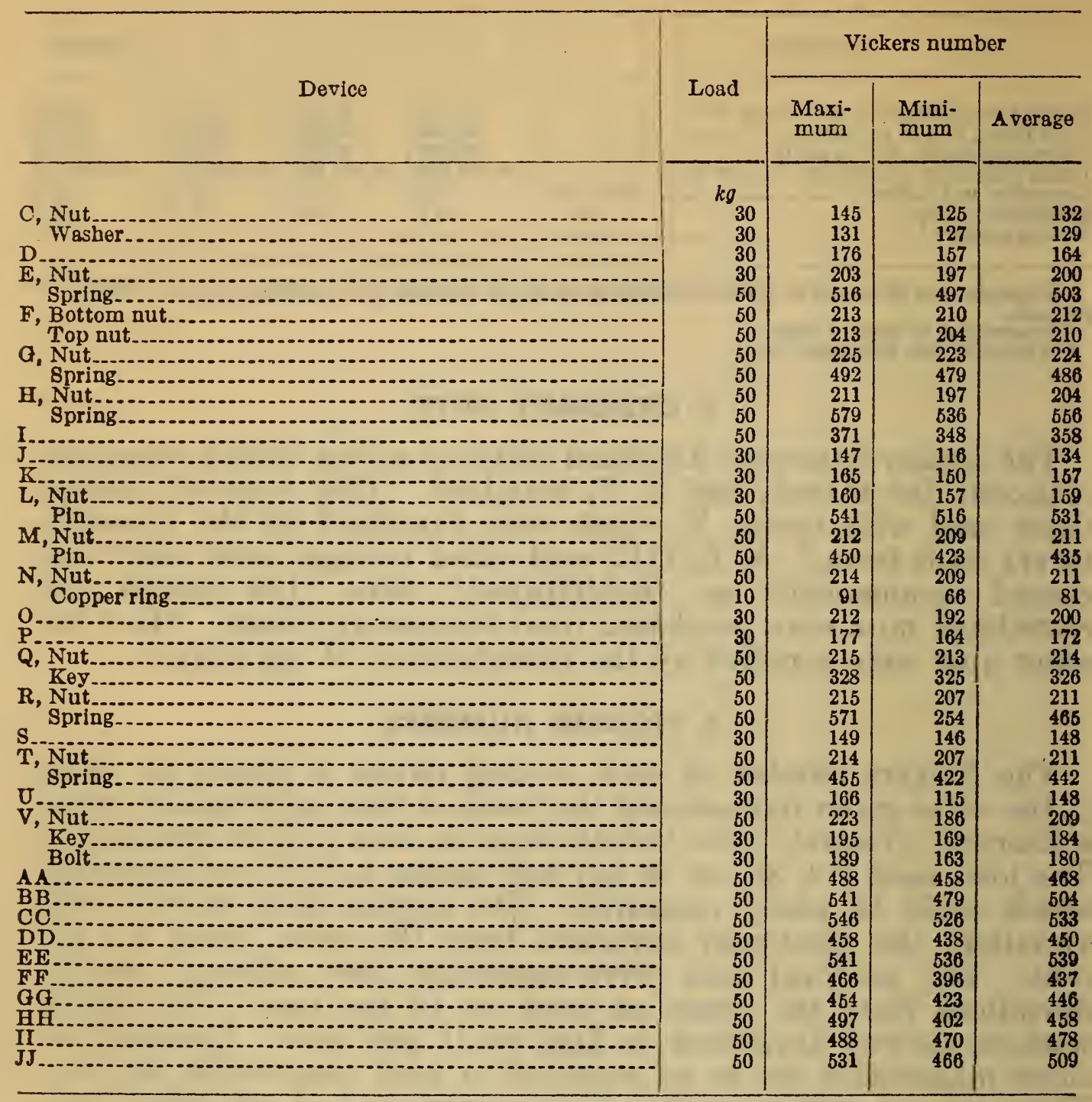

\section{TESTING EQUIPMENT}

\section{TORQUE-TENSION MACHINE}

The torque-tension machine was designed for this investigation and is shown in Figures 25 and 26.

The pendulum axle, $a$, was mounted in the frame, $b$, on ball bearings, $c$, so that it rotated freely. The bolt, $d$, rotated with the axle of the pendulum, the head being locked to the axle by a wedge-shaped collet, $e$, hexagonal inside and outside. In the other end of the axle was an annular recess, $f$, into which the replaceable bearing washer, $g$, fitted snugly. This washer was keyed to the axle so that it rotated with it. These washers had a Vickers number of 200 when indented with a diamond pyramid under a load of $30 \mathrm{~kg}$. The locking device, $h$, was screwed on the bolt until the face of the device came into contact with the washer. Surrounding the device was the driving sprocket, $i$, rotating on the same axis as the axle of the pendulum. This sprocket could be rotated in either direction by the manually operated mechanism, $j$. A coupling, $k$, connected the driving sprocket with the locking device. 
B. S. Journal of Research, RP386

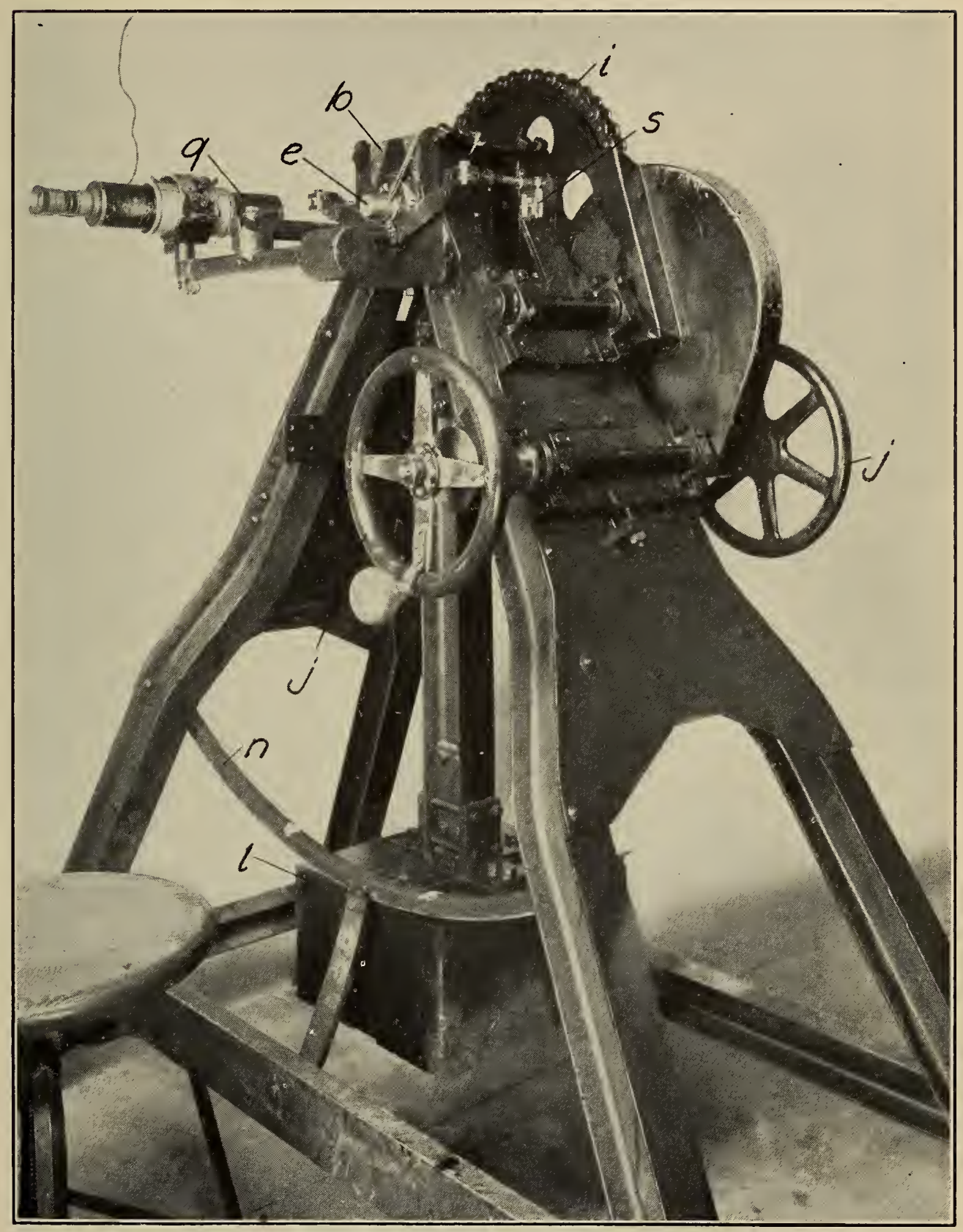

FIGƯRE 25.-Torque-tension testing machine 
B. S. Journal of Research, RP386

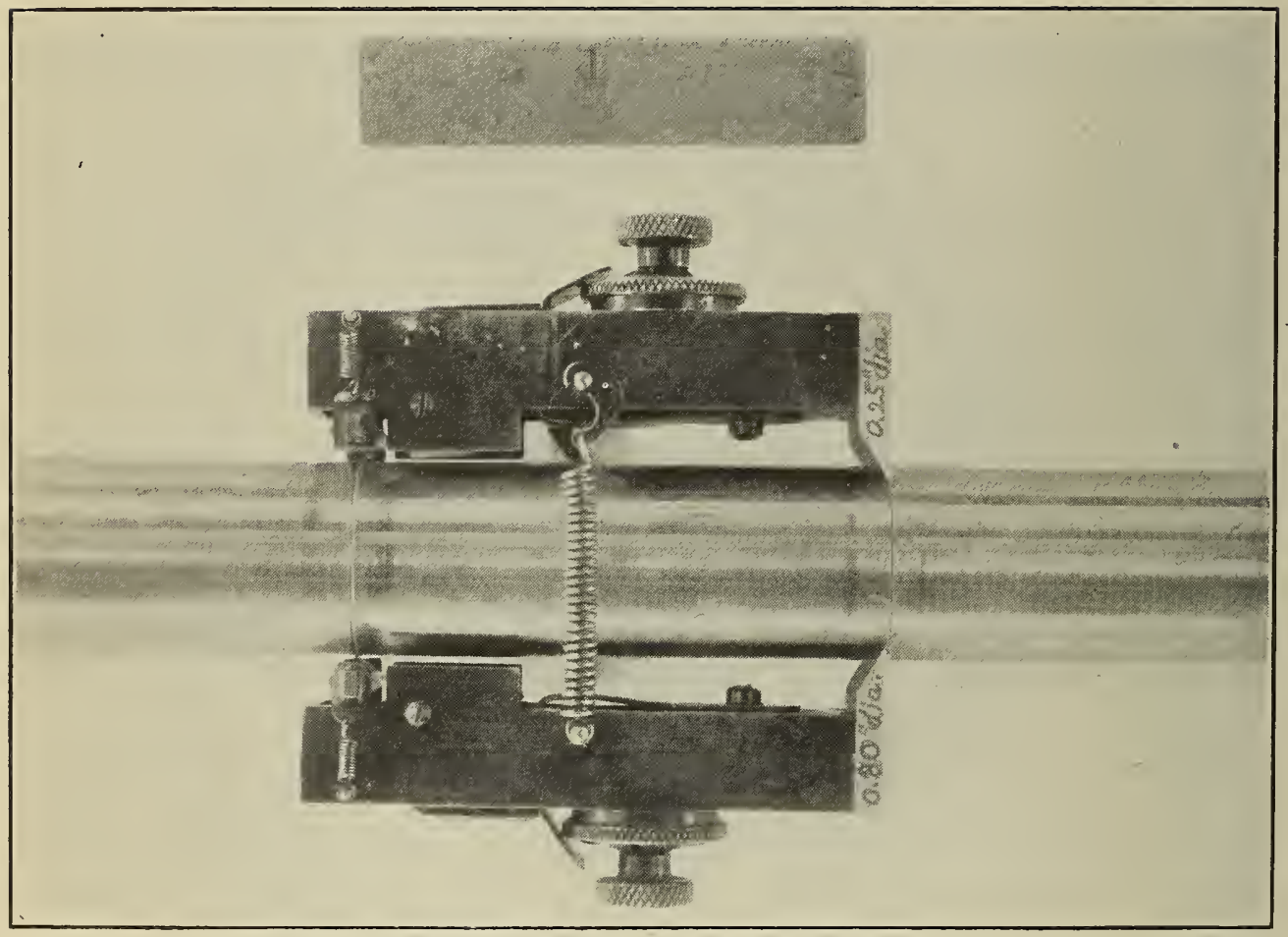

FIGURE 27.-Tuckerman optical strain gages 
To the pendulum axle, $a$, was rigidly attached the pendulum, $l$. When the driving sprocket was rotated so as to tighten the device on the bolt, the tensile stress in the bolt, $d$, increased. This stress was measured, using two Tuckerman optical strain gages, $m$, one on each side of the shank of the bolt. The pendulum axle was cut away to allow the strain gages to be attached to the bolt.

Tightening the device on the bolt also increased the torque on the bolt and the pendulum axle. The torque caused rotation of the pendulum axle in the ball bearings, moving the pendulum from its lowest position until the torque exerted by the pendulum in one direction of rotation equaled the torque exerted by the device in the opposite direction.

A pointer on the pendulum moved over a curved scale, $n$, which was graduated to indicate the torque exerted by the pendulum. Simultaneous readings of the strain gages and of the torque scale were used to determine the relation of torque to tension for the device being tested.

In a similar way the uncrewing torque was measured, when the device was loosened, by rotating the driving sprocket in the opposite direction, permitting the pendulum to swing to its lowest position, zero on the scale, and then up on the other side of the scale.

This machine was calibrated by applying two horizontal forces to the axle of the pendulum, acting in

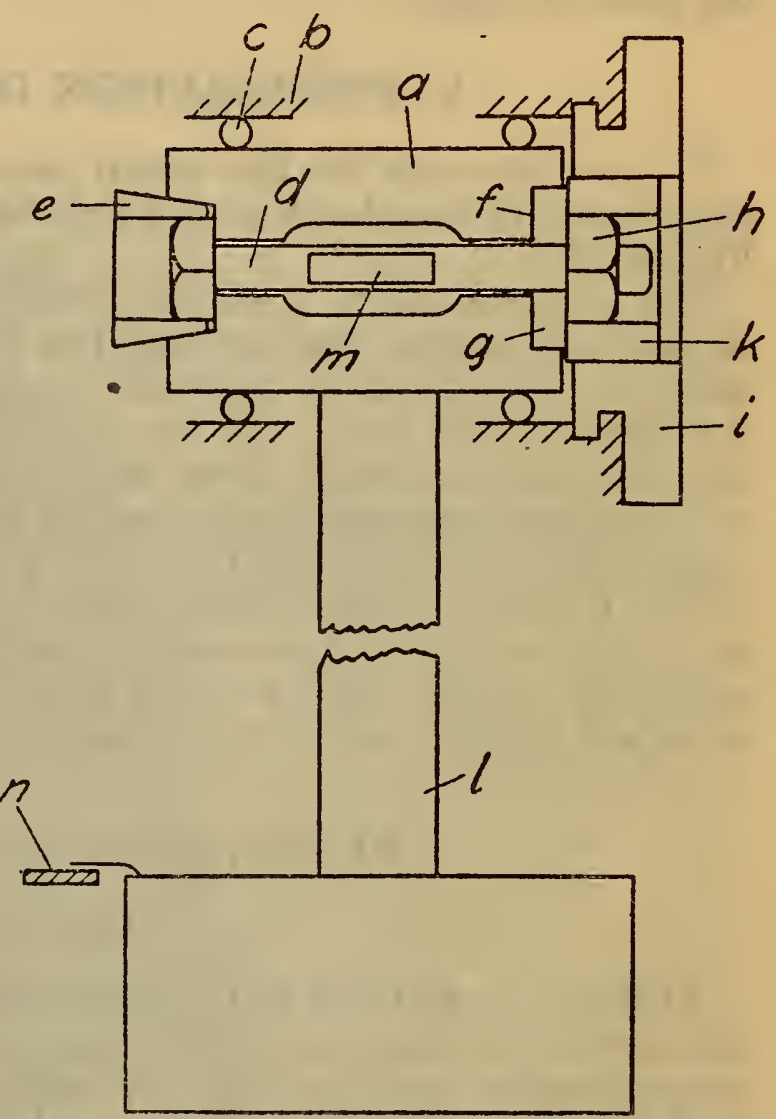

FIGURE 26.-Torque-tension testing machine, schematic drawing opposite directions, to form a couple. The perpendicular distance between the forces was 40 inches. The forces were applied by dead weight to flexible steel bands passing over pulleys having ball bearings. The error in the readings of the machine did not exceed one-half of 1 per cent.

\section{TUCKERMAN OPTICAL STRAIN GAGE}

The Tuckerman optical strain gages, ${ }^{11}$ having a 2-inch gage length, are shown in Figure 27, mounted on one of the bolts.

These gages are used with an autocollimator, $q$, and auxiliary prism, $s$, Figure 25. This autocollimated observing system permitted the

11 A description of the Tuckerman optical strain gage and autocollimated observing system will be found in the Proceedings of the American Society for Testing Materials, vol. 23, 1923, Pt. II, technical papers, pp. 602-610; in Engineering, London, vol. 116, 1923, pp. 222-223; and in Paper No. 335, World Engineering Congress, Tokyo, Japan, pp. 33-36, Precision Machines and Instruments for the Measurement of Length. by George K. Burgess. 
strain in the bolt to be measured within one-millionth of an inch per inch, corresponding to a stress in the body of the bolt of $29 \mathrm{lb}$. per sq. in. The two strain gages and autocollimator were calibrated with an interferometer.

As direct observation of the seating of the knife-edges and lozenges of the strain gages in the grooves in the bolt was prevented by the pendulum axle and the frame of the machine, a laryngoscope was used to observe these contact points when the strain gages were put into place. This instrument consisted of a periscope and a small electric light adjacent to the reflecting prism of the periscope for illuminating the field of vision.

\section{PREPARATION OF SPECIMENS}

To provide seats for the strain gages two grooves, 2 inches apart, were rolled in the shank of the bolt by means of the fixture shown in Figure 28.

The upper section, $a$, of the fixture was hinged, allowing it to be swung back so that the bolt could be placed in the fixture. A spacing collar, $b$, was placed on the bolt to locate the grooves with respect to the head of the bolt. As the bolt, supported on the rollers, $c-c$, was manually rotated, force was gradually applied to the grooving rollers by screwing down the loading knob, $d$. Stops, $e-e$, controlled the depth of the grooves by limiting the travel of the upper section.

The included angle of the groove nearest to the head of the bolt, in which the knife edge rested, was $60^{\circ}$. The included angle of the other groove was $120^{\circ}$, so as to permit the lozenge of the strain gage to rotate slightly without touching the sides of the grooves.

\section{MEASURING SPECIMENS}

\section{GENERAL}

Although variations in the dimensions of the threads, either on the bolt or in the nut, would be expected to affect to some extent the torque-tension relationship, no method of measuring the errors in lead or of the thread contour was found which could be used on all the devices.

The methods which are used for ordinary threads could not be used for the nuts and bolts having deformed threads; therefore the devices having ordinary threads were not measured by the usual methods. Moreover, such measurements would have been tedious and expensive.

As it was believed that differences in the dimensions of the threads sufficiently great to affect the torque-tension relationships would be indicated by measuring the diametral clearance between the nut and the bolt when assembled and the obliquity of the bearing face of the nut, these measurements were made on all ordinary nuts and on all the other devices on which it was practicable. These values were used to determine whether the ordinary bolts and nuts complied with the purchase specifications.

Each bolt and device was examined visually. None of the devices submitted by the manufacturers showed any defects. A few of the ordinary nuts did not have full threads and were therefore discarded. 
B. S. Journal of Research, RP386

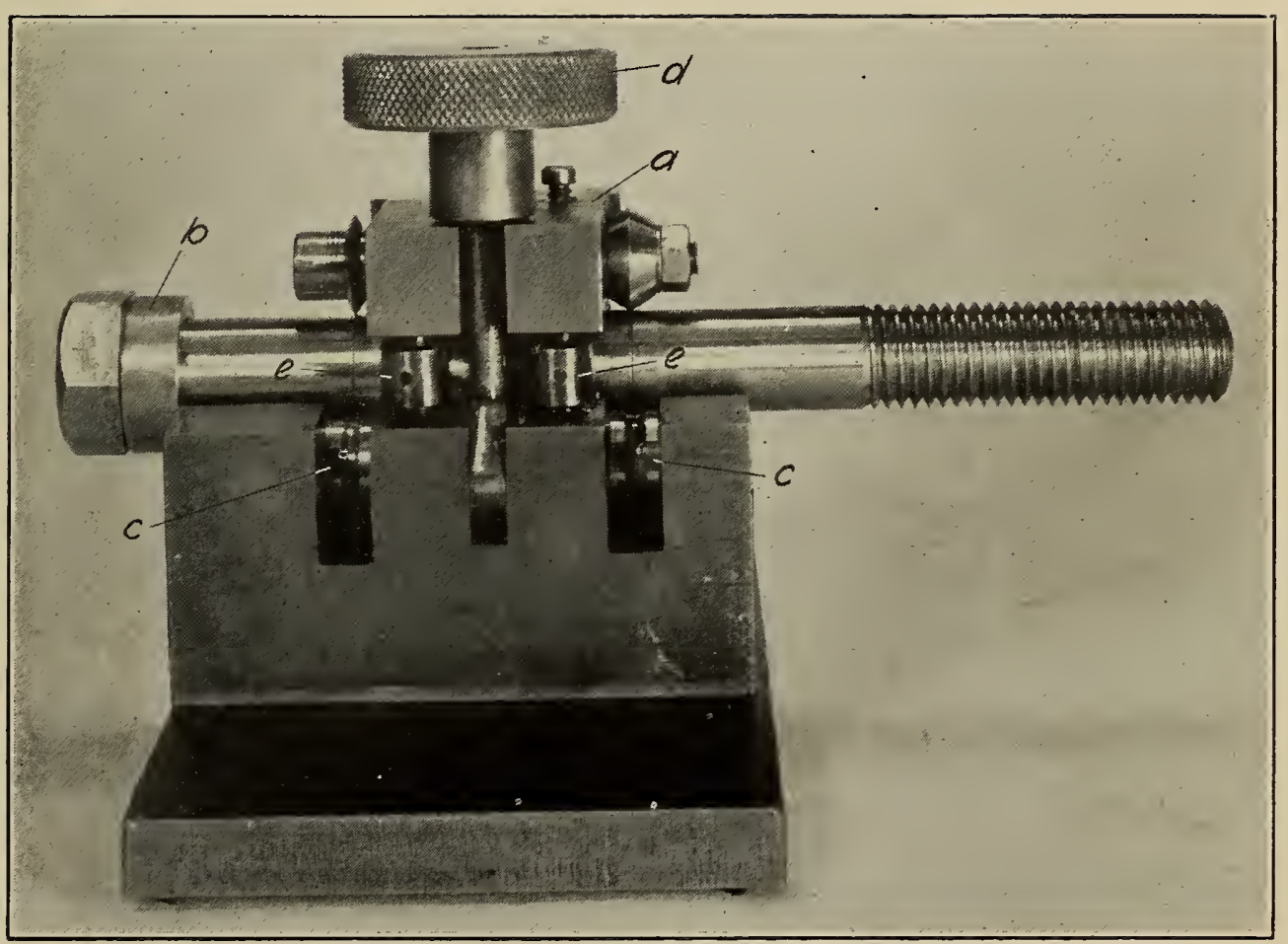

FigURE 28.-Fixture for grooving bolts 



\section{CLEARANCE BETWEEN THREADS OF NUT AND BOLT}

The clearance between the threads in the nut and those on the bolt was measured by the fixture shown in Figure 24. The bolt was secured in the fixture by the clamping plate, $a$, and thumbscrew, $b$. The spindle of the dial micrometer rested on a corner of the nut directly over the axis of the bolt. A small upward force was applied to the nut by the fingers while the nut was rotated back and forth through a small angle, and the maximum reading recorded. This operation was repeated with a small downward force applied to the nut. The difference between these two readings was taken as the diametral clearance between the nut and bolt. The results are given in Table 4.

TABLE 4.-Diametral clearance between threads of nut and bolt

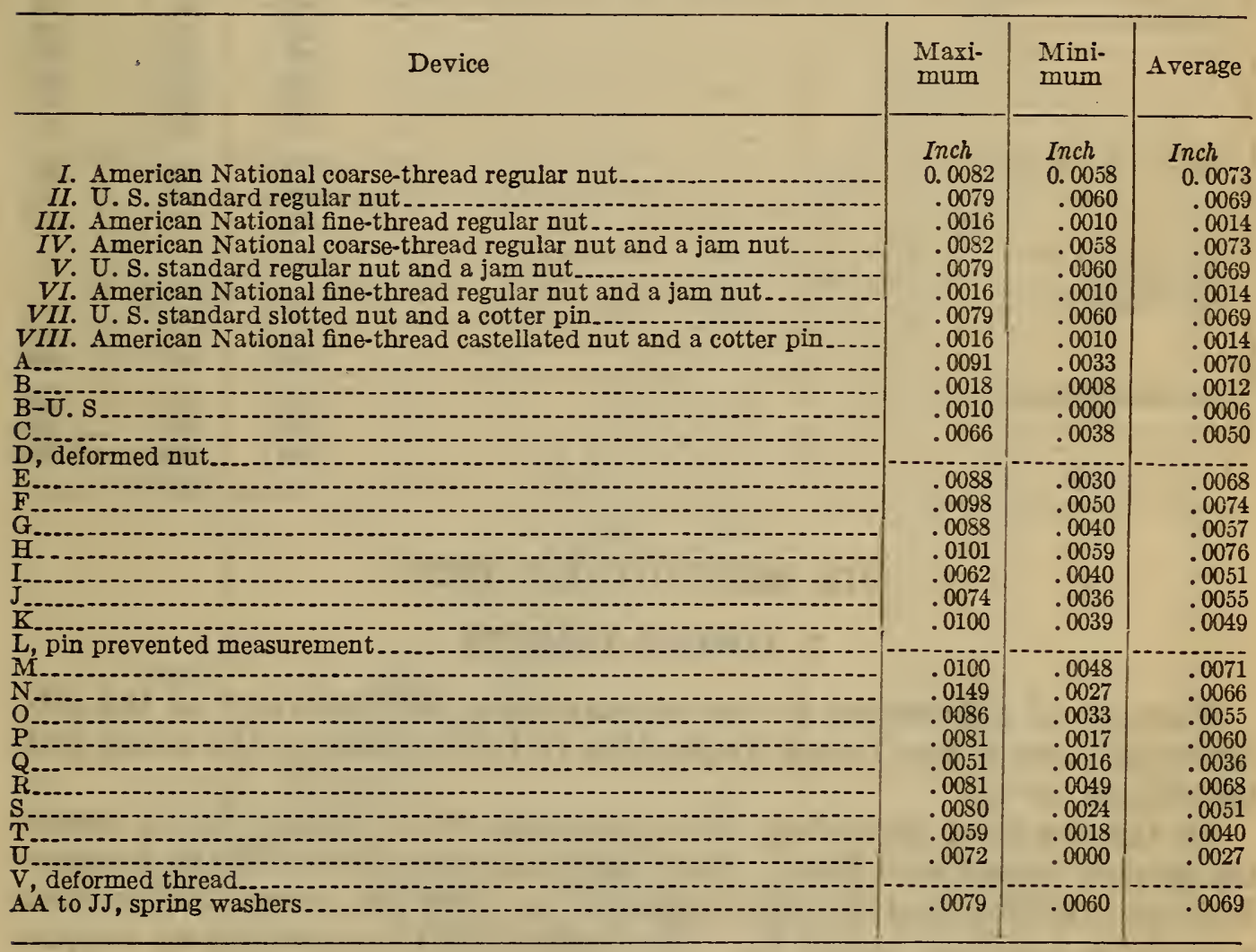

\section{OBLIQUITY OF FACE OF NUT}

The obliquity of the bearing faces of the nuts was measured, using the fixture shown in Figure 29. Nuts having deformed threads and those having certain locking features which interfered with the bolt threads could not be measured, as they could not be screwed on the mandrel.

The mandrel was mounted between the centers, $b-b$, and the dial micrometer adjusted to bring the spindle into contact with the bearing face of the nut, $17 / 32$ inch from center. The mandrel was then rotated, and the maximum and minimum readings of the dial recorded. The difference between these readings was taken as a measure of the obliquity of the bearing face. If the difference was zero, the bearing face was perpendicular to the axis of the nut. The values for each device are given in Table 5. 
TABLE 5.-Obliquities of face of nuts

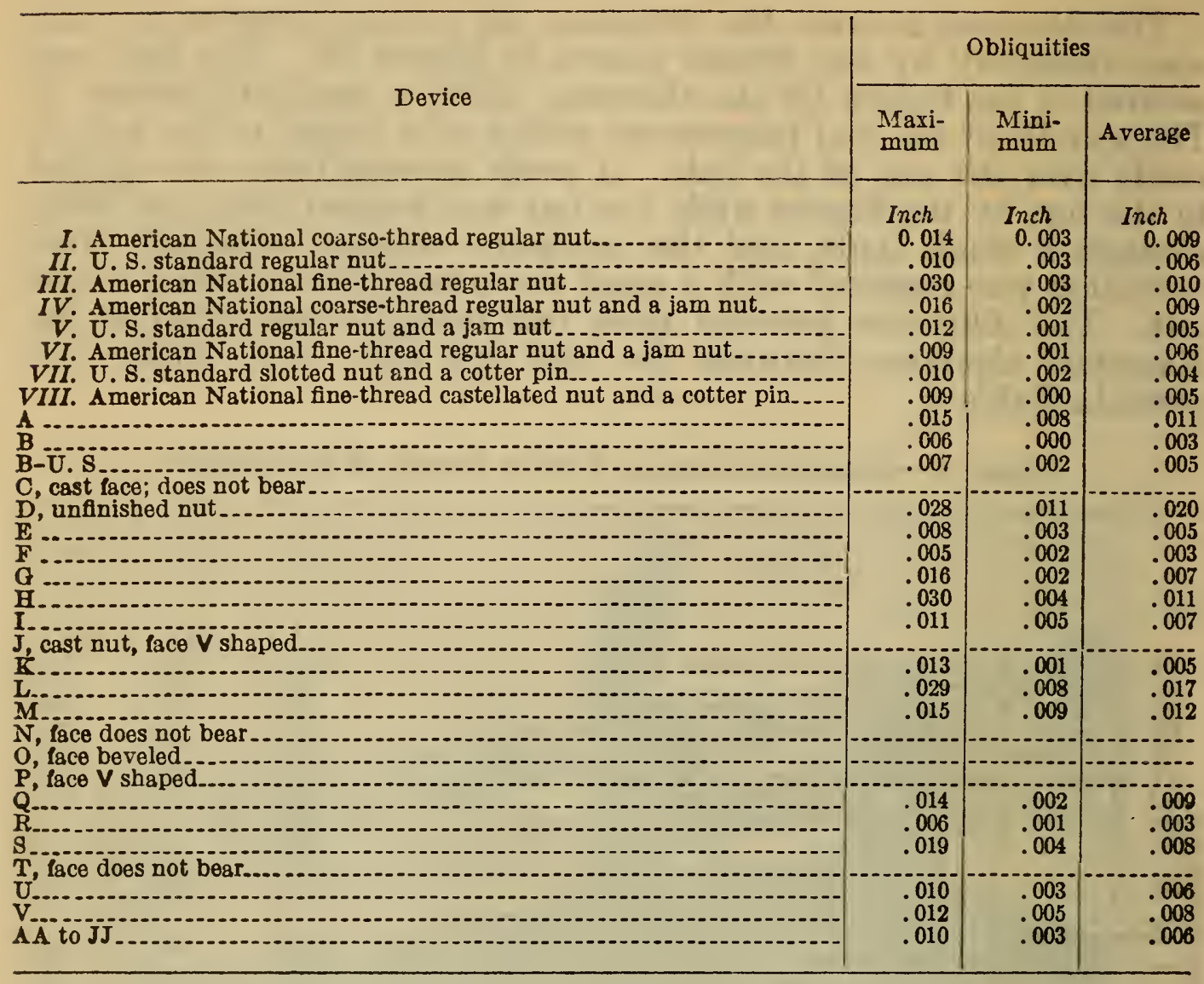

\section{METHOD OF TEST}

\section{TORQUE-TENSION}

Because of differences in the construction and behavior of the different devices it was found impossible to follow exactly the same test procedure for all.

In the simplest procedure five specimens were used. Three specimens were tested as follows: Each specimen was placed in the torquetension machine and the nut screwed on until the stress in the bolt was about $5,000 \mathrm{lb}$. per sq. in. The stress and the screwing-on torque were recorded, as at $a$, Figure 30 , which is a typical torque-tension graph drawn to assist the reader in understanding the method of testing.

The nut was then screwed off slightly and the initial screwing-off torque at that stress in the bolt was recorded, as at $b$. The nut was then further screwed on until the stress in the bolt was about 7,000 lb. per sq. in., as at $c$, and screwed off slightly to obtain the initial screwing-off torque for that stress, as at $d$. The stresses were successively increased to obtain the values at $e, f$, etc., up to about 20,000 lb. per sq. in. in the body of the bolt.

To determine the relation between the stress in the bolt and the continuous screwing-off torque as the stress was decreased from 10,000 lb. per sq. in. to zero and from $20,000 \mathrm{lb}$. per sq. in. to zero, two specimens were tested. With one of these specimens the nut was screwed 
on, without backing off at intermediate stresses, until the stress in the bolt was about 10,000 lb. per sq. in. as at $g$, Figure 30 , then screwed off to obtain the values of continuous screwing-off torque, $h, i, j$, and zero. The other specimen was screwed on to about $20,000 \mathrm{lb}$. per sq. in. as at $o$, then the nut was screwed off to obtain the values $p, q, r, s, t$, and zero. For many of the devices this simple procedure was not feasible. For these it was found that the slight unscrewing of the device necessary to determine the initial screwing-off torque altered the bearing surfaces enough to make further values of the screwing-on torque significantly different from the values obtained by continuous screwing on. For these devices nine specimens were tested. For three speci-

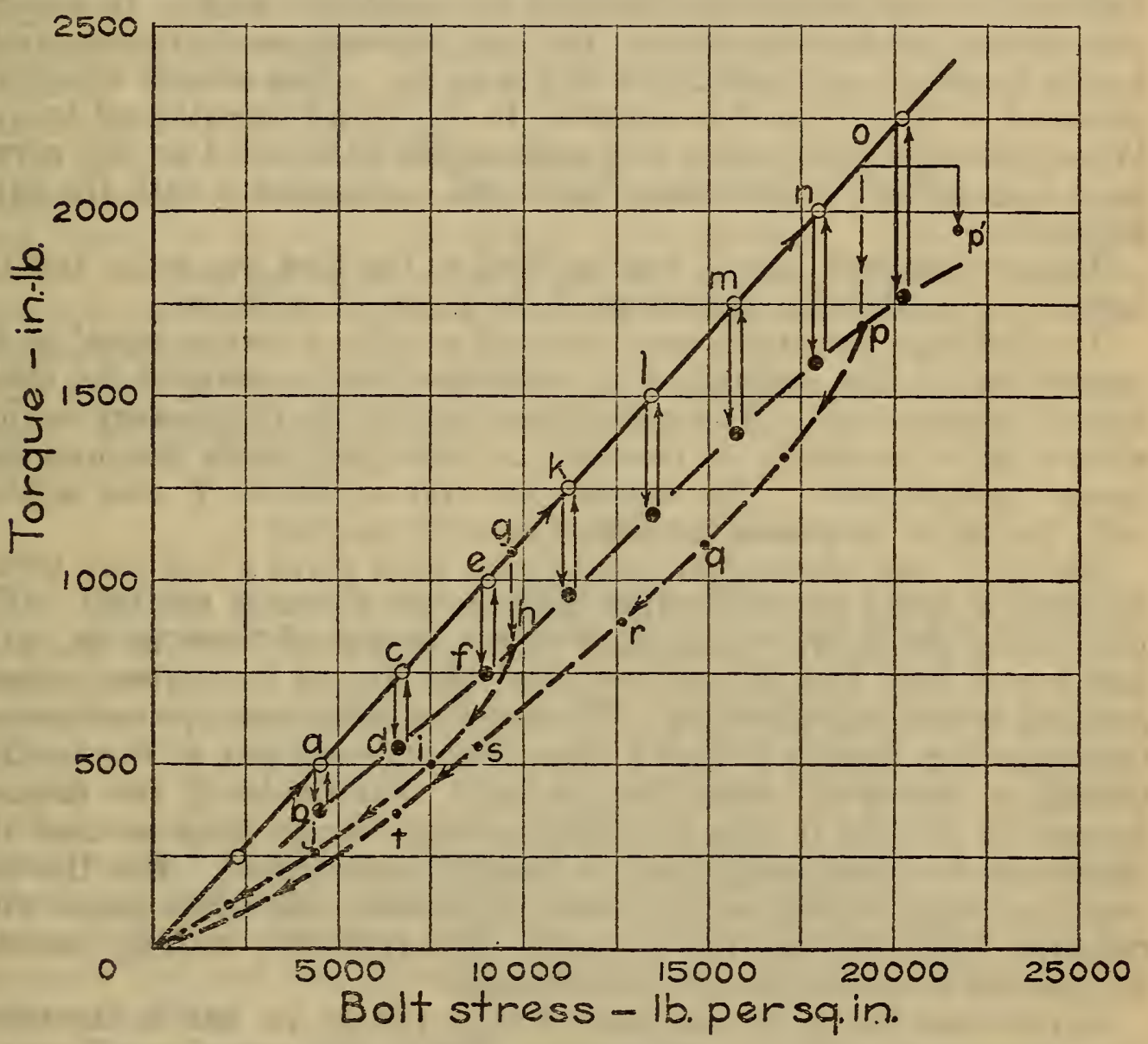

FIGURE 30.-Typical torque-tension graph to illustrate method of testing

mens the nut was screwed on, without backing off, until the stress in the bolt was about $10,000 \mathrm{lb}$. per sq. in. and the values $a, c, e$, and $g$, Figure 30 , obtained. The nut was then screwed off to obtain the values of $h, i, j$, and zero. In the same way three specimens were tested stressing the bolt to about $15,000 \mathrm{lb}$. per sq. in. and three stressing the bolt to about 20,000 lb. per sq. in. For specimens stressed to $20,000 \mathrm{lb}$. per sq. in., the values as shown by Figure 30 are $a, c, e, k, l, m, n$, and $o$ for the screwing-on torques, and $p, q, r, s, t$, and zero for the screwing-off torques. Three devices, H, Q, and II, were tested before this procedure was standardized. For these, 11 specimens were tested. For $\mathrm{H}$ continuous screwing-off curves at 1,500 in. lbs. torque were not made on two specimens but were later made on two additional specimens. Even with this larger number of 
specimens it was possible to determine the initial screwing-off torque at only three different stresses. There seemed to be no need for increasing this number further. For $\mathrm{Q}$ and II screwing-on and initial screwing-off torques were measured on nine specimens. For the other two, continuous screwing-off torques were determined.

Where the locking device used two nuts, a further change in the test procedure became necessary. Nine specimens were tested as before, with the following modification. The first nut was screwed on, reading the values of the screwing-on torque and stress as $a, c, e, g$, Figure 30 , until the desired stress $(10,000,15,000$, or $20,000 \mathrm{lb}$. per sq. in.) was reached. The first nut was then held so that it did not turn on the bolt and the jam nut screwed on with the required torque. In general, this altered the tensile stress in the bolt, in some cases imperceptibly, and in no case more than $2,000 \mathrm{lb}$. per sq. in. This altered stress was recorded as the stress corresponding to the initial screwing-off torque. Where this change of stress was appreciable it is noted on the curves by a bent arrow, as shown in Figure 30, connecting $o$ with the extra point $p^{\prime}$.

The screwing-off torque was applied to the first nut only, and the initial and continuous screwing-off torque read as before.

The ordinary jam nuts were screwed on with a torque equal to the torque on the first (regular) nut, multiplied by the ratio of the thickness of the two nuts. The special jam nuts of the proprietary devices were applied as closely as possible, in conformity with the manufacturers' instructions. The special jam nut of device $\mathrm{F}$ was applied with the same torque as the first nut.

Device I was screwed on hand-tight, then given a half turn with a wrench; this did not noticeably increase the stress in the bolt. The jam nut of device $K$ was applied with a torque of 1,000 in. lb., as it was found that this torque deformed the nut to the extent recommended by the manufacturer. The same modification of procedure was necessary for devices $\mathrm{S}$ and $\mathrm{V}$ since the carrying out of the locking procedure alters the stress in the bolt. For device $Q$ the impact, caused by driving in the pin, displaced the strain gage so that the alteration of stress could not be directly determined. For the last two specimens, which were screwed off to zero, the strain gages were removed while driving the pin, and then replaced, making possible an indirect determination of the change.

In one case the stress increased $300 \mathrm{lb}$. per sq. in. and in the other case decreased 2,000 lb. per sq. in. The initial screwing-off curves are therefore plotted as if there had been no change in stress. For all jam nuts (IV, $V, V I, \mathrm{~F}, \mathrm{I}$, and $\mathrm{K})$ and for devices $\mathrm{Q}$ and $\mathrm{S}$, the screwing-on torques recorded are the same as if no locking device had been used. The locking device affects only the screwing-off torques.

In plotting all of these torque-tension curves large open circles were used for screwing-on torques and large solid circles for the initial screwing-off torques. For the continuous screwing-off torques small solid circles were used.

A new bolt was used for each specimen, also a new regular nut, if one was used with the device. The face of the bearing washer was reground for each test, using a cylindrical grinder and a fine feed. The grinder marks were circular about the axis of the bolt, and the faces were smooth, flat and parallel. 
When the spring washers were tested, it was found that the continuous screwing-off torque fluctuated considerably, caused probably, by the ends of the spring washers cutting into the bearing washer and into the nut, then releasing suddenly. This, however, did not prevent the use of the simplest test procedure except in the case of device II.

For device II these fluctuations in the torque displaced the strain gages making it impossible to obtain satisfactory readings of the stress in the bolt when the nut was unscrewed. Consequently, the second procedure with 11 specimens was used for this device.

Each locking device, bolt, and bearing washer was first thoroughly cleaned in carbon tetrachloride and then flushed with a good grade of light mineral machine oil before it was placed in the torque-tension machine. The relation between the viscosity and temperature of the oil is shown in Figure 31.

The bolt was placed in the axle of the pendulum and the head wedged so that it rotated with the pendulum. The strain gages were placed on the bolt and seated in the grooves. The device was screwed on the bolt and coupled to the driving sprocket. As the sprocket was rotated to screw the nut on the bolt the strain in the bolt increased.

To determine the stress in the bolt from the strain, the average strain was multiplied by the average Young's modulus of elasticity $28,900,000 \mathrm{lb}$. per sq. in.

\section{DEFLECTION OF SPRING WASHERS}

The relation between the compressive forces and the deflections of the spring washers was determined in a universal testing machine. Three specimens of each locking device were taken at random. Each specimen was placed on a bolt between two hardened collars, and the bolt was then loaded in tension. A dial micrometer was adjusted so that the spindle rested on the upper end of the bolt. Simultaneous readings of load and deflection were recorded until the spring washer was flat. Then the load was decreased and readings of load and deflection recorded until the load was again zero. Each specimen was loaded repeatedly in this way until the behavior of the specimen did not change appreciably, many of them being loaded five or six times.

\section{RESULTS}

The results obtained in the torque-tension machine are shown graphically in Figures 32 to 72 , inclusive. The number of specimens tested $(5,9$, or 11$)$ indicates the particular test procedure used. The coordinates of each point on these graphs are the averages of the stress and torque values obtained on all specimens tested in the same way. The stresses are in all cases the averages of the tensile stresses in the bodies of the bolts. To obtain the stress in the bolt at the root of the American National coarse and U. S. standard thread or at the pitch line of the thread, the stresses given must be multiplied by 1.46 and 1.20 , respectively. The stresses shown for the American National fine thread, Figures 34, 37, and 39, must be multiplied by 1.12 and 1.06 to find the stresses at the root and at the pitch line of the threads, respectively. 
The screwing-on and initial screwing-off torques for stresses of $5,000,10,000,15,000$, and $20,000 \mathrm{lb}$. per sq. in. in the bolt, read from the curves, are given in Table 6 . The ratios of the screwing-off torque for each device to the screwing-off torque for the American National coarse-thread nut at stresses of $10,000,15,000$, and 20,000 lb. per sq. in. are also given.

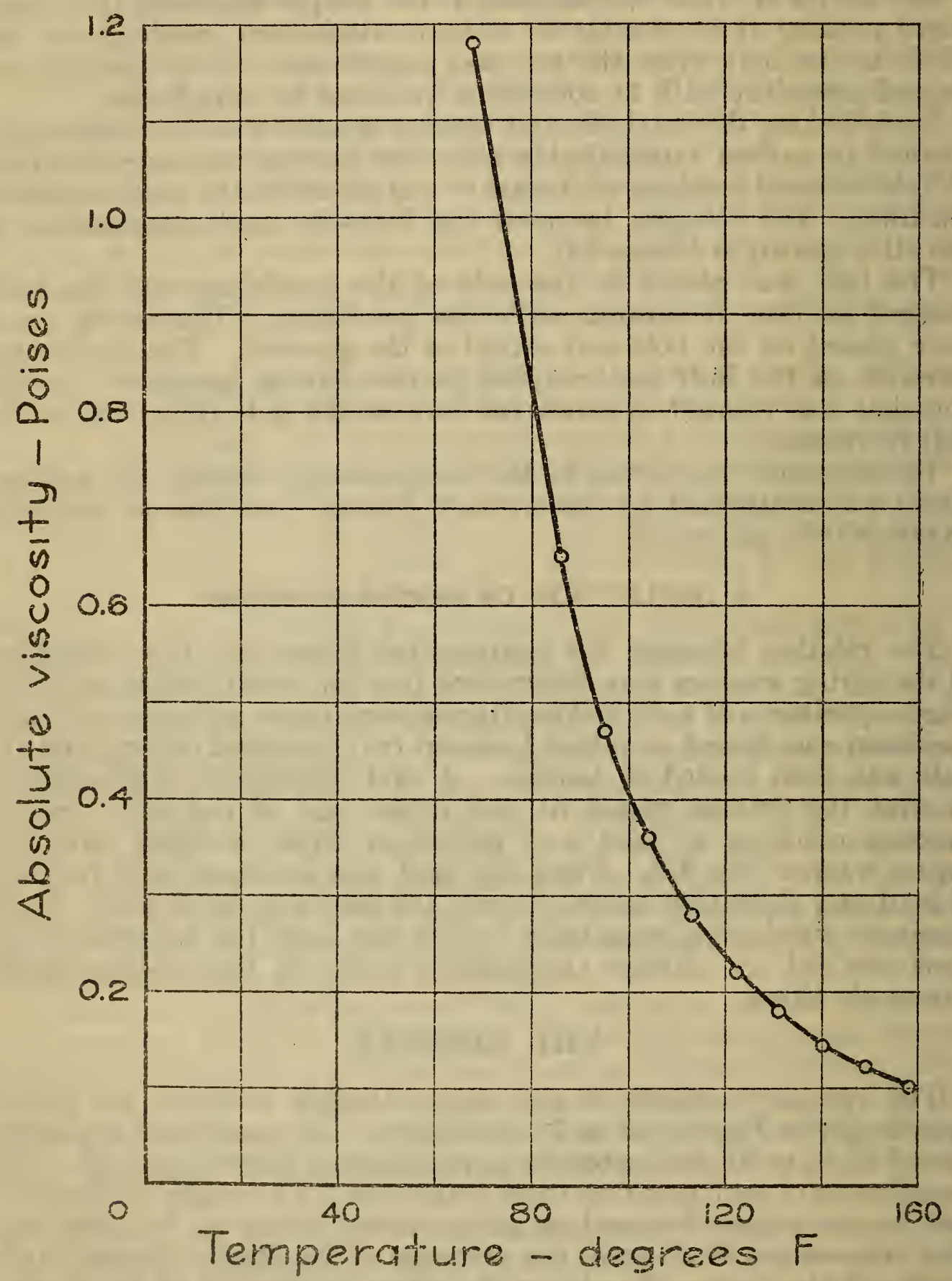

FIGURE 31.-Viscosity-lemperature curve for the lubricating oil

These ratios were plotted, arranging them in numerical order, beginning with the lowest value. The ratios for stresses of 10,000 lb. per sq. in. are shown in Figure 77, those for 15,000 lb. per sq. in. in Figure 78, and for 20,000 lb. per sq. in. in Figure 79. 
TABLE 6.-Values of torque and stress

\begin{tabular}{|c|c|c|c|c|c|c|c|c|c|c|c|c|}
\hline \multirow{3}{*}{$\begin{array}{l}\text { Sym- } \\
\text { bol of } \\
\text { device }\end{array}$} & \multirow{3}{*}{$\begin{array}{l}\text { Fig- } \\
\text { ure } \\
\text { No. }\end{array}$} & \multirow{2}{*}{\multicolumn{2}{|c|}{$\frac{\begin{array}{c}\text { Stress, } 5,000 \\
\text { lb. per sq. in. }\end{array}}{\begin{array}{c}\text { Torque, inch- } \\
\text { pounds }\end{array}}$}} & \multicolumn{3}{|c|}{$\begin{array}{l}\text { Stress, } 10,000 \text { lb. per } \\
\text { sq. in. }\end{array}$} & \multicolumn{3}{|c|}{$\begin{array}{l}\text { Stress, } 15,000 \text { lb. per } \\
\text { sq. in. }\end{array}$} & \multicolumn{3}{|c|}{$\begin{array}{l}\text { Stress, } 20,000 \mathrm{lb} \text {. per } \\
\text { sq. in. }\end{array}$} \\
\hline & & & & \multicolumn{2}{|c|}{$\begin{array}{l}\text { Torque, inch- } \\
\text { pounds }\end{array}$} & \multirow{2}{*}{$\begin{array}{c}\text { Ratio } \\
\text { to } \\
\text { Ameri- } \\
\text { can } \\
\text { Na- } \\
\text { tional } \\
\text { coarse } \\
\text { initial } \\
\text { screw- } \\
\text { ing off }\end{array}$} & \multicolumn{2}{|c|}{$\begin{array}{l}\text { Torque, inch- } \\
\text { pounds }\end{array}$} & \multirow{2}{*}{$\begin{array}{c}\text { Ratio } \\
\text { to } \\
\text { A meri- } \\
\text { can } \\
\text { Na- } \\
\text { tional } \\
\text { coarse } \\
\text { initial } \\
\text { screw- } \\
\text { ing off }\end{array}$} & \multicolumn{2}{|c|}{$\begin{array}{l}\text { Torque, inch- } \\
\text { pounds }\end{array}$} & \multirow{2}{*}{$\begin{array}{l}\text { Ratio } \\
\text { to } \\
\text { Ameri- } \\
\text { can } \\
\text { Na- } \\
\text { tional } \\
\text { coarse } \\
\text { initial } \\
\text { screw. } \\
\text { ing off }\end{array}$} \\
\hline & & $\begin{array}{l}\text { Screw- } \\
\text { ing on }\end{array}$ & $\begin{array}{l}\text { Initial } \\
\text { screw- } \\
\text { ing off }\end{array}$ & $\begin{array}{l}\text { Screw- } \\
\text { ing on }\end{array}$ & $\begin{array}{l}\text { Initial } \\
\text { screw- } \\
\text { ing off }\end{array}$ & & $\begin{array}{l}\text { Screw- } \\
\text { ing on }\end{array}$ & $\begin{array}{l}\text { Initial } \\
\text { screw- } \\
\text { ing off }\end{array}$ & & $\begin{array}{l}\text { Screw- } \\
\text { ing on }\end{array}$ & $\begin{array}{l}\text { Initial } \\
\text { screw- } \\
\text { ing off }\end{array}$ & \\
\hline$I$ & 32 & 420 & & 840 & 690 & 1.00 & 1,260 & 1,060 & 1.00 & 1,680 & 1,440 & 1.00 \\
\hline $\begin{array}{r}I I \\
I I I\end{array}$ & 33 & $\begin{array}{l}110 \\
410\end{array}$ & & 830 & 750 & 1. 09 & $\begin{array}{l}1,250 \\
\text {. }\end{array}$ & 1,100 & 1.04 & 1,660 & 1,450 & 1. 01 \\
\hline $\begin{array}{l}I I I \\
I V\end{array}$ & $\begin{array}{l}34 \\
35\end{array}$ & $\begin{array}{l}350 \\
420\end{array}$ & $\ldots$ & $\begin{array}{l}690 \\
800\end{array}$ & $\begin{array}{l}600 \\
820\end{array}$ & $\begin{array}{r}.87 \\
1.19\end{array}$ & $\begin{array}{l}1,030 \\
1,210\end{array}$ & $\begin{array}{r}920 \\
1,080\end{array}$ & $\begin{array}{r}.87 \\
1.02\end{array}$ & $\begin{array}{l}1,370 \\
1,590\end{array}$ & $\begin{array}{l}1,200 \\
1,30\end{array}$ & .83 \\
\hline$V$ & $\begin{array}{l}50 \\
36 \\
\end{array}$ & 440 & & 870 & 660 & .96 & $\begin{array}{l}1,210 \\
1,310\end{array}$ & $\begin{array}{l}1,100 \\
1\end{array}$ & $\begin{array}{l}1.02 \\
1.04\end{array}$ & $\begin{array}{l}1,090 \\
1,750\end{array}$ & $\begin{array}{l}1,550 \\
1,50\end{array}$ & $\begin{array}{l}.93 \\
\text { 1. } 13\end{array}$ \\
\hline $\begin{array}{c}V I \\
V I U\end{array}$ & 37 & 390 & & 750 & 640 & .93 & 1,100 & 980 & $\begin{array}{r}.92 \\
100\end{array}$ & & 1,310 & .08 \\
\hline $\begin{array}{l}V I I I \\
V I I I\end{array}$ & $\begin{array}{l}38 \\
39\end{array}$ & 440 & 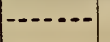 & $\begin{array}{l}820 \\
750\end{array}$ & $\begin{array}{l}750 \\
780\end{array}$ & $\begin{array}{l}1.09 \\
1.13\end{array}$ & $\begin{array}{l}1,200 \\
1,07\end{array}$ & $\begin{array}{l}1,140 \\
1050\end{array}$ & 1.08 & $\begin{array}{l}1,580 \\
1,40\end{array}$ & 1,480 & 1. 90 \\
\hline $\begin{array}{r}V I 1 \\
\text { A }\end{array}$ & . & $\begin{array}{l}410 \\
560\end{array}$ & & $\begin{array}{l}750 \\
980\end{array}$ & $\begin{array}{l}780 \\
850\end{array}$ & $\begin{array}{l}\text {. } 13 \\
1.23\end{array}$ & $\begin{array}{l}1,00 \\
1,400\end{array}$ & $\begin{array}{l}1,050 \\
1,220\end{array}$ & $\begin{array}{r}.99 \\
1.15\end{array}$ & $\begin{array}{l}1,40 \\
1,820\end{array}$ & $\begin{array}{l}1,320 \\
1,600\end{array}$ & $\begin{array}{r}.92 \\
1.11\end{array}$ \\
\hline $\mathbf{B}$ & 41 & 1,050 & 1,020 & 1,950 & 1,800 & $\begin{array}{l}2.61 \\
\text { 2. }\end{array}$ & 2,260 & 2,020 & 1.91 & $\begin{array}{l}2,8<0 \\
2,580\end{array}$ & 2,230 & $\begin{array}{l}1.11 \\
1.55\end{array}$ \\
\hline & 42 & 940 & 870 & 1,780 & 1,700 & 2.46 & 2,290 & 2,100 & $\begin{array}{l}1.98 \\
1.98\end{array}$ & 2,610 & 2,350 & $\begin{array}{l}1.60 \\
1.63\end{array}$ \\
\hline & 43 & 570 & 480 & 1,290 & 1,100 & 1.59 & 2,560 & 2,040 & 1.92 & 2,910 & 2,450 & $\begin{array}{l}1.70 \\
\text { S }\end{array}$ \\
\hline I & 44 & 1,040 & 960 & 1,400 & 1,270 & 1.84 & 1,760 & 1,580 & 1.49 & 2,120 & 1,900 & $\begin{array}{l}1.30 \\
\end{array}$ \\
\hline & 45 & 440 & 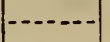 & 840 & 710 & 1.03 & 1,250 & 1,040 & .98 & 1,650 & 1,360 & .94 \\
\hline & 46 & 450 & $\cdots$ & 870 & 1,010 & 1.46 & 1,280 & 1,780 & 1.68 & 1,700 & 2,550 & 1. 77 \\
\hline$G$ & 47 & 430 & 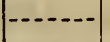 & 820 & ) & 1.04 & & 1,030 & .97 & 1,590 & 1,300 & .90 \\
\hline & 48 & 375 & 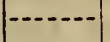 & $\begin{array}{l}740 \\
870\end{array}$ & 5 & .74 & & 910 & .86 & 1,480 & 1,270 & $\begin{array}{r}.88 \\
188\end{array}$ \\
\hline$\frac{1}{\pi}$ & 49 & $\begin{array}{l}430 \\
460\end{array}$ & 390 & $\begin{array}{l}870 \\
820\end{array}$ & 750 & 1.09 & 1,300 & 1,140 & 1.08 & 1,750 & 1,550 & 1.08 \\
\hline$\stackrel{J}{K}$ & $\begin{array}{l}50 \\
51\end{array}$ & $\begin{array}{l}460 \\
420\end{array}$ & & $\begin{array}{l}820 \\
850\end{array}$ & $\begin{array}{l}680 \\
760\end{array}$ & $\begin{array}{r}.99 \\
1.10\end{array}$ & $\begin{array}{l}1,1,270 \\
1,270\end{array}$ & $\begin{array}{l}1,010 \\
1,170\end{array}$ & $\begin{array}{r}.95 \\
1.10\end{array}$ & $\begin{array}{l}1,710 \\
1,690\end{array}$ & $\begin{array}{l}1,430 \\
1,570\end{array}$ & $\begin{array}{r}.99 \\
1.09\end{array}$ \\
\hline $\mathbf{L}$ & $\begin{array}{l}11 \\
52\end{array}$ & $\begin{array}{l}420 \\
470\end{array}$ & & $\begin{array}{l}800 \\
830\end{array}$ & 70 & 1. 01 & 1, 170 & 1,030 & .97 & $\begin{array}{l}\text {, } \\
1,510\end{array}$ & $\begin{array}{l}1,00 \\
1,360\end{array}$ & $\begin{array}{r}.09 \\
.94\end{array}$ \\
\hline $\mathbf{M}$ & 53 & 580 & & 1,020 & 65 & .94 & 1,420 & 880 & .92 & 1,800 & $\begin{array}{l}1,310 \\
\text { S }\end{array}$ & .91 \\
\hline N & 54 & 400 & & 800 & 50 & .72 & 1,340 & 900 & .85 & 1,900 & 1,2 & .90 \\
\hline o & 55 & 460 & $360^{-1}$ & 830 & 63 & .91 & 1,190 & 87 & .82 & 1,490 & i, & 7 \\
\hline $\mathrm{P}$ & 56 & 410 & 350 & 770 & 62 & .90 & 1,130 & J & .85 & i, & & \\
\hline Q & 57 & 510 & & 990 & 870 & 1.26 & 1,470 & 1,3 & 1. 28 & 0 & & 1. \\
\hline $\mathbf{R}$ & 58 & 500 & 430 & 900 & 830 & 1. 20 & 1,310 & i, & 1.15 & & 1,6 & 1. 12 \\
\hline $\mathrm{S}$ & 59 & 450 & $\ldots$ & 800 & 800 & $\begin{array}{l}1.16 \\
\text {. }\end{array}$ & 1,270 & 1,100 & 1.04 & 1,690 & 1,4 & .97 \\
\hline$T$ & 60 & 560 & 850 & 1,000 & 850 & 1. 23 & 1,430 & 1,110 & 1.05 & 1,880 & 1,4 & .99 \\
\hline$\overline{\mathrm{U}}$ & 61 & 470 & & 880 & 690 & 1.00 & 1,300 & 1,130 & 1.07 & 710 & | & 1.08 \\
\hline & 62 & $\begin{array}{c}510 \\
440\end{array}$ & & $\begin{array}{l}880 \\
800\end{array}$ & $\begin{array}{l}760 \\
630\end{array}$ & 1.10 & 1,200 & 980 & .92 & 1,500 & 1,200 & .83 \\
\hline $\begin{array}{l}\mathrm{AA} \\
\mathbf{B B}\end{array}$ & 64 & $\begin{array}{l}440 \\
450\end{array}$ & $\begin{array}{l}540 \\
340\end{array}$ & $\begin{array}{l}800 \\
780\end{array}$ & $\begin{array}{l}63 \\
58\end{array}$ & .91 & & j & .87 & & $\begin{array}{l}1,200 \\
1,100\end{array}$ & .83 \\
\hline $\mathrm{CC}$ & 65 & 540 & 640 & 960 & 73 & $\begin{array}{l}.00 \\
1.06\end{array}$ & 1,380 & 1,040 & .98 & $\begin{array}{l}1,800 \\
1,80\end{array}$ & 1,430 & $\begin{array}{r}.90 \\
.99\end{array}$ \\
\hline $\mathrm{DD}$ & 66 & 480 & 520 & 900 & 65 & .94 & $\begin{array}{l}1,280 \\
\text { a }\end{array}$ & 950 & .90 & $\begin{array}{l}1,640\end{array}$ & $\begin{array}{l}1,260 \\
1,260\end{array}$ & .88 \\
\hline EE & $\begin{array}{l}00 \\
67\end{array}$ & $\begin{array}{l}480 \\
470\end{array}$ & $\begin{array}{l}520 \\
420\end{array}$ & $\begin{array}{l}900 \\
850\end{array}$ & $\begin{array}{l}00 \\
74\end{array}$ & $\begin{array}{l}.94 \\
1.07\end{array}$ & $\begin{array}{l}1,280 \\
1,20\end{array}$ & 1,020 & .96 & $\begin{array}{l}1,040 \\
1,590\end{array}$ & $\begin{array}{l}1,3 \\
1,3\end{array}$ & $\begin{array}{l}.88 \\
.92\end{array}$ \\
\hline F & $\begin{array}{l}07 \\
68\end{array}$ & $\begin{array}{l}4.0 \\
510\end{array}$ & 440 & $\begin{array}{l}940 \\
940\end{array}$ & 84 & 1. 22 & $\begin{array}{l}1,380 \\
\text { S }\end{array}$ & $\begin{array}{l}1,210 \\
1\end{array}$ & 1. 14 & & 1, & 1. 11 \\
\hline$G$ & 69 & 430 & $\begin{array}{l}4+40 \\
360\end{array}$ & $\$$ & 63 & .91 & $\begin{array}{l}1,070 \\
\text { a }\end{array}$ & $\begin{array}{l}1,200 \\
\end{array}$ & .85 & & 1,180 & .82 \\
\hline $\mathrm{HH}$ & 70 & 500 & 350 & 860 & 57 & .83 & 1,190 & 00 & .78 & 1,510 & 1,110 & .77 \\
\hline II & 71 & 610 & $\ldots$ & 1,000 & 75 & 1.09 & 1,370 & 980 & .92 & 1,690 & 1,210 & .84 \\
\hline JJ & 72 & 500 & 380 & 840 & 600 & .87 & & & & 1,500 & 1,1 & .76 \\
\hline
\end{tabular}

The results of the deflection tests of spring washers are shown graphically in Figure 73.

The appearance of the nuts and bearing washers after the tests of the spring washers is shown in Figures 74, 75, and 76.

\section{DISCUSSION}

\section{GENERAL}

To aid in interpreting these results it was thought desirable to form some estimate of deviations of the test results for nominally identical specimens. For this purpose a thorough study was made of the data for the regular nuts.

In screwing on, devices $I$ and $I V$ (regular American National coarsethread nuts) were like devices under like test conditions. Similarly 
in screwing on, devices $I I, V, \mathrm{I}, \mathrm{K}$, and $\mathrm{S}$ (regular U. S. standard nuts) were alike. Device VII was from different stock, but differed from these nominally only in the slot for the cotter pin. Also, in screwing on, devices $I I I$ and $V I$ were alike. Device VIII was from different stock, but differed from these nominally only in the castellated top. Within each of these groups the deviation of the screwing-on torque of the individual device from the mean is a measure of the variation in the behavior of nominally identical devices.

The maximum deviation from the mean of the screwing-on torques in any one of these groups for stresses above 10,000 lb. per sq. in. is 6.1 per cent. Differences of less than 6 per cent between screwing-on torques for different devices are therefore probably of no significance.

No such large group of like specimens was available for a study of initial screwing-off torques. The detailed study was confined to devices $I, I I$, and $I I I$. Between individual specimens the maximum deviations from the mean which were found, expressed as percentages of the screwing-on torque, were:

Screwing-on torque Per cent

Difference between screwing-on and screwing-off torques.

The differences between individual specimens of the other devices were in most cases considerably greater than for the regular nuts. Consequently, differences of less than 6 per cent, or even more, in these quantities are probably of no significance. It is to be noted that if the screwing-on and the screwing-off torques on the same nut and bolt were independent the differences should be expected to show larger deviations, approaching 9 per cent in value.

\section{PERSY'S THEORY}

Omitting negligible second-order terms, Persy's theoretical discussion applied to $3 / 4$-inch regular nuts leads to the following relations:

American National coarse and U. S. standard thread screwing-on torque

$$
\frac{T}{S}=0.442 R f^{\prime}+0.175 f+0.00703
$$

Screwing-off torque

$$
\begin{gathered}
\frac{t}{S}=0.442 R f^{\prime}+0.175 f-0.00703 \\
\text { Difference } \frac{(T-t)}{S}=0.0141
\end{gathered}
$$

American National fine-thread screwing-on torque

$$
\bar{T}=0.442 R f^{\prime}+0.181 f+0.00439
$$


Screwing-off torque

$$
\begin{gathered}
\frac{t}{S}+0.442 R f^{\prime}+0.181 f-0.00439 \\
\text { Difference } \frac{(T-t)}{S}=0.00879
\end{gathered}
$$

where $\mathrm{T}=$ screwing-on torque (in. $\mathrm{lb}$.).

$t=$ screwing-off torque (in. lb.).

$S=$ stress in bolt (lb. per sq. in.).

$R=$ effective bearing radius of nut on washer (in.).

$f^{\prime}=$ coefficient of friction of nut on washer.

$f=$ coefficient of friction of nut threads on bolt threads.

In these expressions three quantities, $R, f^{\prime}$, and $f$, occur, which are known to vary considerably with small changes in the bearing surfaces, such as smoothness of finish, lubrication, etc.

In view of the variations found in the experiments between nominally identical devices, no close check of these formulæ could be expected. They can, however, serve in some cases to give a general idea of the behavior of regular nuts and bolts.

\section{CLEARANCES AND OBLIQUITY OF BEARING FACE OF NUT}

Detailed studies were made of the individual test results from regular nuts. The scatter diagrams plotted showed a wholly random distribution. Within the limits used in these tests, neither clearance of nut on bolt nor obliquity of the bearing face of the nut measurably affected the torques.

\section{DEVICES}

Devices $I, I I$, and $I I I$. Regular nuts

From Persy's theory we should conclude that for these devices the screwing-on torque should be proportional to the stress, that the initial screwing-off torque and the continuous screwing-off torque should be the same and proportional to the stress. If the coefficients of friction remained constant, the difference between the screwing-on and screwing-off torques should be the same for $I$ and $I I$, smaller for $I I I$, and be calculable from the equations. If, in addition, the coefficients of friction were the same in all three devices we should expect the screwing-on torques for $I$ and $I I$ to be nearly identical and greater than for $I I I$.

The curves show that, with accidental variations found in the behavior of devices, these conclusions are fairly well borne out. The screwing-on curves are straight lines through the origin. The initial screwing-off and continous screwing-off curves show greater discrepancies, which may be due to changes in the coefficients of friction. The fact that the continuous screwing-off curves for device $I$ lie somewhat above the initial screwing-off curve, for device $I I$ almost coincide with it, and for device $I I I$ lie somewhat below, can not be caused by any differences in the design of the three devices, but are probably caused by differences in the small changes in the condition of the bearing surfaces during the test. 


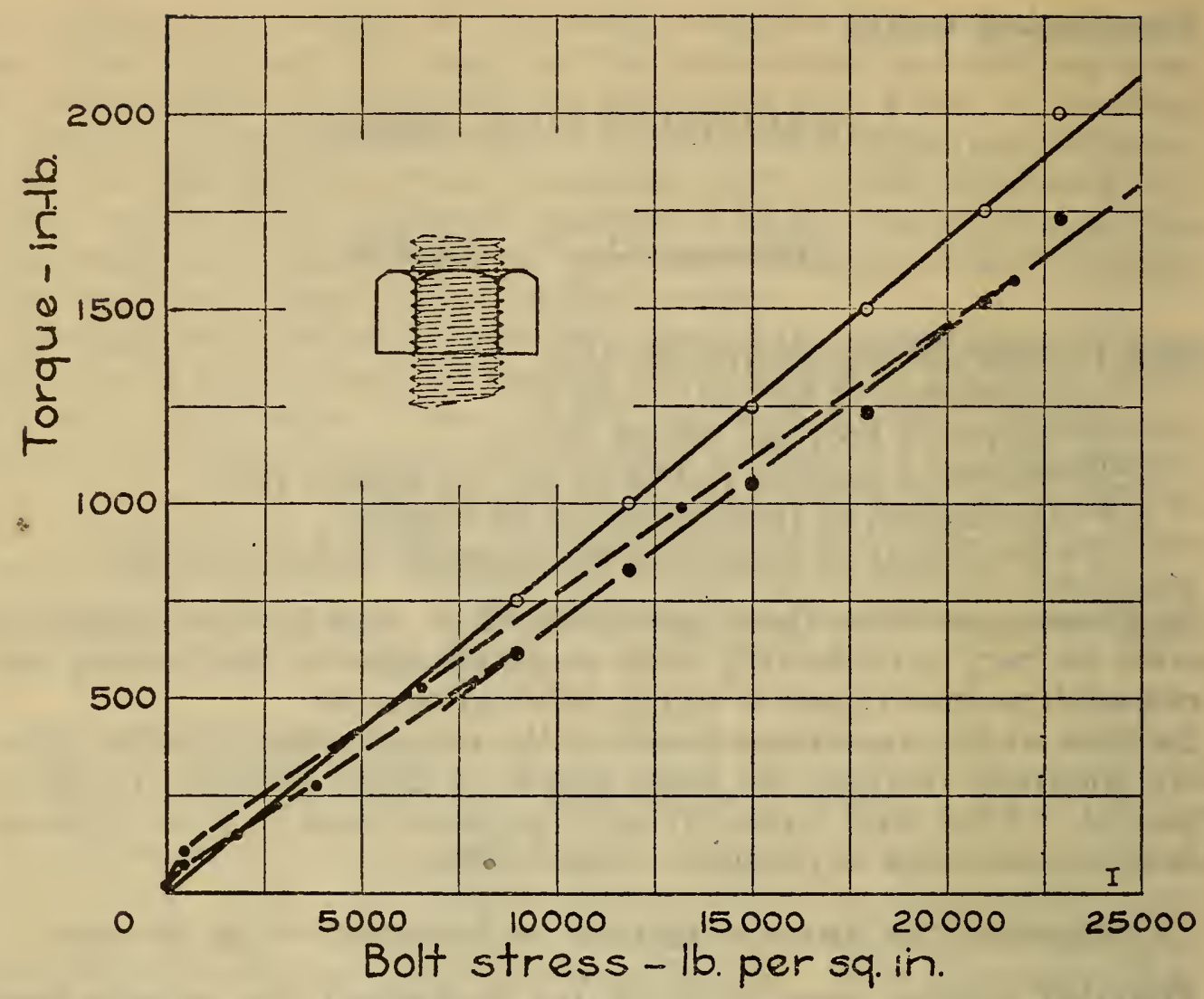

FIGURE 32.-Torque-tension curves for device I. American National coarse-thread regular nut. Five specimens were tested

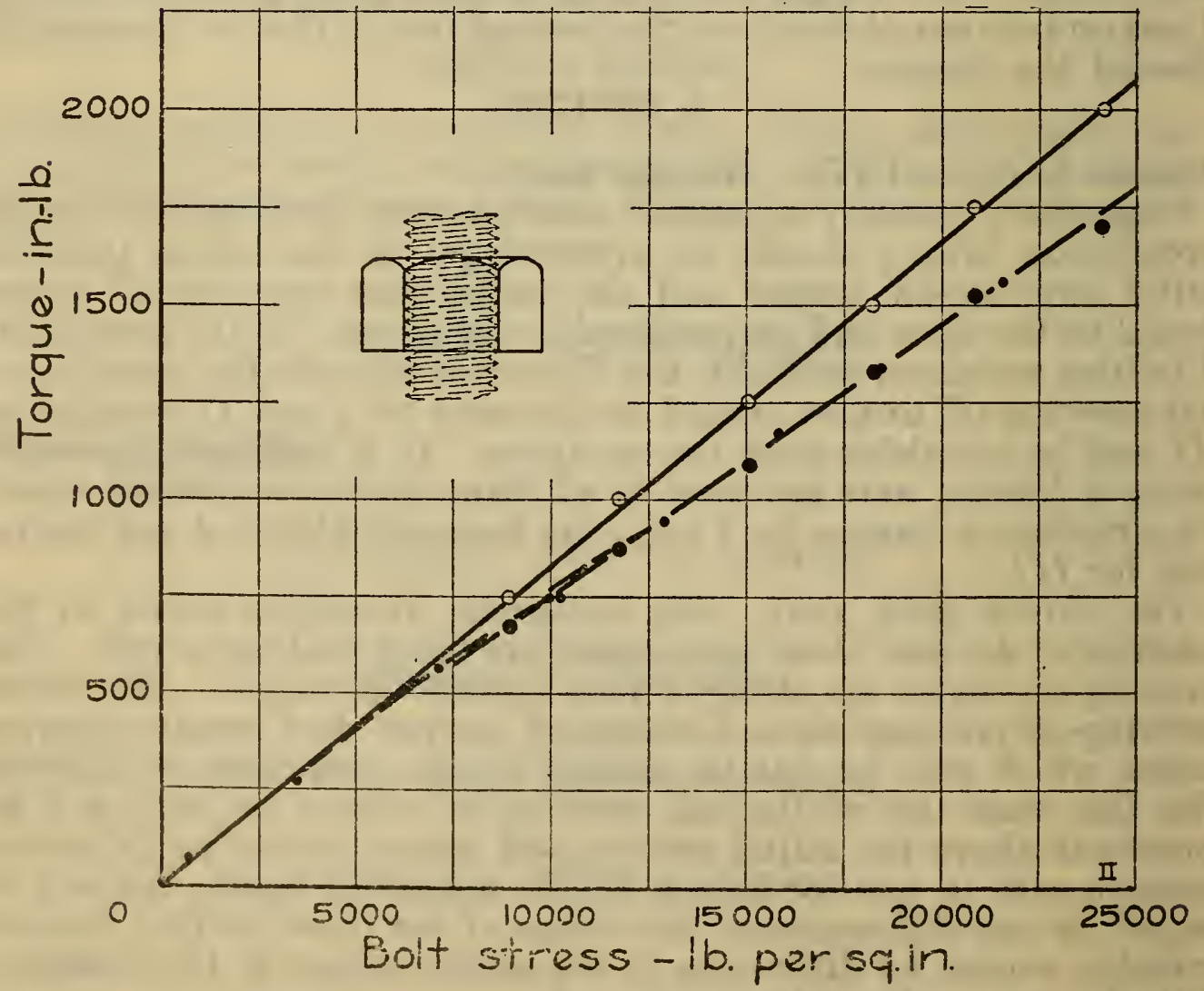

FIGURE 33.-Torque-tension curves for device II. U. S. standard regular nut. Five specimens were tested 
A comparison of the differences between the screwing-on and initial screwing-off stresses is given in Table 7.

TABLE 7.-Ratio of difference between screwing-on and initial screwing-off torques to stress in bolt

\begin{tabular}{|c|c|c|c|c|c|c|}
\hline 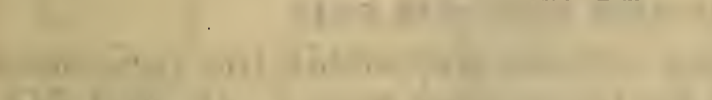 & \multicolumn{4}{|c|}{$\frac{T-t}{S}$} & \multicolumn{2}{|c|}{$\begin{array}{l}\text { Number of } \\
\text { resdings }\end{array}$} \\
\hline 1. Device & \multirow{2}{*}{$\begin{array}{l}\text { Theo- } \\
\text { retical }\end{array}$} & \multicolumn{3}{|c|}{ Observed } & \multirow{2}{*}{$\begin{array}{l}\text { Larger } \\
\text { than } \\
\text { theo- } \\
\text { retical } \\
\text { value }\end{array}$} & \multirow{2}{*}{ Total } \\
\hline 4 & & Min. & Max. & Aver. & & \\
\hline $\begin{array}{l}\text { I. American National coarse-thread regular nut.... } \\
\text { II. U. S. standard regular nut } \\
\text { III. American National fine-thread regular nut. }\end{array}$ & $\begin{array}{c}\text { In . } \\
0.0141 \\
.0141 \\
.0088\end{array}$ & $\begin{array}{c}\text { In.3 } \\
0.0094 \\
.0066 \\
.0053\end{array}$ & $\begin{array}{c}\text { In. } \\
0.0188 \\
.0152 \\
.0112\end{array}$ & $\begin{array}{c}\text { In. } \\
0.0132 \\
.0098 \\
.0079\end{array}$ & $\begin{array}{l}6 \\
3 \\
3\end{array}$ & $\begin{array}{l}18 \\
17 \\
14\end{array}$ \\
\hline
\end{tabular}

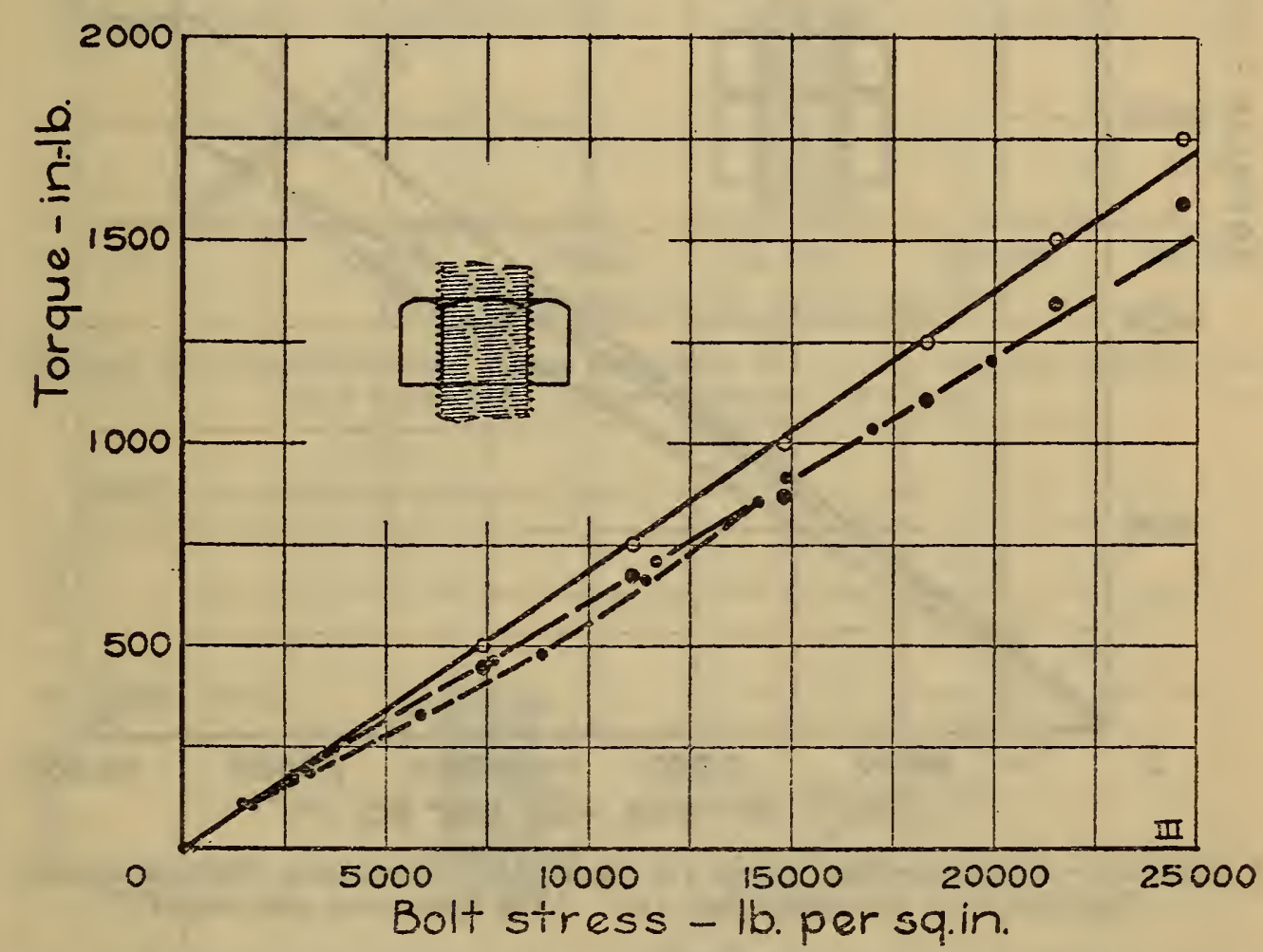

Figure 34.-Torque-tension curves for device III. American National finethread regular nut. Five specimens were tested

The average in each case lies considerably below the theoretical value, and the scatter of the observations is large. This seems to indicate definitely a change of the condition of the bearing surfaces during the test.

The screwing-on torques for devices $I$ and $I I$ are considerably higher than those calculated from the table given by Case. ${ }^{12}$ Case gives 0.15 as the coefficient of friction "when a reasonably welllubricated bolt is tightened." Other authors, without specifying the conditions of lubrications, give torques corresponding to coefficients of friction ranging in different cases from 0.074 to 0.21 . 
On the assumption that $f=f^{\prime}$; that is, that the coefficient of friction between nut and bolt is the same as between nut and washer, the average value of $f$ was calculated by Persy's theory from the screwingon torques at 20,000 lbs. per sq. in. stress. The values were: For device $I, f=0.20$; for device $I I, f=0.19$; and for device $I I I, f=0.17$. Devices $I V, V$, and $V I$. Regular nuts with jam nuts.

The screwing-on torques for these devices are, within the variations previously discussed, the same as for the regular nuts $I, I I$, and $I I I$. The initial screwing-off torques and continuous screwing-off torques show differences larger in magnitude but of the same character as found in $I, I I$, and $I I I$. Thus the curves for continuous screwing off

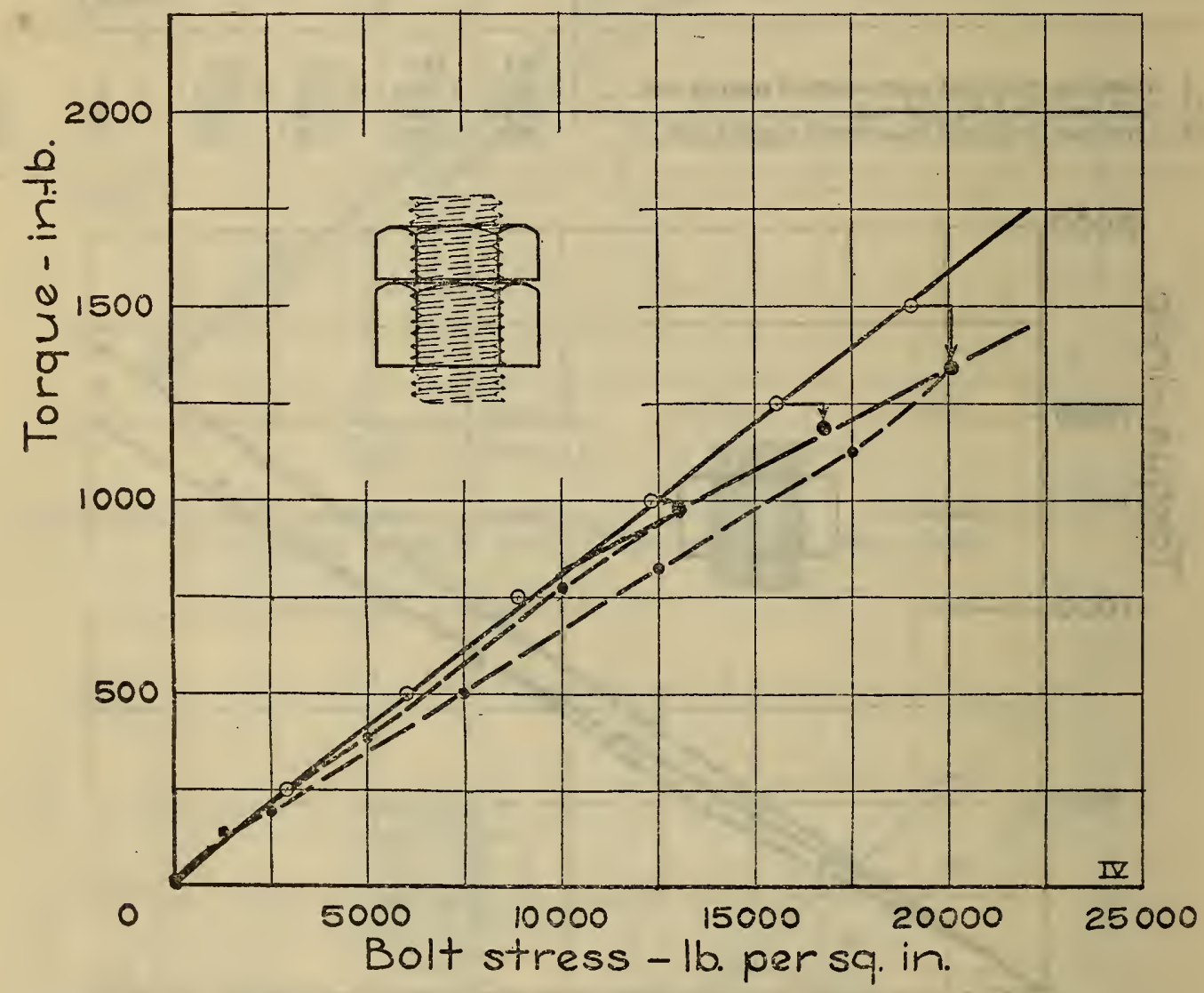

FIgURe 35.-Torque-tension curves for device IV. American National coarsethread regular nut and a jam nut. Nine specimens were tested

for device $V$ lies considerably above the initial screwing-off curve, for device $V I$ it almost coincides with it, and for device $I V$ it lies considerably below it. The differences between the screwing-on and screwing-off torques, although less uniform, average practically the same as for the regular nuts $I, I I$, and $I I I$. There was, however, for the jam nuts, a small but definite final screwing-off torque at zero stress which was not present with the regular nuts alone.

Device VII. U. S. standard slotted nut and a cotter pin (fig. 38).

The curve for the screwing-on torques is approximately a stright line, but the deviation of the individual points from the straight line is greater than for any of the preceding devices. In addition, the average straight line prolonged cuts the axis of zero stress at about 100 inch-pounds torque. 


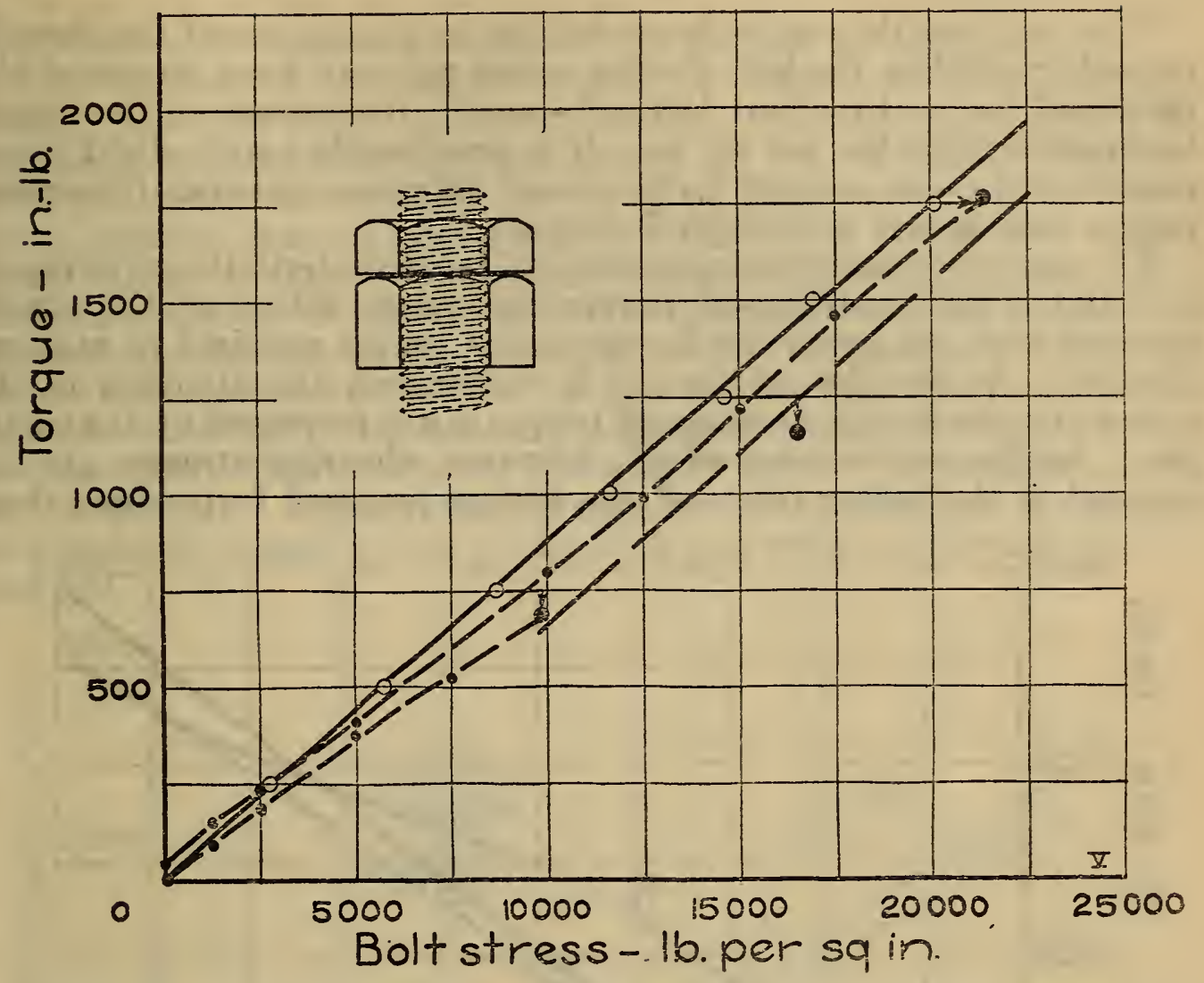

FIGURe 36.-Torque-tension curves for device $V$. U. S. standard regular nut and a jam nut. Nine specimens vere tested

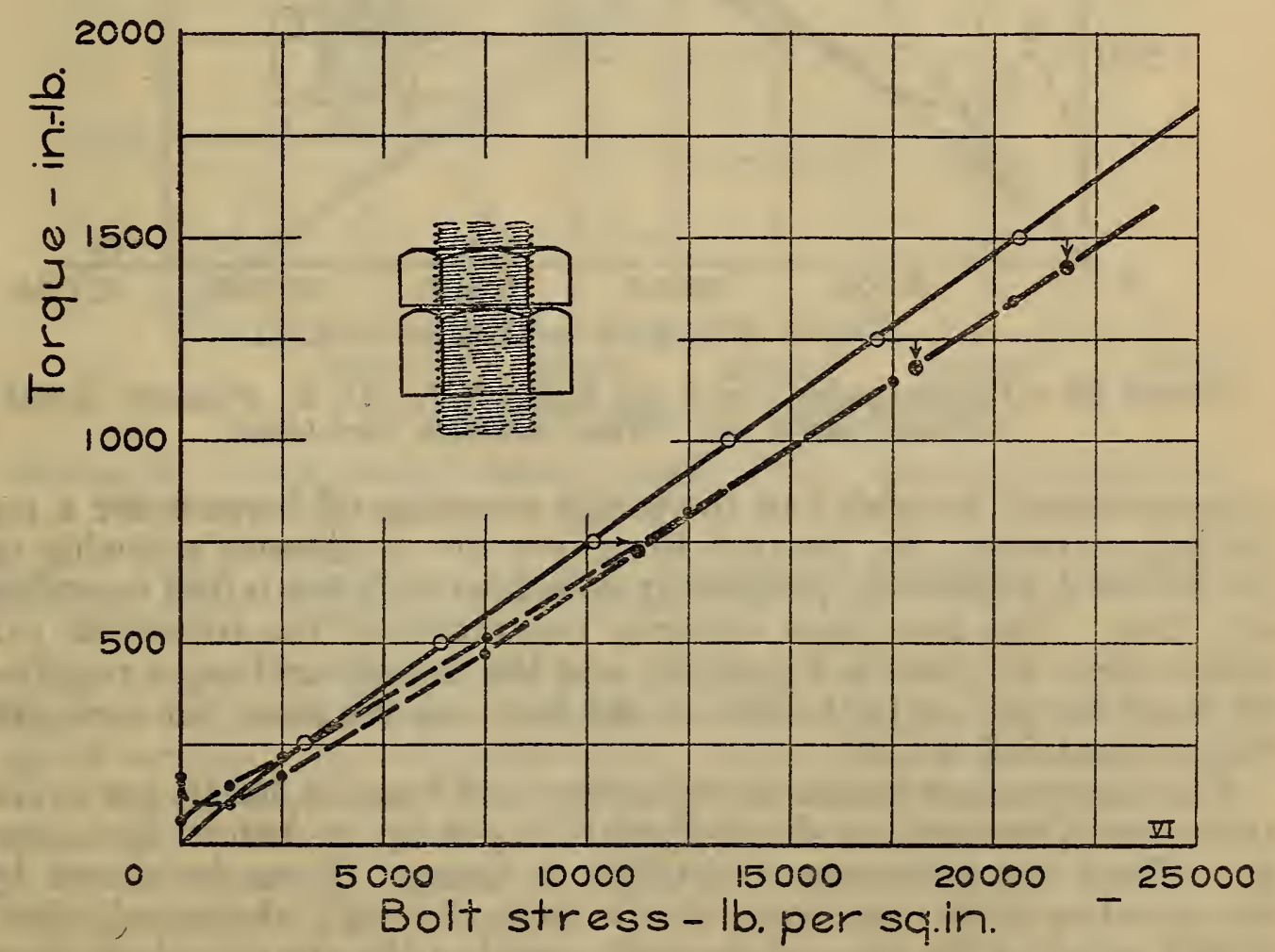

Figdre 37.-Torque-tension curves for device VI. American National finethread regular nut and a jam nut. Nine specimens were tested 
This suggests that slight irregularities in the surface of the threads caused by drilling the hole for the cotter pin may have increased the frictional torque by about 100 inch-pounds for stresses in the neighborhood of $5,000 \mathrm{lbs}$. per sq. in. It is possible that such slight irregularities may also account for the small difference between the screwing-on and initial screwing-off torques.

The curves for continuous screwing off lie above both the screwing-on and the initial screwing-off curves for many values of the stress, showing that the cotter pin increased the torque required to unscrew the nut. As the slot in the nut is wider than the diameter of the cotter pin, the initial screwing-off torque is not increased by the cotter pin. As the nut is screwed off, however, shearing stresses are developed in the cotter pin, and the torque required to produce these

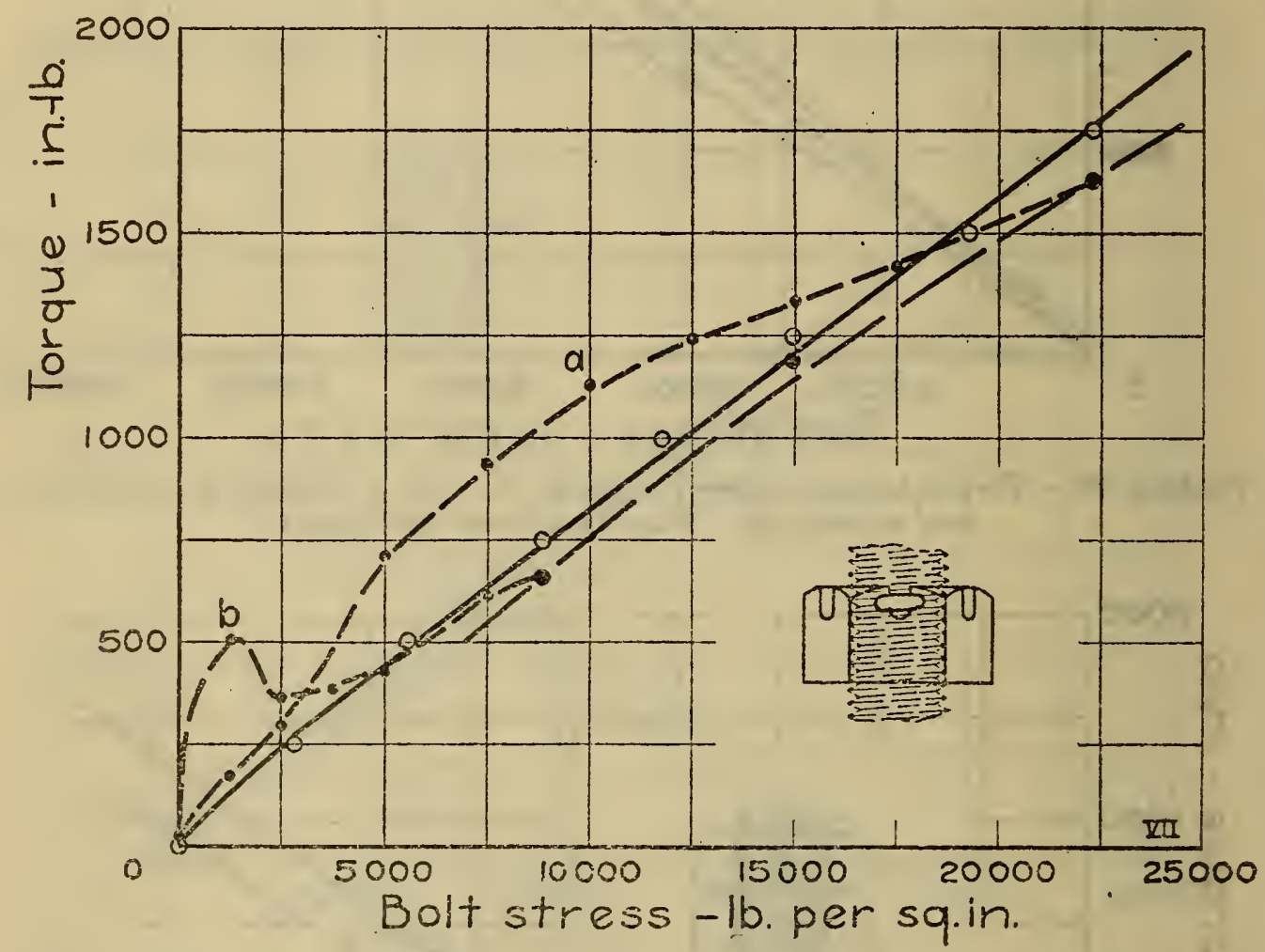

Figore 38.-Torque-tension curves for device VII. U. S. standard slotted nut and a cotter pin. Nine specimens were tested

stresses should be added to the initial screwing-off torques for a nut having no cotter pin, because the curve for continuous screwing off for device $I$, Figure 33, practically coincides with the initial screwingoff curve. The maximum shearing resistances of the cotter pin evidently were at $a$ and $b$, Figure 38 , and the maximum torque required to shear the pin on both sides of the bolt was the same for each pin, being about $350 \mathrm{in}$. lb.

For the specimen continuously screwed off from $22,500 \mathrm{lb}$. per sq. in. the stress decreased to about $10,000 \mathrm{lb}$. per sq. in. before the cotter pin offered the maximum resistance to shear. It can be shown by computation that the body of the bolt ( 6.5 in.) shortened about $0.0028 \mathrm{in}$. when the stress decreased, and that the nut must have been rotated about 0.028 turn. The side of the slot at the major diameter of the thread must have moved about 0.07 in. As the slot was ${ }_{16}^{\prime \prime}$ in. 
wide and the cotter pin $1 / 8$ in. in diameter, there was a clearance of $1 / 16$ in. $(0.0625$ in.) between the pin and the sides of the slot.

The continuous screwing-off curves in Figure 38 show that, although the screwing-off torque decreased, the cotter pins offered increasingly greater resistance, as shown by the increasing difference from the initial screwing-off curve. The maximum shearing resistance, however, was not developed until the side of the slot had moved about 3116 in. or sheared about one-half way through the pin. It is obvious that part of this deformation was crushing of the bolt and of the nut and bending of the cotter pin. For the specimen screwed off from a stress of about $9,000 \mathrm{lb}$. per sq. in. the nut was not screwed off quite so much before the shearing resistance of the cotter pin became a maximum. This was in all probability due to the position of the pin in the slot. The sudden increase in the screwing-off torque at $b$ was probably caused by the pin bending and wedging between the bolt and nut.

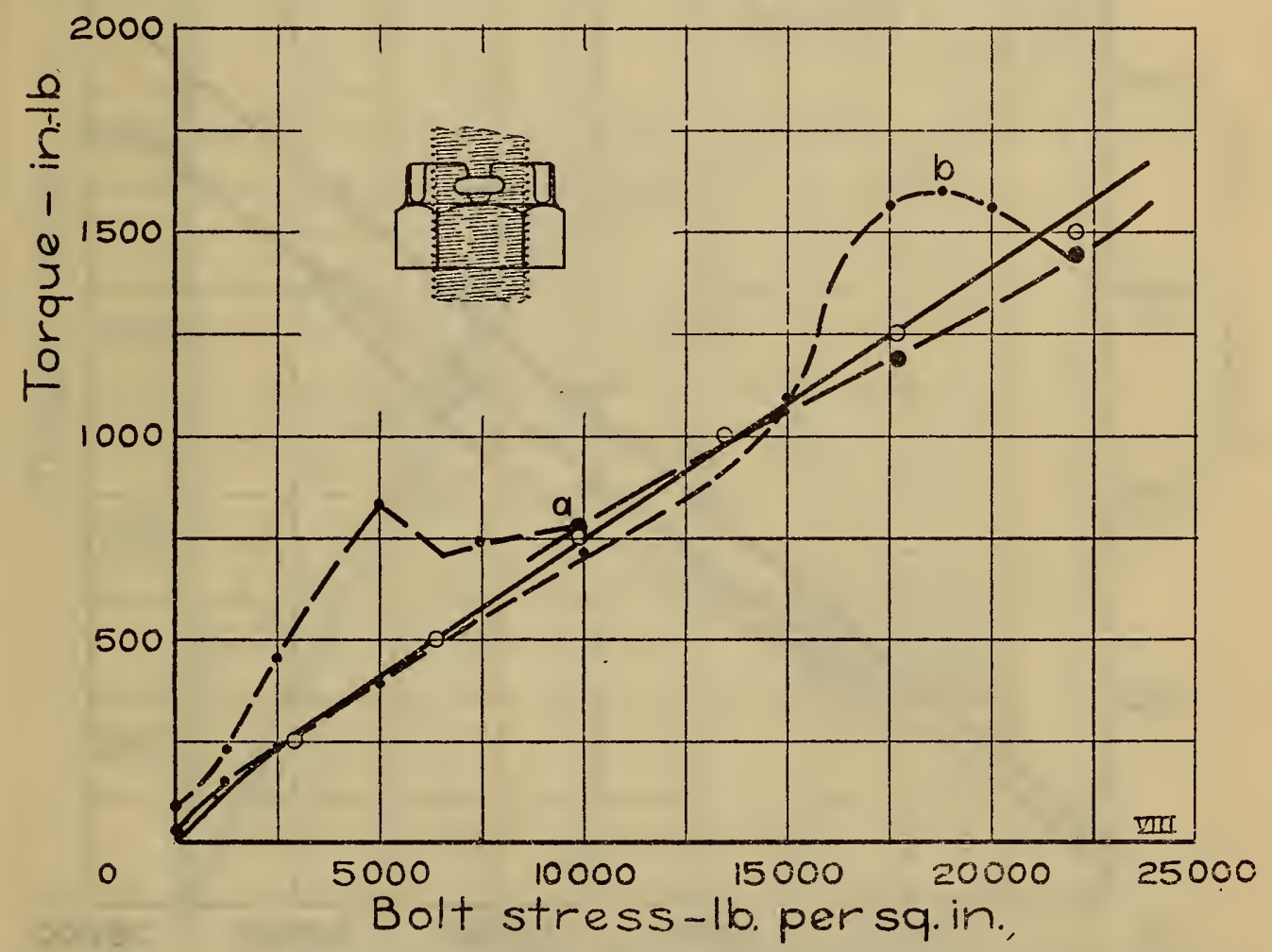

Figure 39.-Torque-tension curves for device VIII. American National finethread castellated nut and a cotter pin. Nine specimens were tested

Device VIII. American National fine-thread castellated nut with a cotter pin. (Fig. 39.)

The curves for this device are similar to those for device VII. There is not much difference between the screwing-on and the screwing-off torques. No fully satisfactory explanation has been found for the screwing-off torque being slightly greater than the screwing-on torque at $a$. It is possible that it may also be ascribed to irregularities in the bolt threads, caused by drilling the hole for the cotter pin.

As for device VII the maximum torque required to shear the pin on both sides of the bolt was about 350 inch-pounds. This value should be the same because the cotter pins for both devices had a diameter of $1 / 8$ inch. 
The curves for continuous screwing off, unlike those for device VII, rise rapidly from the initial value because the slots in the nuts were only $5 / 32$ inch wide and the clearance between pin and slot only $1 / 32$ inch instead of $1 / 16$ inch. The maximum shearing resistance of the pins was, therefore, developed when the side of the nut had moved only about 0.02 inch or about one-third of the movement for device VII.

The curves show that for the specimen continuously screwed off from about $22,500 \mathrm{lb}$. per sq. in. the cotter pin was sheared through when the stress was about $15,000 \mathrm{lb}$. per sq. in. and that the curve then followed closely the initial screwing-off curve. The maximum value

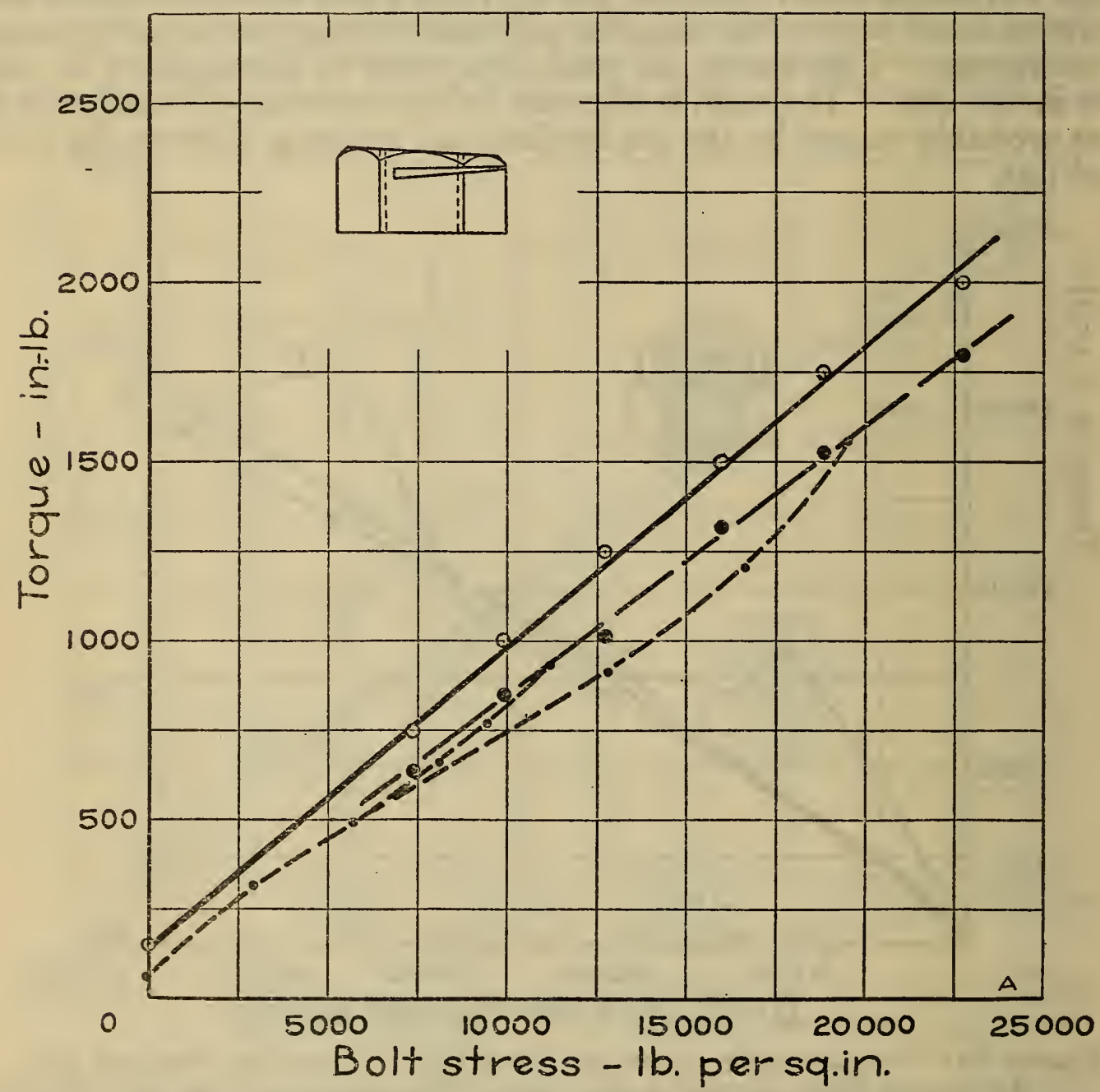

FigURe 40.-Torque-tension curves for device $A$. Five specimens were tested

at $b$ (fig. 39) was appreciably higher than the initial screwing-off torque. However, it seems evident that if the cotter pin had been a snug fit in the slot the maximum torque would have been somewhat higher.

Device A (fig. 40).

The curves for this device are similar to those for device $I I$ except that the torque (about $150 \mathrm{in.}$ lb.) required to screw-on the nut raised the screwing-on curve by this amount. The differences between the screwing-on and the screwing-off curves are about the same as for device $I I$. This curve intersects the axis of zero stress at about 75 in. lb. showing that the nut had been permanently deformed and that 
the torque required to screw on the same nut would thereafter be about $75 \mathrm{in.} \mathrm{lb}$. instead of $150 \mathrm{in} . \mathrm{lb}$.

Devices B and B-U. S. (figs. 41 and 42 ).

As the only difference in these devices was the width across the flats of the hexagon of the nut, they will be discussed together.

The screwing-on and the screwing-off torques are proportional to the stress up to $a$, when the stress is about $10,000 \mathrm{lb}$. per sq. in. The differences in the stress at $a$, Figures 41 and 42 , for the two devices,

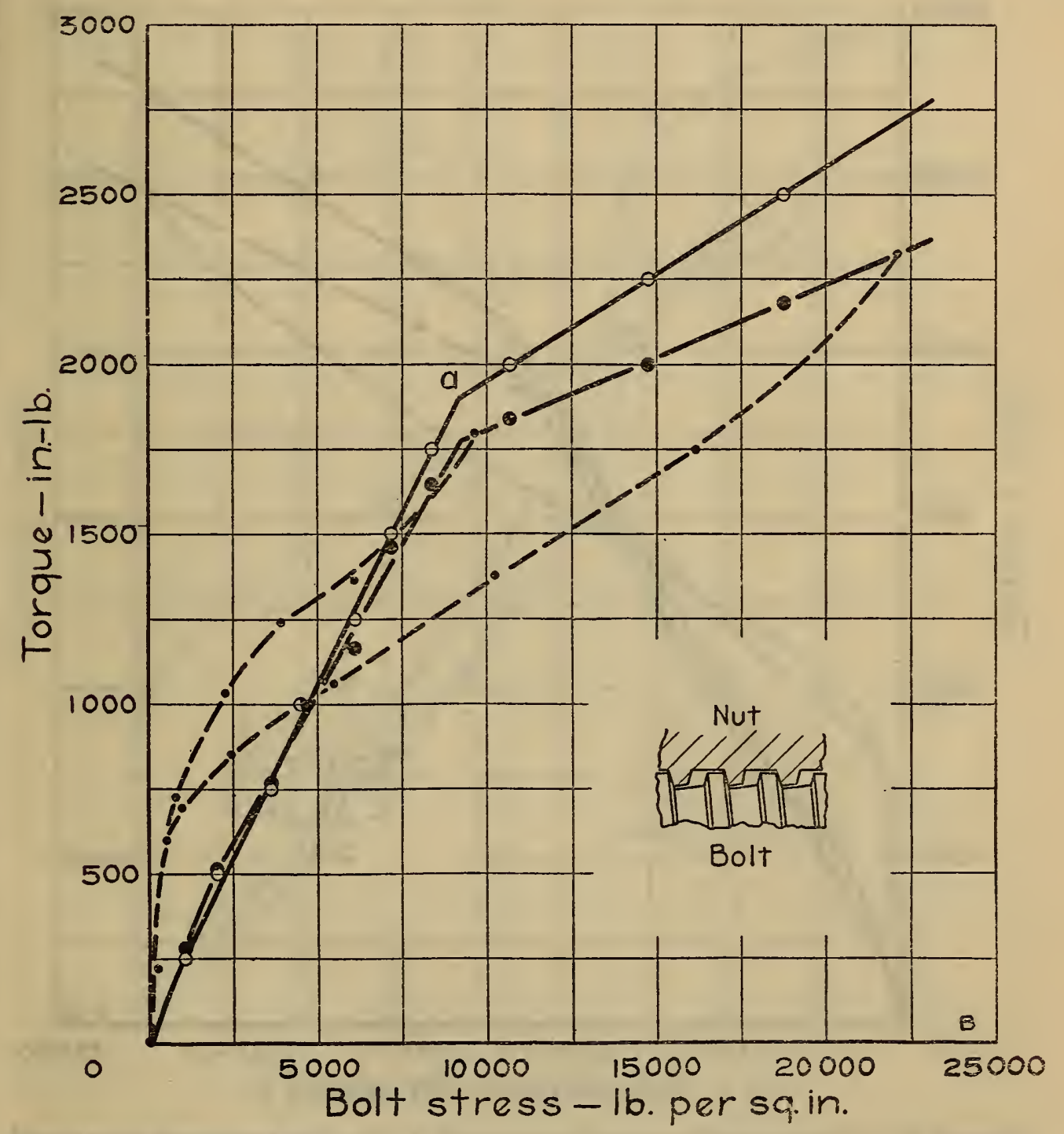

FIGURE 41.-Torque-tension curves for device B. Five specimens were tested

are probably due to small differences in the dimensions of the specimens. For stresses above $a$ there is a straight-line relation between torque and stress for both screwing on and screwing off, and the lines intersect the axis of zero stress at about the same point.

From zero to the point $a$ on these graphs only the helical cones are in contact, and both the screwing-on and screwing-off torques increase very rapidly as the stress increases, due to the friction between the helical cones. The curves for continuous screwing off from stresses close to or below $a$ show that the torque is considerably greater than either the screwing-on or the initial screwing-off torque for the same 
stress. The change in the slope of the screwing-on and the initial screwing-off curves at $a$ is caused by the thrust faces $c$ in Figure 2 coming into contact. As the stress is increased above the value at $a$, the compressive forces on these thrust faces increase, but the compressive forces on the helical cones are practically unchanged. The curves for continuous screwing off from stresses higher than those at $a$, lie below those for both screwing-on and initial screwing-off until they cross these curves between zero and $a$. For stresses below 5,000

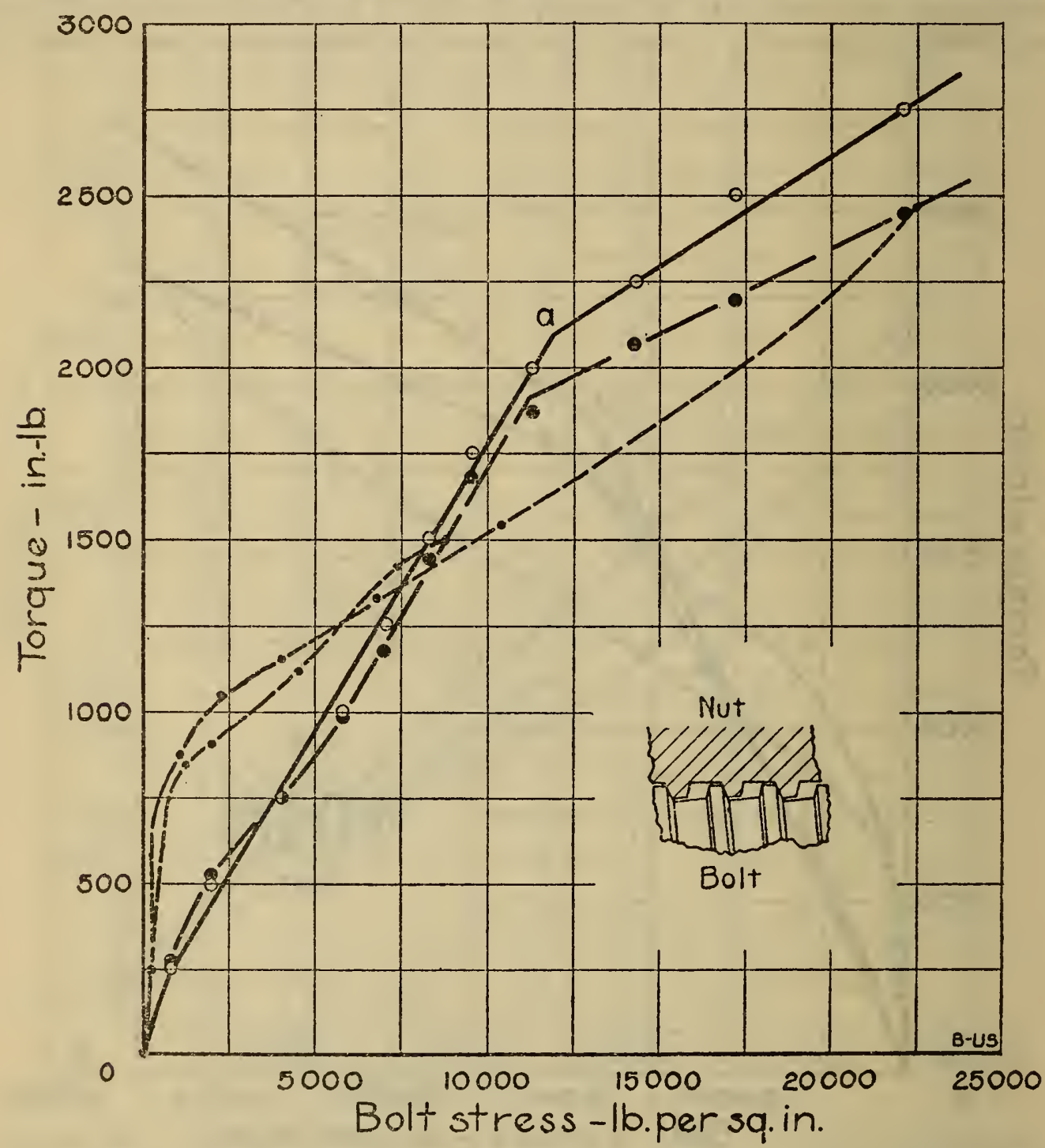

FIGURE 42.-Torque-tension curves for device B-U.S. Five specimens were tested

lb. per sq. in. these torques are much greater than the screwing-on torques or the initial screwing-off torques. As the stress is further decreased they coincide approximately with the curves for screwing-off to zero from stresses below $a$.

\section{Device C (fig. 43).}

As the stress increases to $15,000 \mathrm{lb}$. per sq. in., the screwing-on and initial screwing-off torques for this device increase more rapidly than the stress, being much greater than those for devices $I$ and $I I$ (figs. 32 and 33 , regular nuts). The initial screwing-off torques: are always less than the screwing-on torques, the difference increasing as the 
stress increases. For stresses above $15,000 \mathrm{lb}$. per sq. in., the torques increase much less rapidly. Probably the washer, $b$, Figure 3 , came into contact with the face of the nut. Higher stresses, therefore, did not increase the forces acting at $a$.

The curve for screwing off to zero from $10,000 \mathrm{lb}$. per sq. in, coincides approximately with the initial screwing-off curve. But for continuous screwing off from about $22,000 \mathrm{lb}$ : per sq. in., most of this curve lies above both the screwing-on and initial screwing-off curves. It is approximately parallel to the corresponding curve for device $I I$,

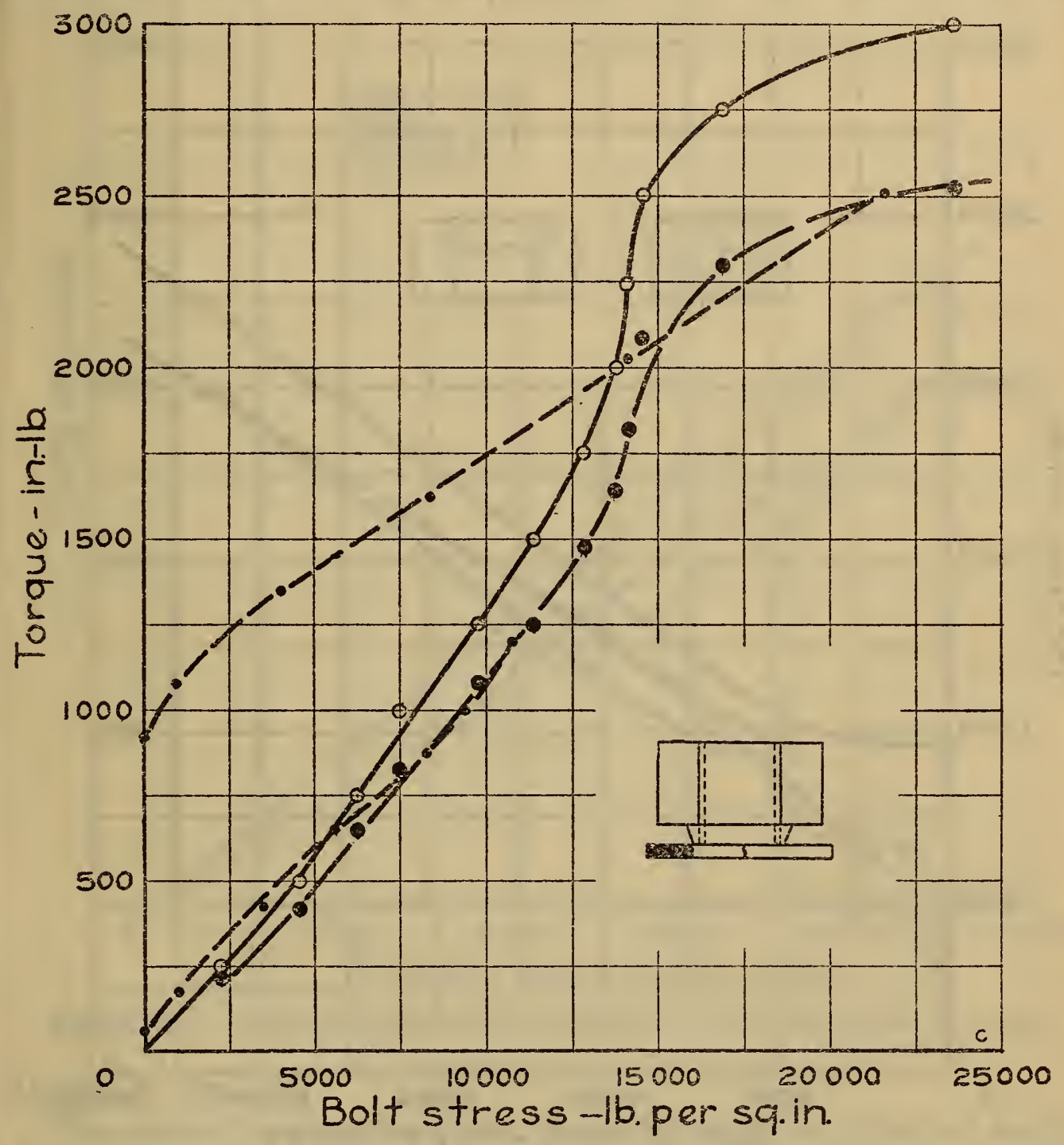

FIGURE 43.-Torque-tension curves for device $C$. Five specimens were tested

but lies about 1,000 inch-pounds higher. It is evident that the angle of the tapered portion of the nut is below the angle of friction, so that when continuously screwing off from high stresses, the washer $b$, Figure 3, continues to exert large forces at $a$, as the stress decreases. The torque required to rotate the nut when the stress was zero was about 1,000 inch-pounds.

Both the screwing-on and the initial screwing-off torques for this device at a stress of $20,000 \mathrm{lb}$. per sq. in. are approximately 1,000 inchpounds greater than for devices $I$ and $I I$, Figures 32 and 33 (regular nuts). 
Device D (fig. 44).

For this device, except for low stresses, there is a straight-line relation between the stress and the screwing-on and the initial screwingoff torques. These curves, if projected, intersect the axis of zero stress at the same point, about 700 inch-pounds. They are roughly parallel to the corresponding curves for device $I I, U$. S. standard nut, but 700 inch-pounds higher. The torque required to rotate the nut under zero stress was initially about 900 inch-pounds, but after the stress had been increased to $5,000 \mathrm{lb}$. per sq. in. this value decreased

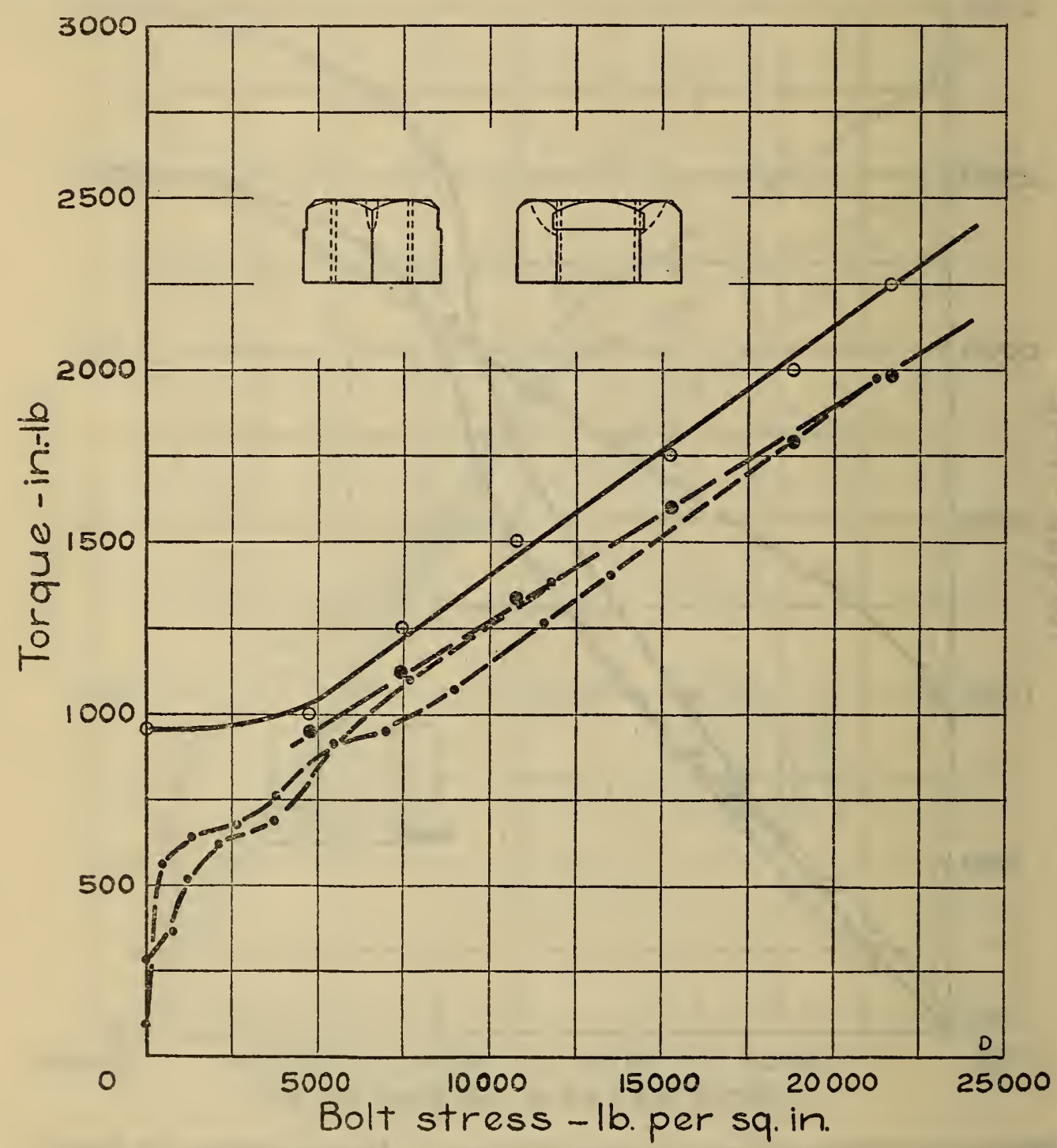

FIGURE 44.-Torque-tension curves for device D. Five specimens were tested

to about 700 inch-pounds, because the initial screwing-off curve intersects the axis at this point.

The curve for continuous screwing off from a stress of about 12,000 lb. per sq. in. followed the initial screwing-off curve, then decreased rapidly at low stresses. The curve for continuous screwing off from a stress of about $22,000 \mathrm{lb}$. per sq. in., if projected, intersects the axis of zero stress at about 400 inch-pounds. The curve indicates that both the nut and the bolt were permanently deformed after the test, the initially deformed portion of the nut being expanded, as shown 
by the lower intercept, and the bolt becoming somewhat tapered, as shown by the rapid decrease of the torque near zero stress. This interpretation was confirmed by supplementary measurements obtained by screwing the device on and off an unstressed bolt.

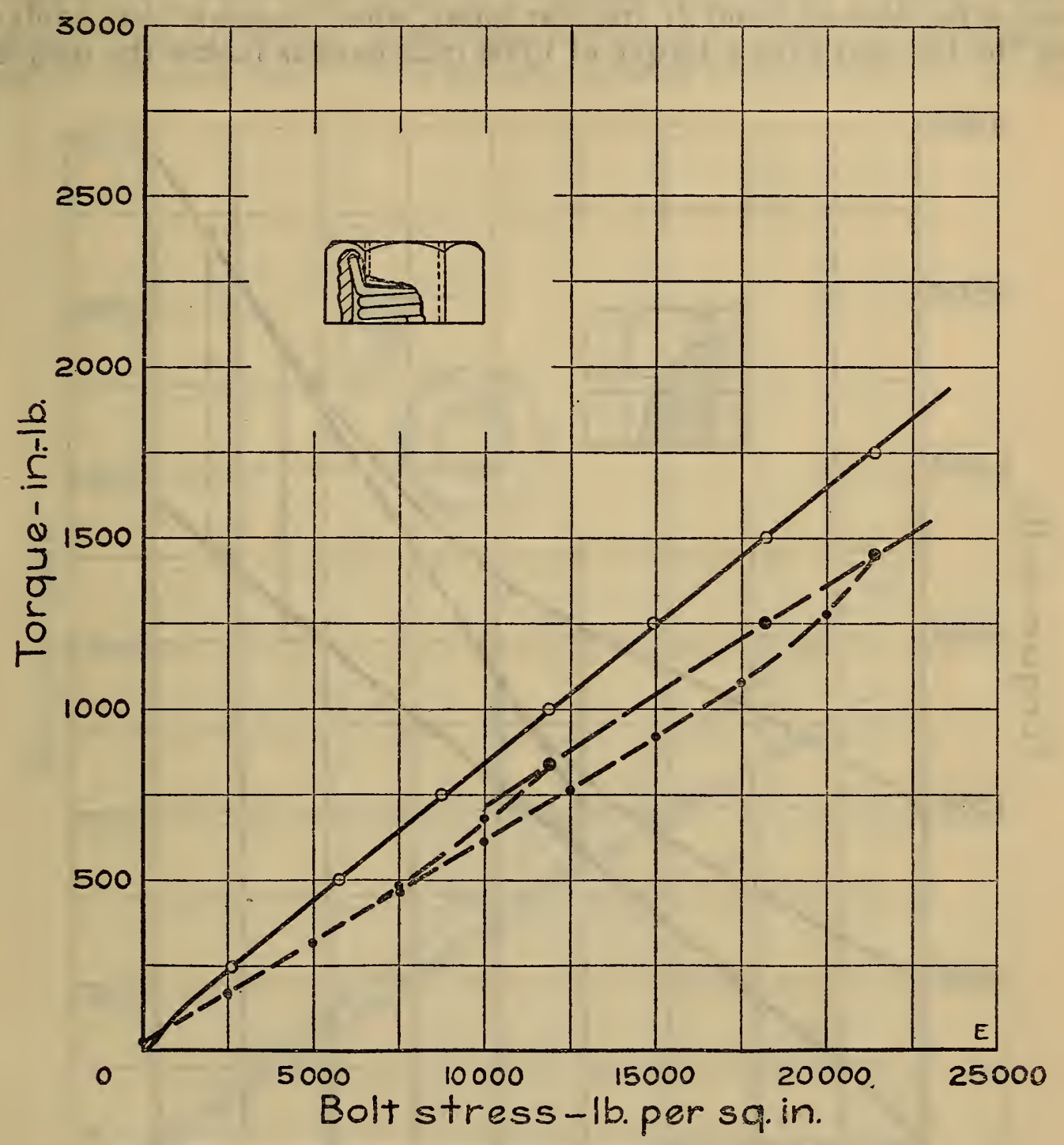

Figure 45.-Torque-tension curves for device $E$. Nine specimens were tested

Device E (fig. 45).

The curves for this device are about the same as those for devices $I$ and $I I$, Figures 32 and 33 (regular nuts). The screwing-on and the initial screwing-off torques are approximately proportional to the stress.

The end $b$ of the spring, Figure 5, was deformed when the device was unscrewed. It could not be used again.

Device F (fig. 46).

The screwing-on torques for this device, as should be expected, were proportional to the stress and the values the same as for those of devices $I$ and $I I$, Figures 32 and 33 (regular nuts). The initial screwing-off torques are considerably greater than the screwing-on 
torques for corresponding stresses, because screwing on the jam nut $d$, Figure 6 , after the nut $a$ has been tightened increased the frictional resistance.

The curves for continuous screwing off lie considerably above the other curves. They are roughly parallel to the initial screwing-off curves for devices $I$ and $I I$ (regular nuts), which suggests that applying the jam nut with a torque of 1,000 inch-pounds makes the torque

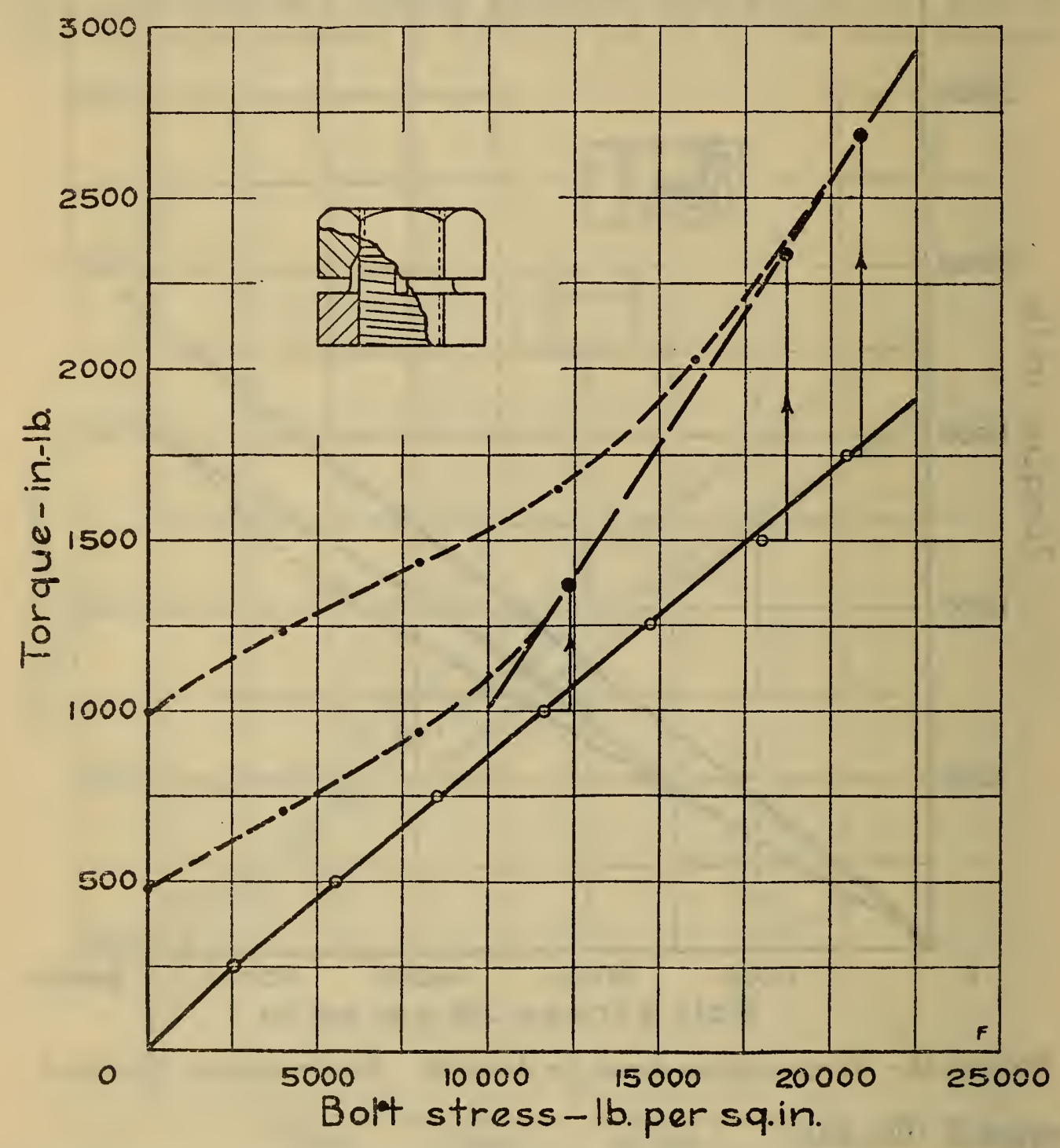

FIgURE 46.-Torque-tension curves for device $F$. Nine specimens were tested

required to rotate the nut under zero stress about 500 inch-pounds, and, applying it with a torque of 1,750 inch-pounds, makes this torque about 1,000 inch-pounds. The initial screwing-off torques are about these amounts greater than those for devices $I$ and $I I$ (regular nuts). The threads in the nuts were not a snug fit on the bolt threads. Therefore it was necessary to deform the cylindrical portion of the nut appreciably before the threads were in contact and the frictional resistance to rotation increased. Apparently the threads came into contact when the torque on the jam nut was about 750 inch-pounds. 
There is a straight-line relation between the stress and the initial screwing-off torque for stresses above this value.

Device G (fig. 47).

The curves for this device are, except for a small torque at zero stress, almost identical with those for devices $I$ and $I I$, Figures 32 and 33 (regular nuts). The torque required to screw the nut on the

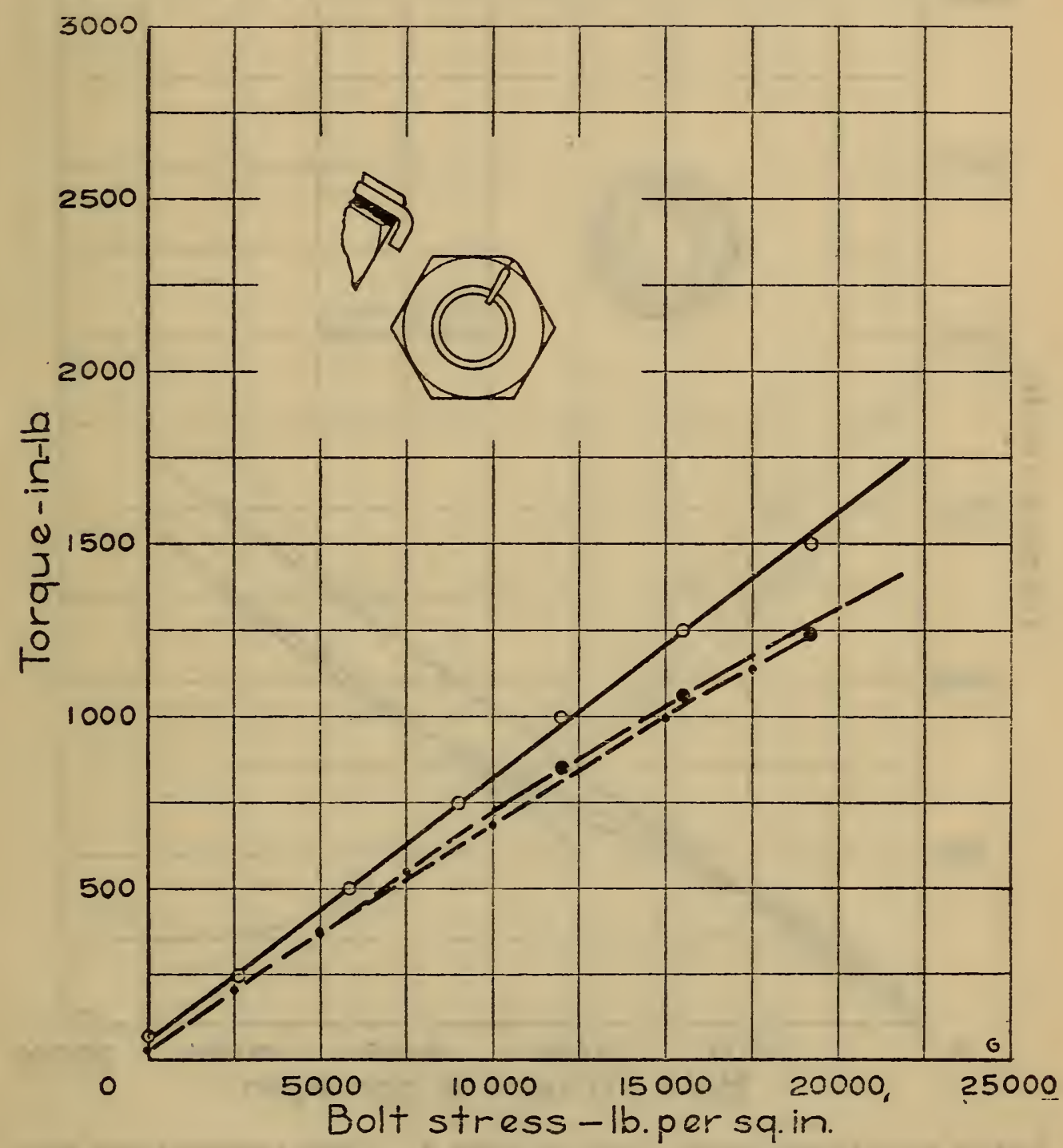

Frgure 47.-Torque-tension curves for device $G$. Nine specimens were tested

bolt was initially about 100 inch-pounds. The pin $b$, Figure 7 , cut a small chip off the tops of the bolt threads. When the nut was screwed off the pin was bent away from the bolt. When the nut was continuously screwed off, the torque required to rotate the nut at zero stress was about 50 inch-pounds. Apparently the screwingon torques were about 100 inch-pounds greater than those for regular nuts and the screwing-off torques about 50 inch-pounds greater. 
Device $\mathrm{H}$ (fig. 48).

The curves for this device are somewhat lower than those for devices $I$ and $I I$, Figures 32 and 33 (regular nuts). The screwing-on torques are proportional to the stress.

The initial screwing-off torques were about the same amount less than the screwing-on torques as those for the regular nuts.

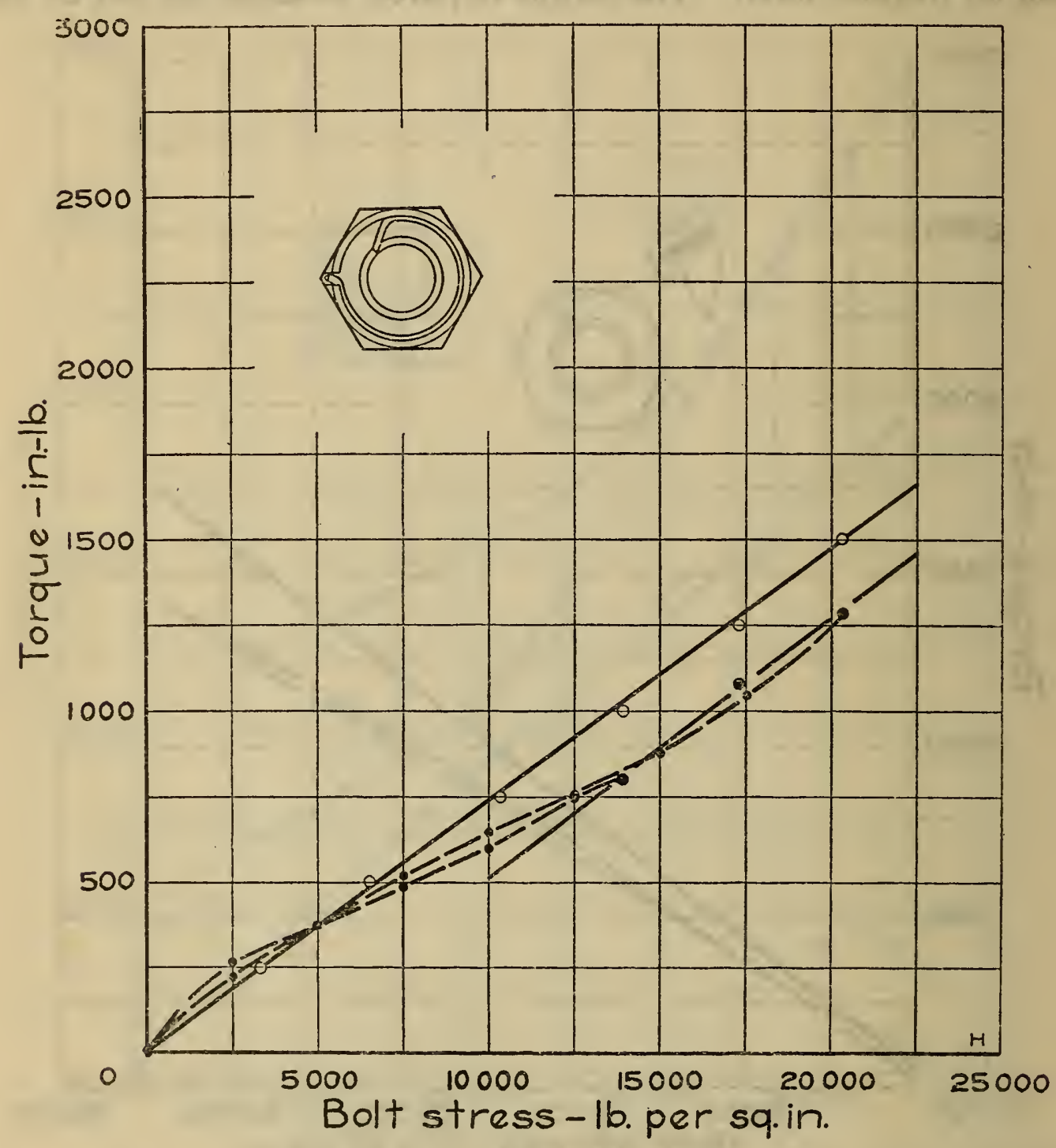

FiguRE 48.-Torque-tension curves for device H. Eleven specimens_werētested

When the nut was screwed off, the end of the spring $c$, Figure 8 , cut into the bolt threads, and after the device was removed from the bolt it was found that this end of the spring had bent into a circular arc, making it necessary to insert a new spring in the nut, if the device was to be used again.

Device I (fig. 49).

The screwing-on and initial screwing-off curves for this device are, as should be expected, almost identical with those for devices $I$ and II, Figures 32 and 33 (regular nuts). When the device applied as in these tests was continuously screwed off from a stress of about 12,000 
lb. per sq. in. the torque was about 150 inch-pounds at zero stress, and about 350 inch-pounds at zero stress when the device was continuously screwed off from a stress of about $20,000 \mathrm{lb}$. per sq. in. If it had been screwed on either more or less than the half turn recomemnded, these torques would have had different values. When screwing off, the torque was applied to the regular nut only. As the device did not rotate, this deflected the segments of the thread until they

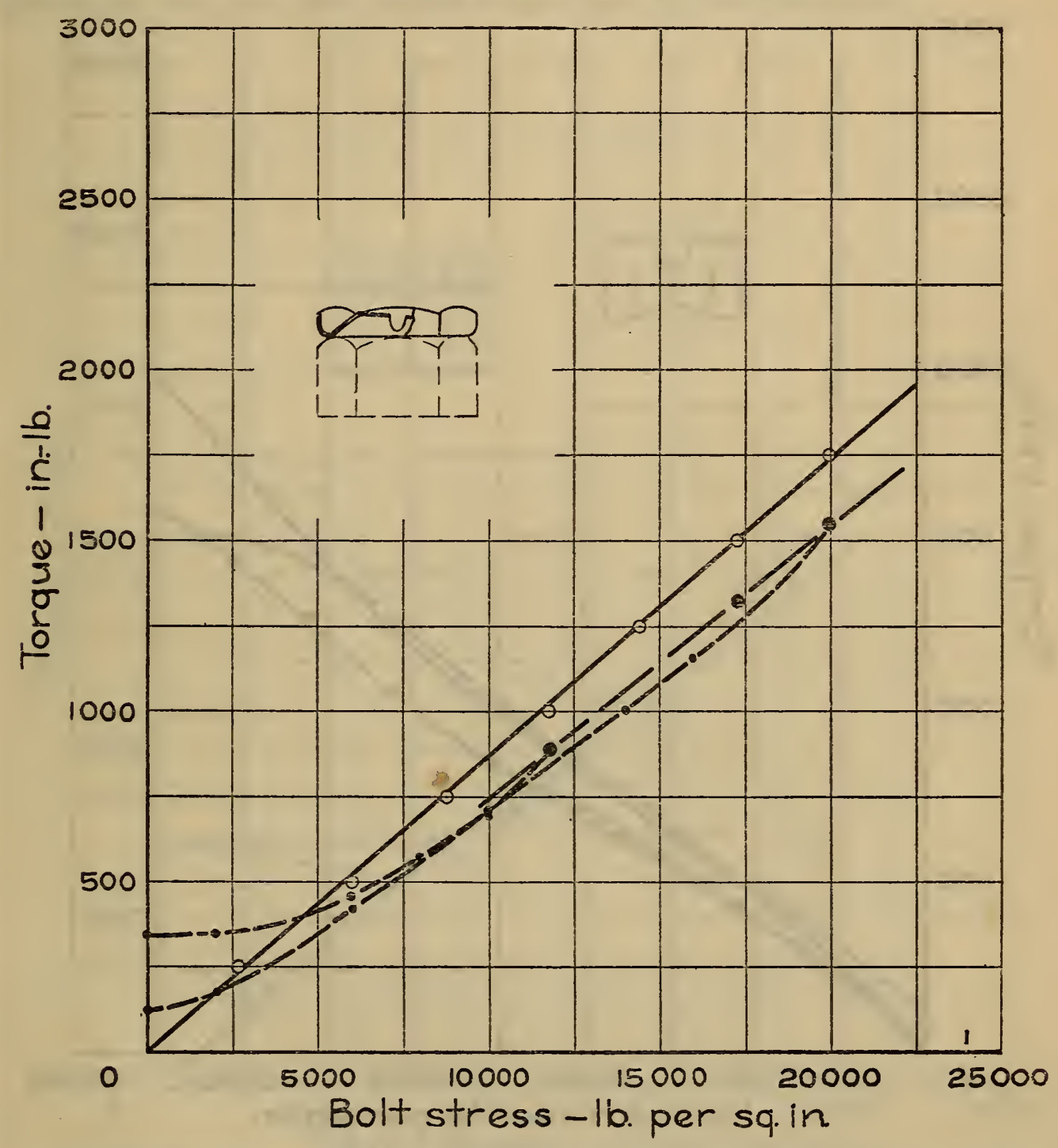

FIGURE 49.-Torque-tension curves for device I. Nine specimens were tested

were firmly seated between the threads of the bolt as the stress approached zero. When the device was removed from the bolt it was found that the threads of the bolt had been sheared by the thread in the device. This, of course, would not occur if the jam nut were removed first.

Device J (fig. 50).

The screwing-on and the initial screwing-off torques for this device were about the same as those for devices $I$ and $I I$, Figures 32 and 33 
regular nuts), but they were not proportional to the stresses, tending at high stresses to increase more rapidly than the stress because of the deformation of the nut.

The curve for continuous screwing off from a stress of about 12,000 lb. per sq. in. almost coincides with the initial screwing-off curve, indicating that the deformation of the device at this stress was not sufficient to affect the torques appreciably.

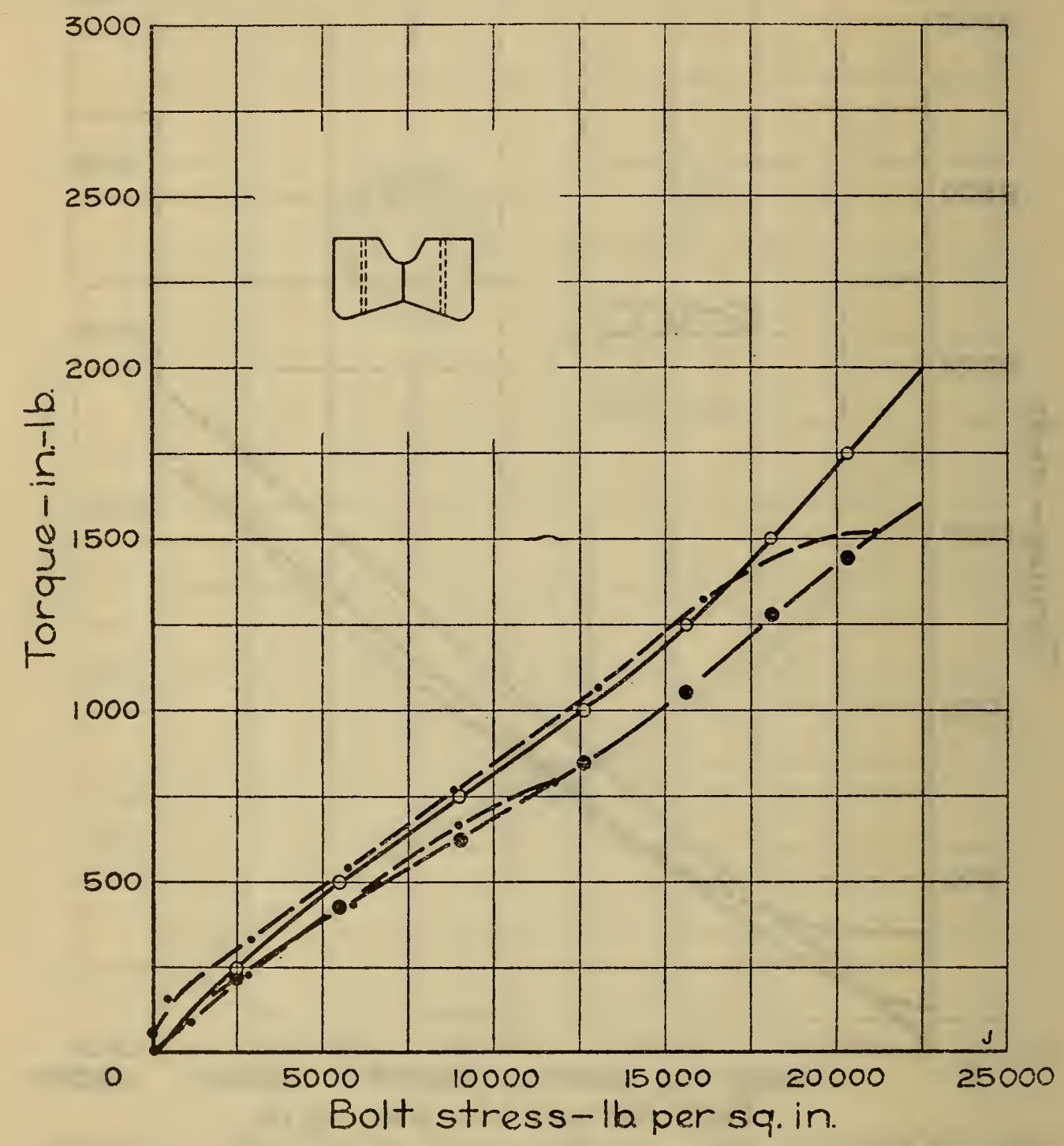

FIGURE 50.-Torque-tension curves for device J. Five specimens were tested

The curve for continuous screwing off from a stress of about 21,000 lb. per sq. in. lies slightly above the screwing-on curve, the torque being about $100 \mathrm{in}$. $1 \mathrm{~b}$. when the stress became zero, indicating that the deformation of the device at stresses above $15,000 \mathrm{lb}$. per sq. in. was sufficient to increase both the screwing-on and the screwing-off torques.

As the stress decreased the deformation decreased, but when the stress became zero the torque was still about 100 in. lb., showing that the device was permanently deformed. 
Device K (fig. 51).

The screwing-on curve for this device is, as should be expected, identical with those for devices $I$ and $I I$, Figures 32 and 33 (regular nuts). The initial screwing-off torques were proportional to the stresses. At first the two curves for continuous screwing off coincide approximately with the initial screwing-off curve but for stresses below about $8,000 \mathrm{lb}$. per sq. in. become almost horizontal. When the stress was zero the torque was about 700 inch-pounds.

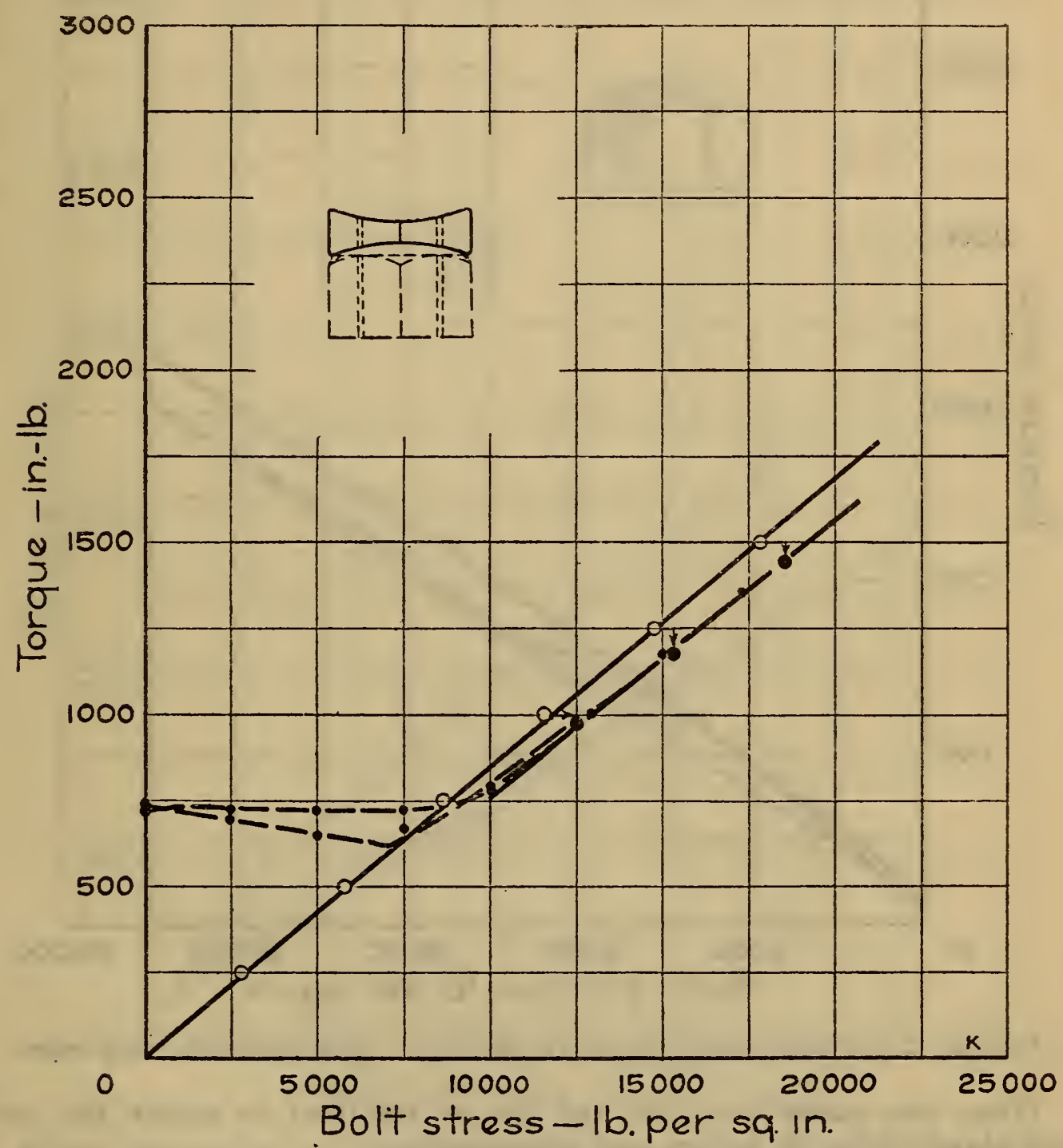

Figure 51.-Torque-tension curves for device $K$. Nine specimens were tested

When the regular nut was continuously screwed off this device did not rotate on the bolt until the stress was about $8,000 \mathrm{lb}$. per sq. in. It deformed until the face in contact with the regular nut was approximately flat. As the stress decreased below this value the device rotated with the regular nut.

When the device was removed from the bolt it was found that the surface which had been in contact with the regular nut remained nearly flat, indicating that the device had been permanently deformed. 
Device L (fig. 52).

Except for the small torques at zero stress these curves are similar to those for devices $I$ and $I I$, Figures 32 and 33 (regular nuts), but show somewhat lower torques.

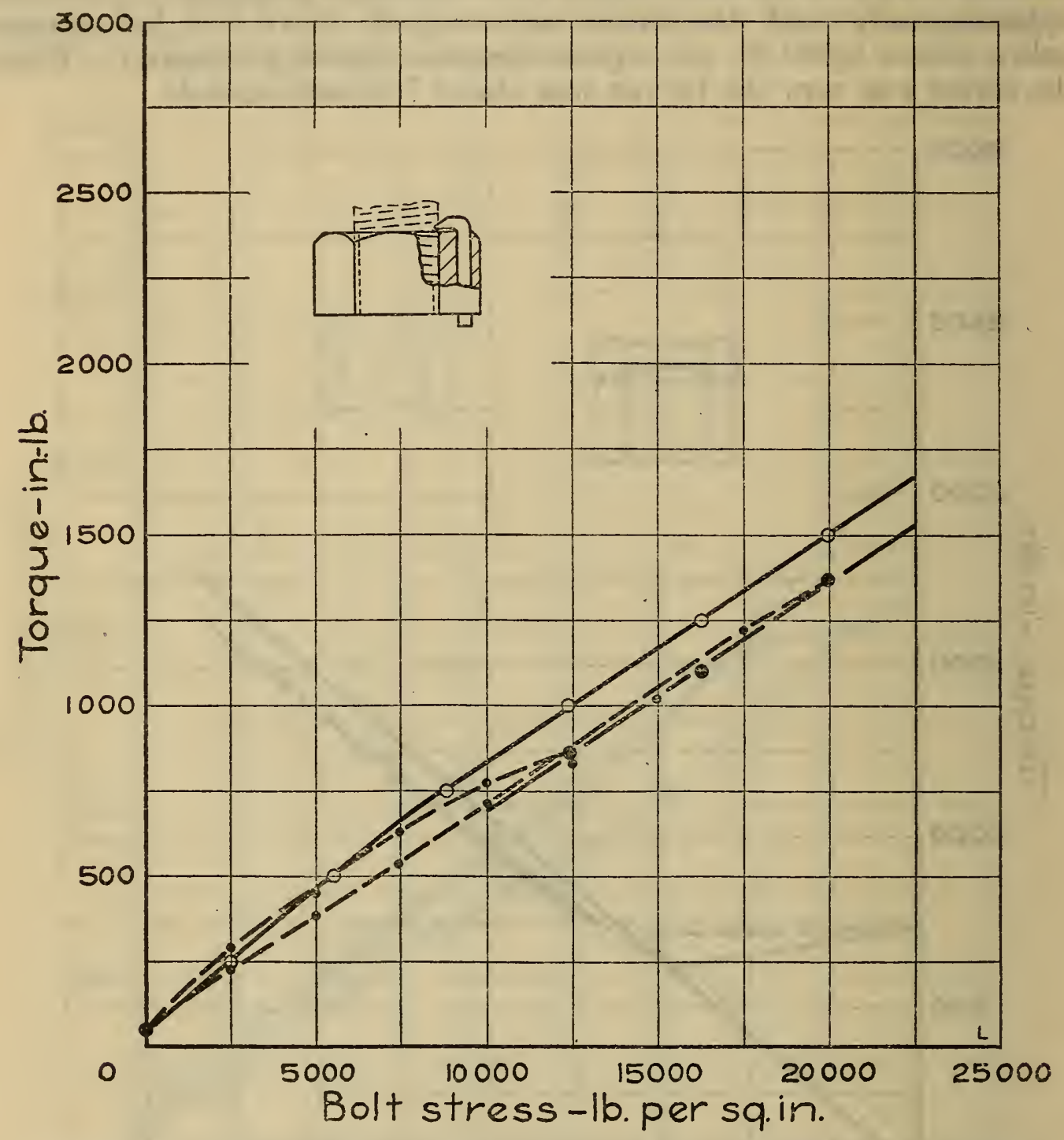

Figure 52.-Torque-tension curves for device $L$. Nine specimens were tested.

When the stress was zero the torque required to rotate the nut was about 50 in. $1 \mathrm{~b}$. before and after testing.

When the device was removed from the bolt it was found that the bolt threads had been roughened by the pin in the device. 
Device M (fig. 53).

At a stress of about 22,000 lb. per sq. in. the screwing-on torque for this device was the same as those for devices $I$ and $I I$, Figures 32 and 33 (regular nuts), but for most stresses between this value and zero the screwing-on torque was about 150 inch-pounds greater.

The initial screwing-off torques at about $20,000 \mathrm{lb}$. per sq. in. were about 100 inch-pounds lower than those for regular nuts, the

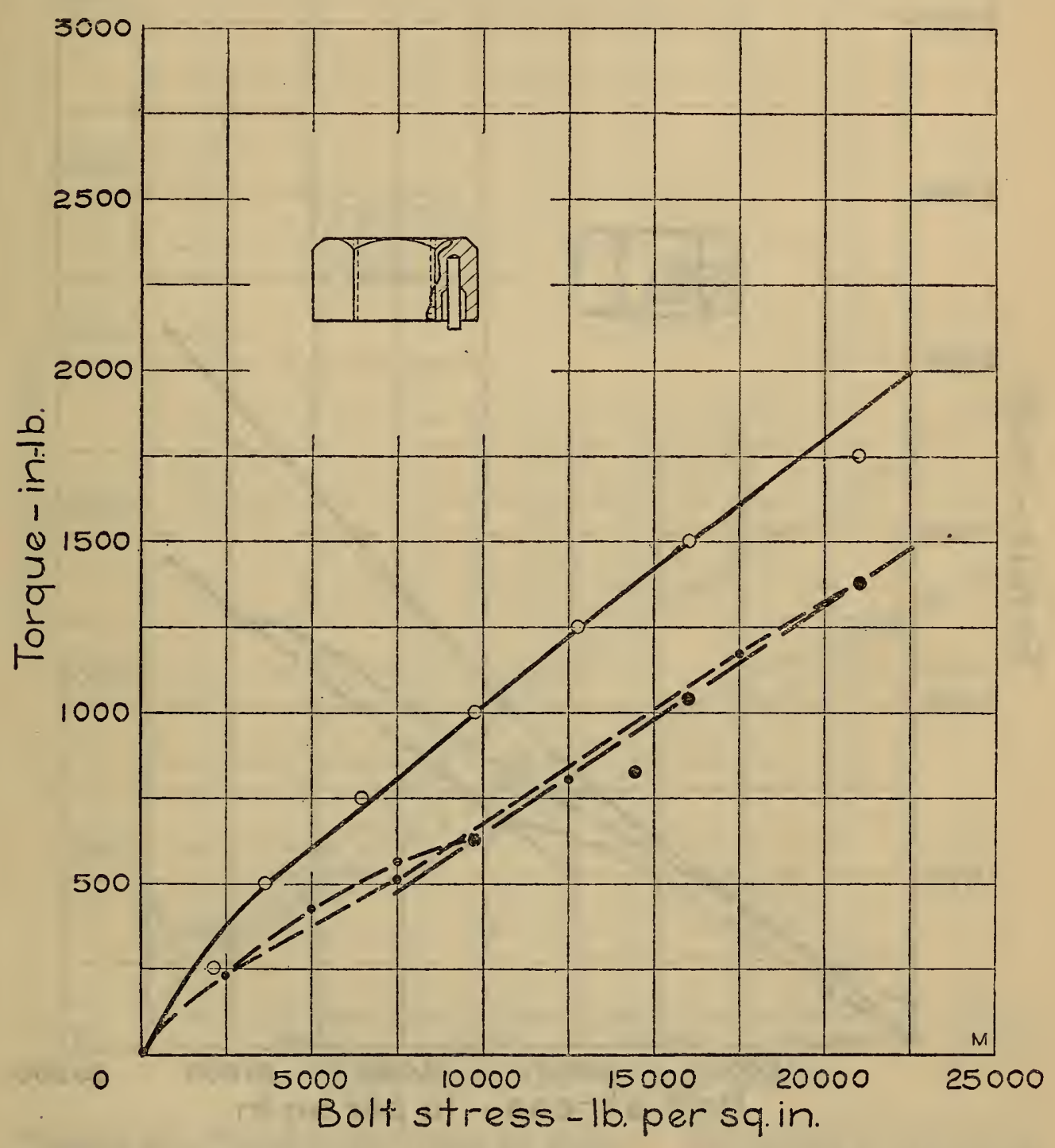

FigURE 53.-Torque-tension curves for device M. Nine specimens were tested

torque being proportional to the stress. The continuous screwing-off torques lie slightly above the initial screwing-off torque curve extended.

When this device was removed from the bolt it was found that the pin in the device had cut into the face of the bearing washer. Chips filled the space around the pin. It would be necessary to remove them before using the device again. 
Device $N$ (fig. 54).

The screwing-on torques for this device were almost the same as those for devices $I$ and $I I$, Figures 32 and 33 (regular nuts), up to a stress of about 13,000 lb. per sq. in. Above this value these torques increased more rapidly as the stress increases.

The initial screwing-off torques were about 150 inch-pounds less than those for regular nuts, but the torques for continuous screwing

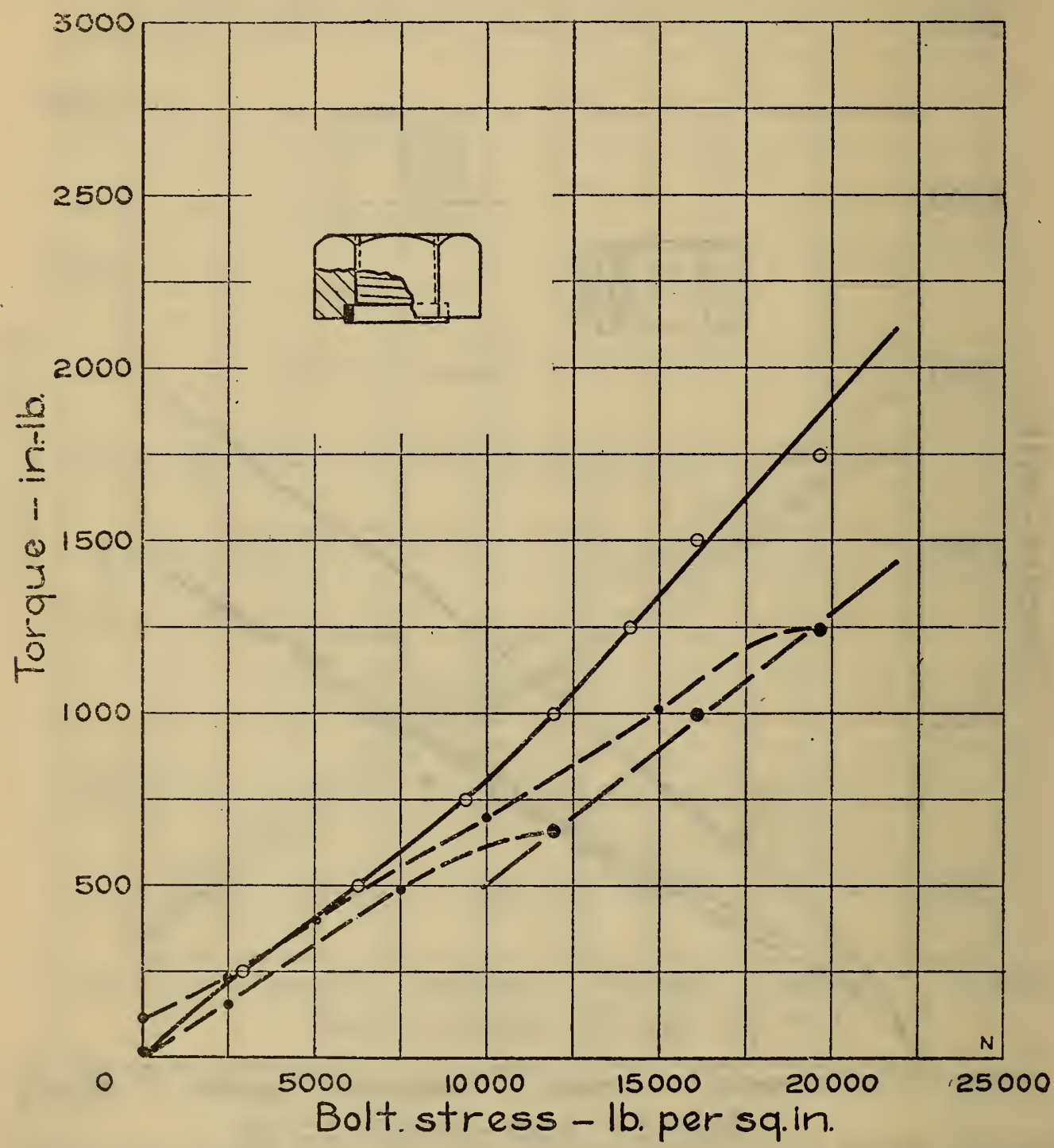

FiguRE 54.-Torque-tension curves for device $N$. Nine specimens were tested

off were only slightly less. When continuously screwed off from a stress of 20,000 lb. per sq. in. the torque at zero stress was about 100 inch-pounds.

When the device was removed from the bolt the ring usually remained on the bolt. To remove it the ends of the strip forming the ring were pried apart with a screw driver. A new copper ring would be needed each time the device was used. 
Device $O$ (fig. 55).

The screwing-on torques for this device are slightly greater than those for devices $I$ and $I I$, Figures 32 and 33 (regular nuts), up to about $10,000 \mathrm{lb}$. per sq. in. For higher stresses they increase less rapidly, until at $20,000 \mathrm{lb}$. per sq. in. stress they are lower than for devices $I$ and $I I$.

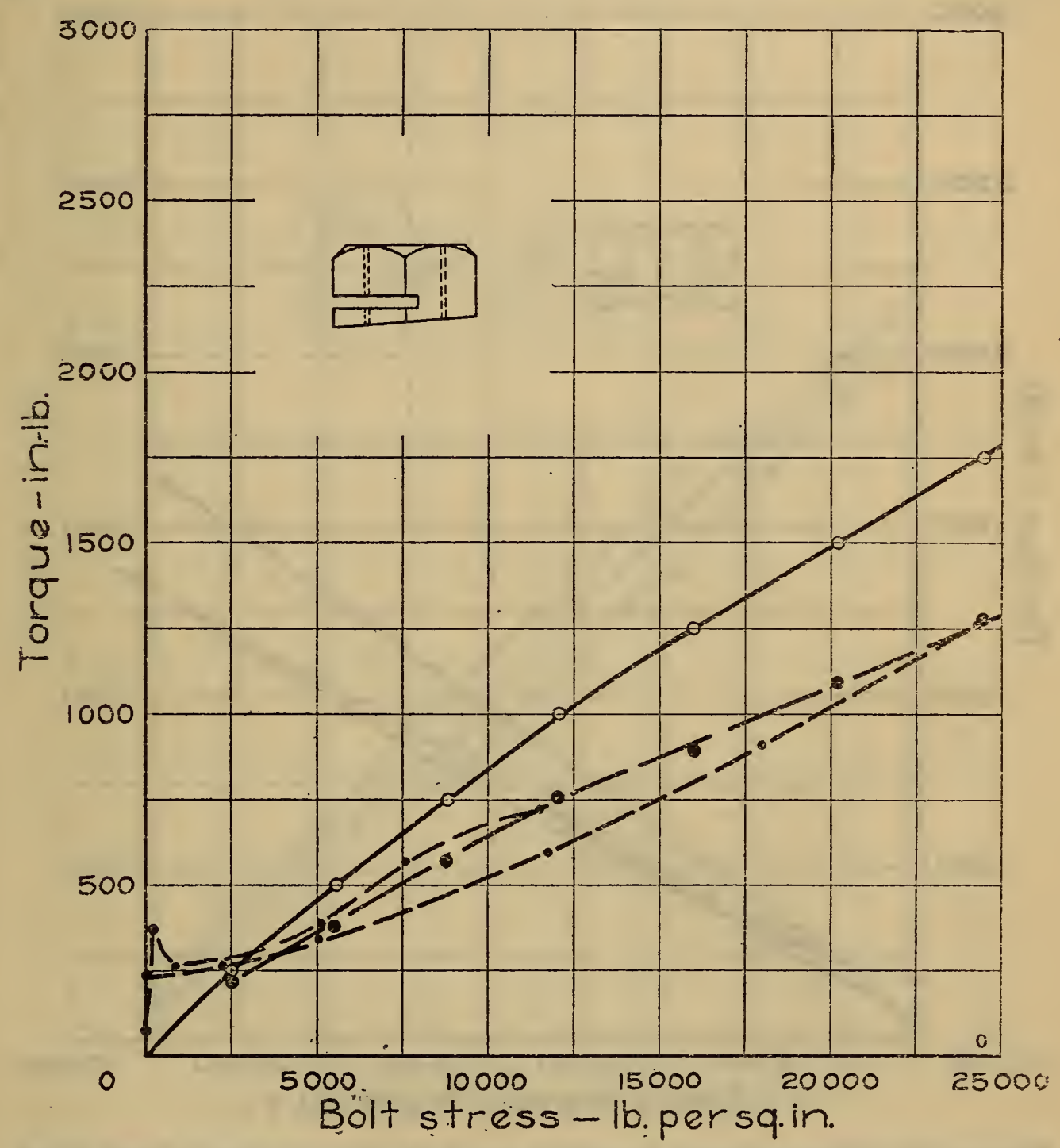

Figure 55.-Torque-tension curves for device O. Five specimens were tested

For high stresses the initial screwing-off torques are considerably less than those for regular nuts.

In continuous screwing off there is still a torque at zero stress, indicating that the device has been permanently deformed after it has been stressed as high as 10,000 lb. per sq. in. 
Device P (fig. 56).

The screwing-on and initial screwing-off torques were somewhat lower than for devices $I$ and $I I$, Figures 32 and 33 (regular nuts).

In continuous screwing off there was still a torque at zero stress, indicating that the device was permanently deformed after it had been stressed as high as 10,000 lb. per sq. in.

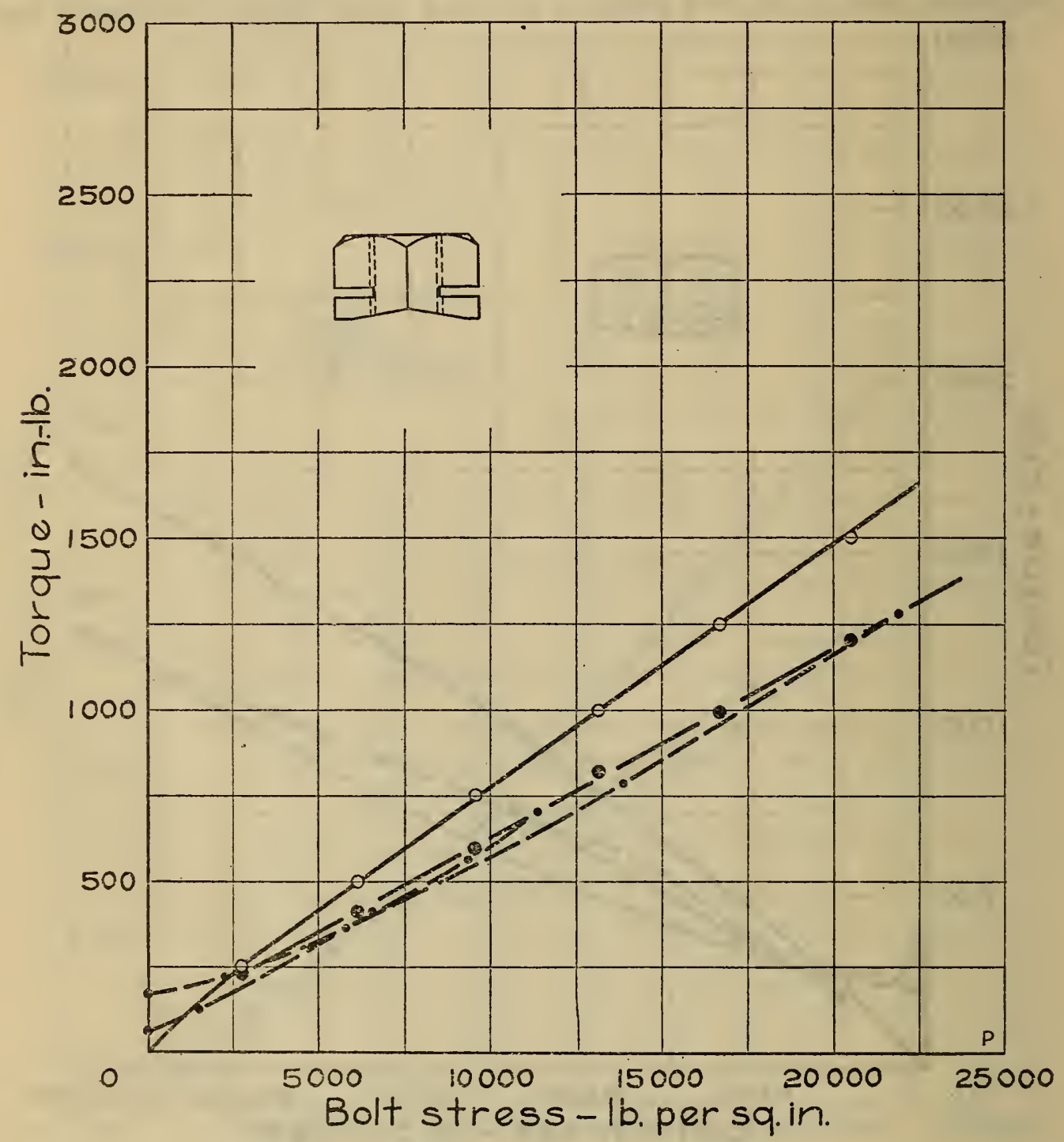

FIGURE 56.-Torque-tension curves for device P. Five specimens were tested 
Device Q (fig. 57).

The screwing-on torques for this device are considerably greater than those for devices $I$ and II, Figures 32 and 33 (regular nuts). They are, as should be expected, proportional to the stresses. The initial screwing-off torques are only slightly less than the screwing-on

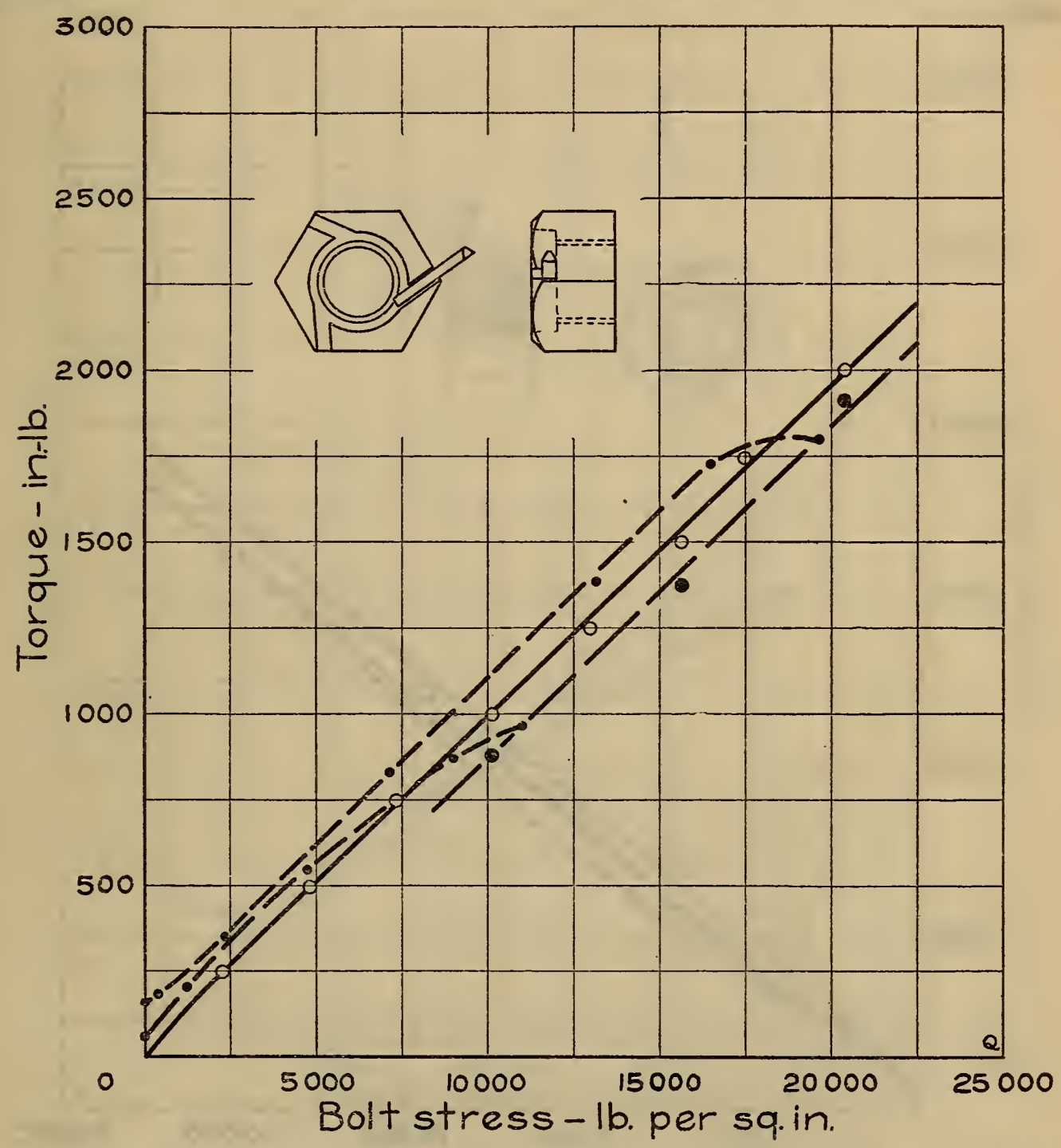

FIGURE 57.--Torque-tension curves for device Q. Eleven specimens were tested

torques. The torques for continuous screwing-off are about 100 inch-pounds greater than the screwing-on torque, this also being the value when the stress is zero.

This device can not be used unless there is sufficient room to insert the pin. 
Device R (fig. 58).

The screwing-on torques for this device were about 50 inch-pounds greater than those for devices $I$ and $I I$, Figures 32 and 33 (regular nuts). In continuous screwing-off there was still a torque at zero stress.

Otherwise the curves are almost identical with those for regular nuts.

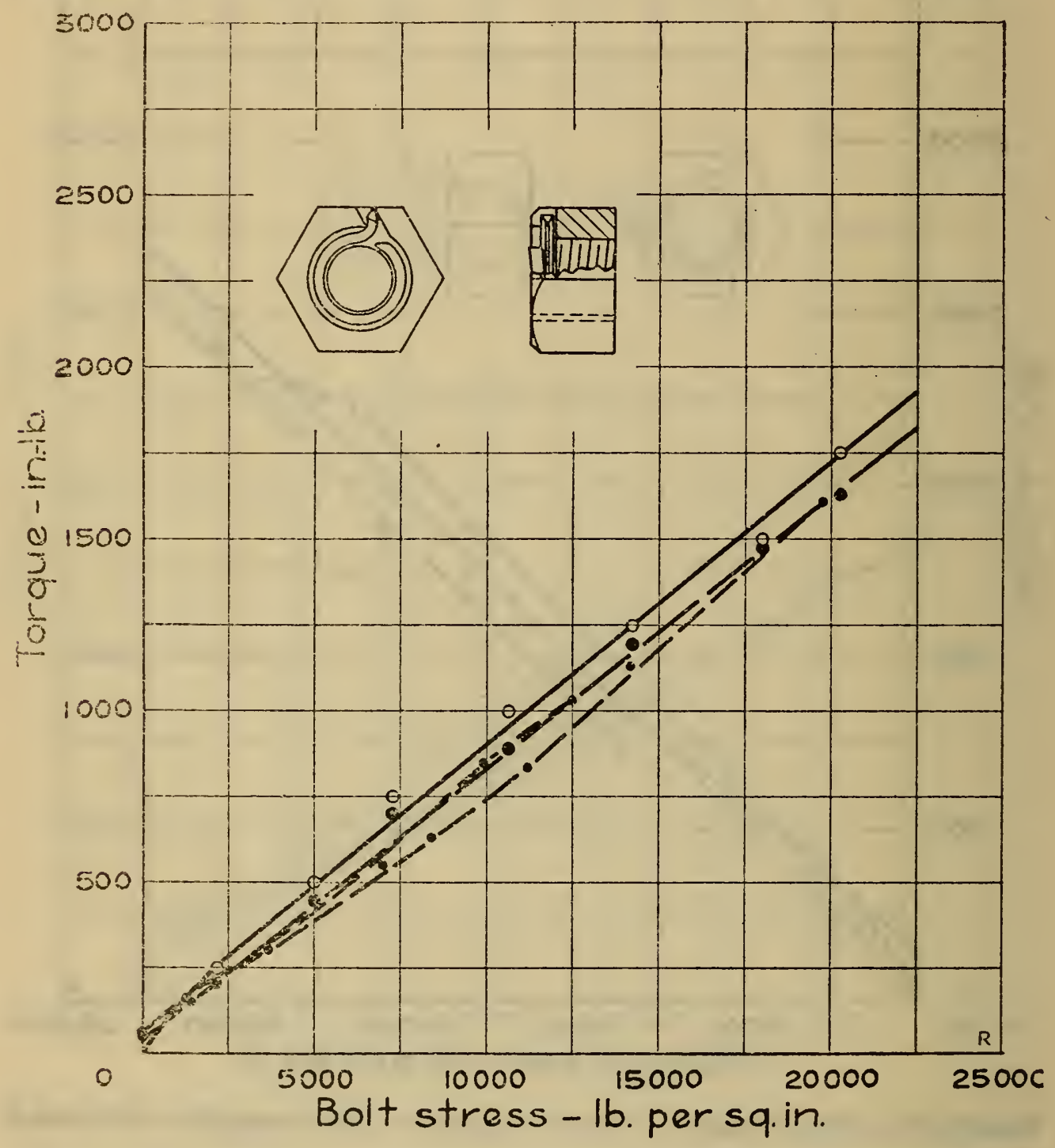

Fiavire 58.-Torque-tension curves for device $R$. Five specimens were tested 
Device S (fig. 59).

The screwing-on and initial screwing-off torques for this device were about the same as those for devices $I$ and $I I$, Figures 32 and 33 (regular nuts). Application of the device after the regular nut was tightened increased the stress slightly.

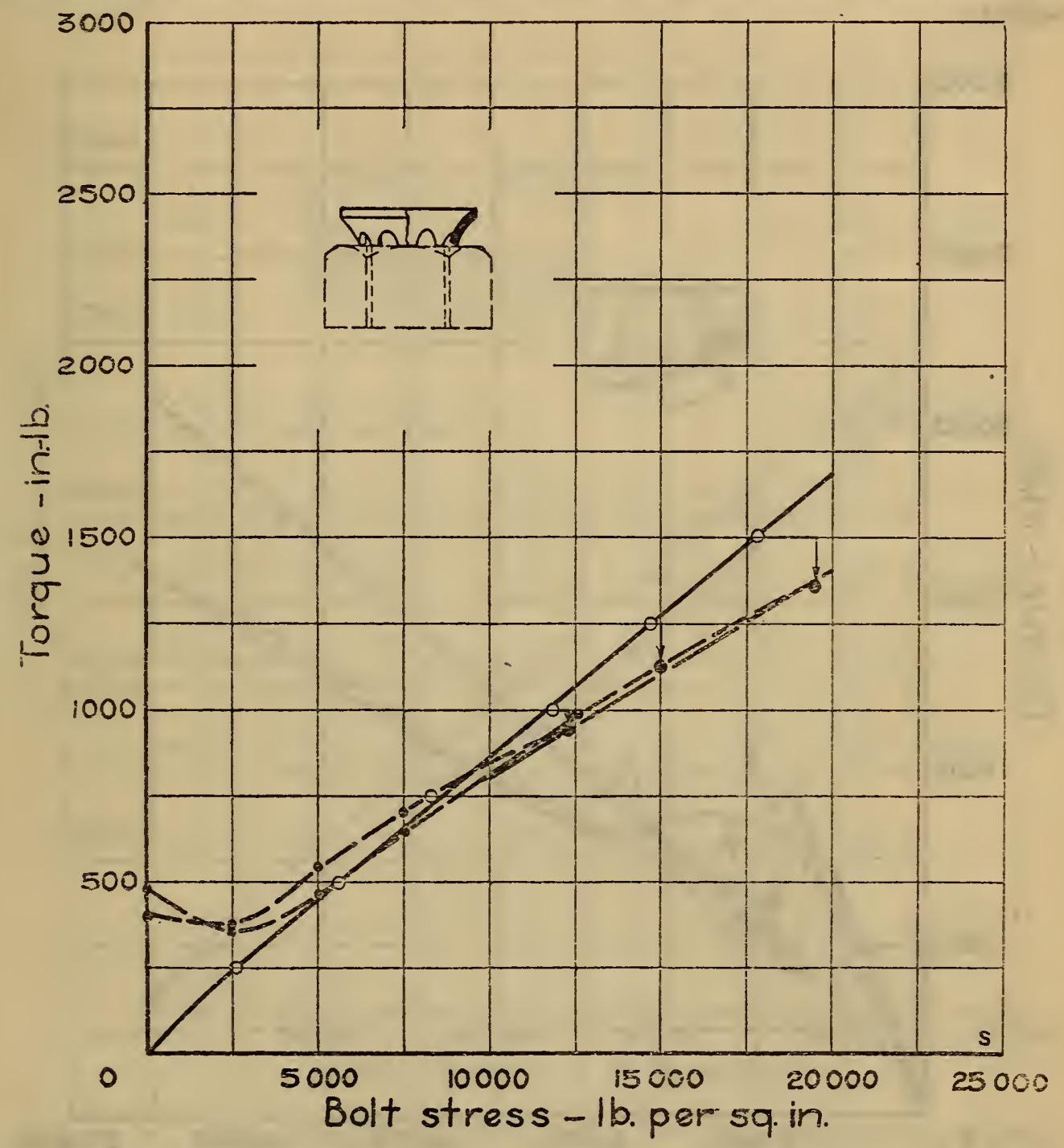

FIgURE 59.-Torque-tension curves for device S. Nine specimens were tested

For continuous screwing-off the torques were greater than the initial screwing-off torques, and for low stresses greater than the screwing-on torques. Below 3,000 lb. per sq. in. the torque increased to 400 or 500 inch-pounds at zero stress.

When the device was removed from the bolt it was found that the threads of the bolt had been roughened. As the device is permanently deformed when it is applied to the bolt, a new one must be used for each application. 
Device T (fig. 60.).

The screwing-on torques for this device are greater than those for devices $I$ and $I I$, Figures 32 and 33 (regular nuts), being about 100 inch-pounds greater for a stress of $5,000 \mathrm{lb}$. per sq. in. and about 200 inch-pounds greater for a stress of $20,000 \mathrm{lb}$. per sq. in. The characteristic shape of this curve will be discussed later under lock washers.

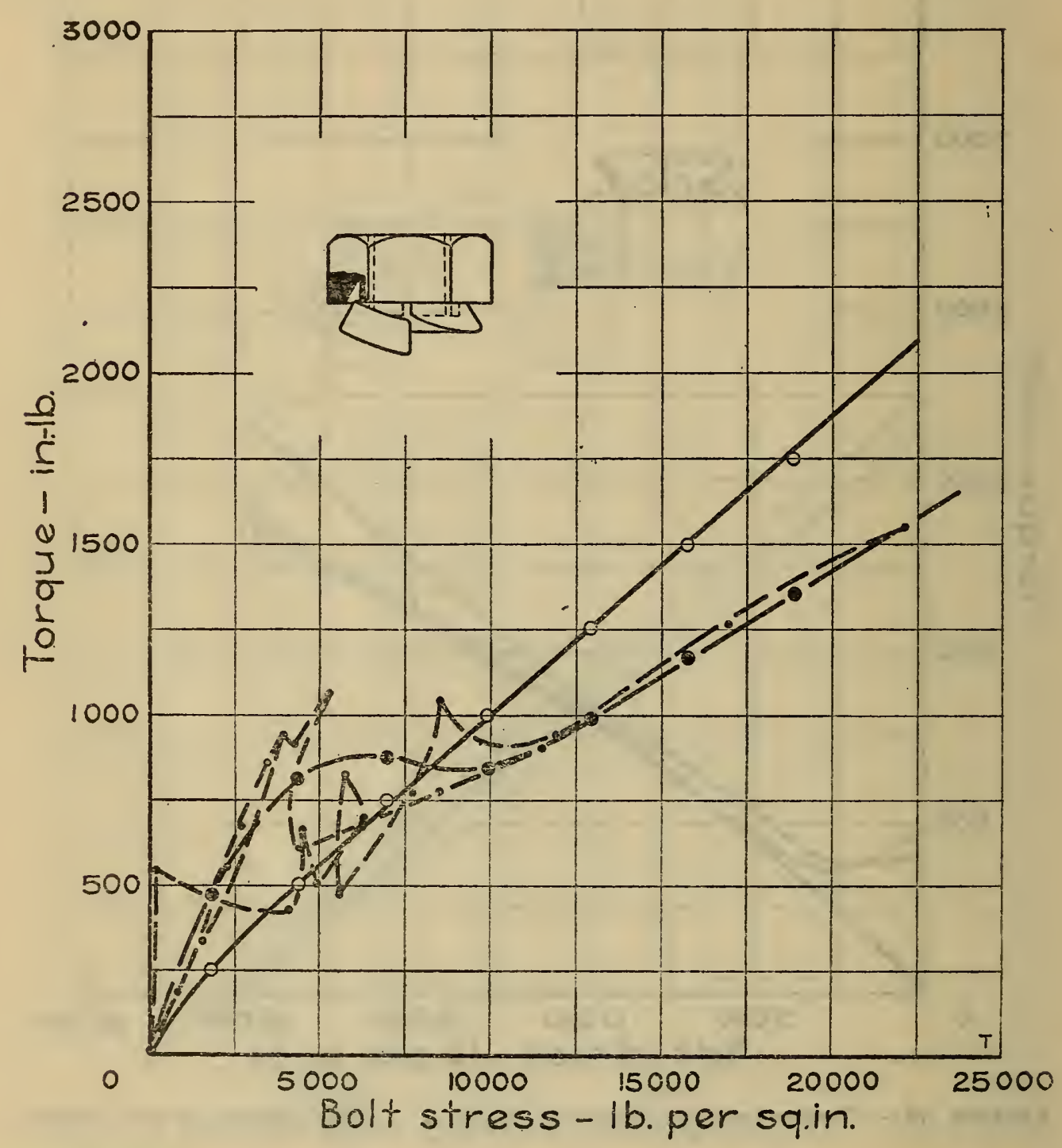

Figure 60.-Torque-tension curves for device T. Five specimens were tested

The initial screwing-off torques, however, are the same as those for regular nuts for high stresses, but are approximately 800 inchpounds (considerably higher than the screwing-on torques) for stresses between 11,000 and 4,000 lb. per sq. in.

For continuous screwing-off, the torques are about the same as the initial screwing-off torques, but the values change greatly for small changes in stress below $10,000 \mathrm{lb}$. per sq. in.

When this device was removed from the bolt it was found that the device had cut into the face of the bearing washer and that the groove in the nut had been roughened.

The parts of this device, after test, are shown at T, Figure 76. 
Device U (fig. 61).

The curves for this device are almost identical with those for devices $I$ and $I I$, Figures 32 and 33 (regular nuts). The screwing-on torques are about 50 -inch pounds higher and the initial screwing-off

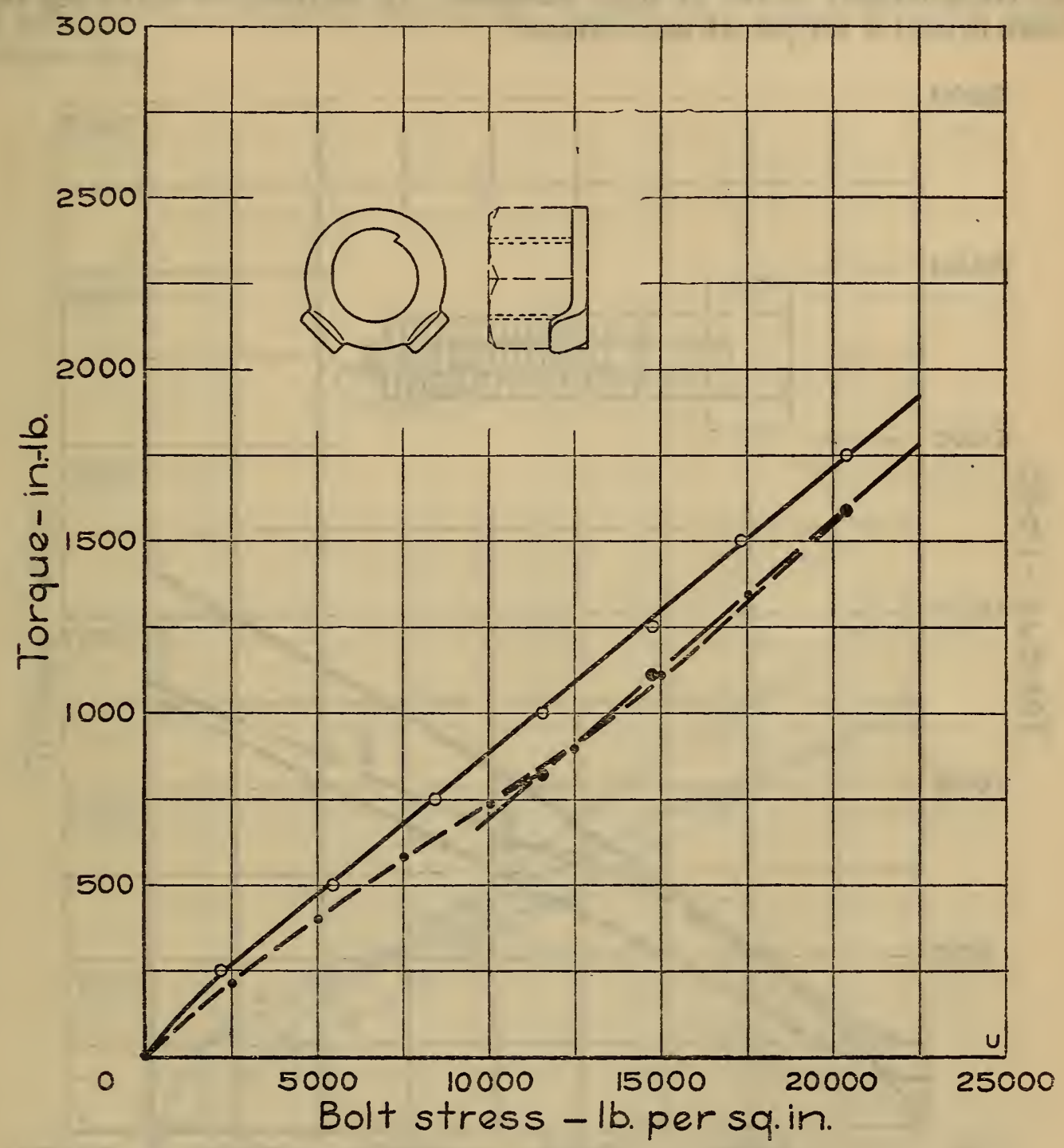

FIgURE 61.-Torque-tension curves for device $U$. iNine specimens were tested torques about 100 inch-pounds higher at a stress of 20,000 lb. per sq. in.

When this device was removed from the bolt it was found that the threads of the bolt had been roughened. 
Device V (fig. 62).

The screwing-on torques for this device are somewhat higher at low stresses and lower at high stresses than those for devices $I$ and $I I$, Figures 32 and 33 (regular nuts). The initial screwing-off torques are considerably lower at high stresses. In continuous screwing off there is still a torque at zero stress.

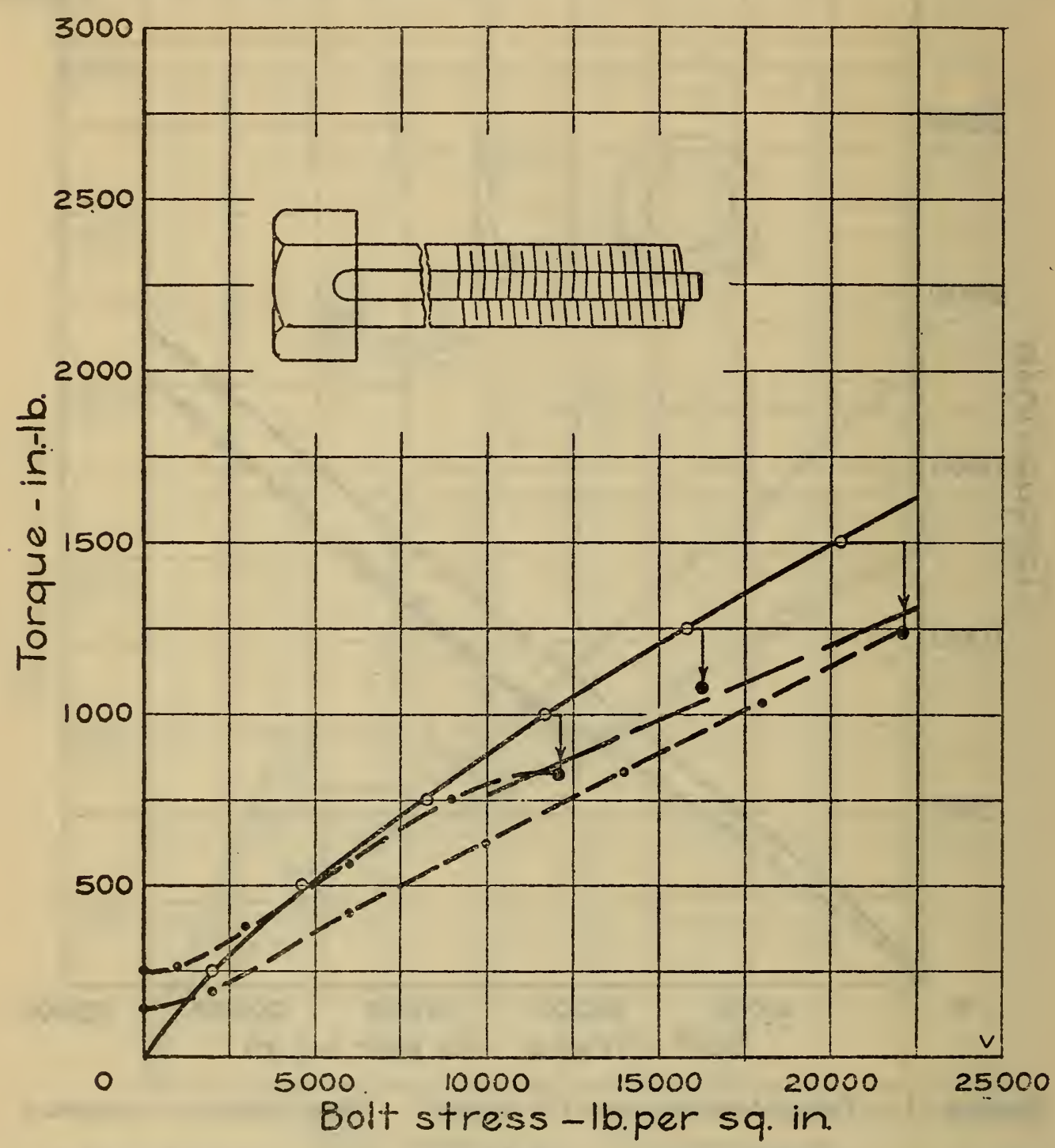

FIGURE 62.-Torque-tension curves for device $V$. Nine specimens were tested

As the key was bent over the nut when this device was applied, a new key was required for each application. When the nut was removed from this device it was found that the threads in the nut had been roughened. 
Devices AA to JJ. Spring washers (figs. 63-72).

The screwing-on curves for the spring washers show a characteristic difference from the curves for regular nuts $(I, I I$, and $I I I)$.

The screwing-on torques, instead of being proportional to the stress, at first rise more rapidly, and in the majority of the cases approach a straight line which intersects the axis of zero stress at some point above zero.

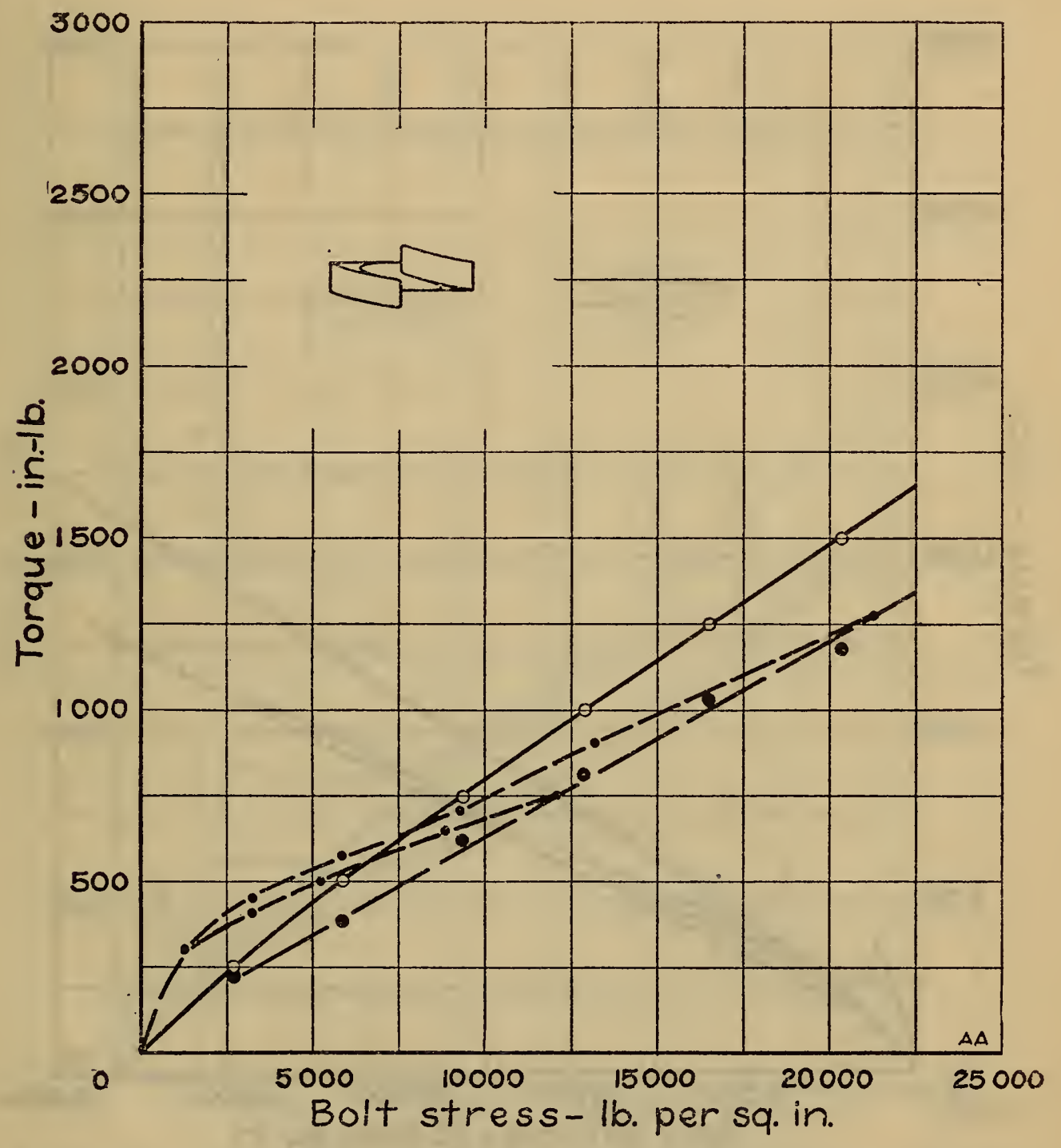

Figure 63.-Torque-tension curves for device $A A$, spring washer. Five specimens were tested

Comparison with the load-deflection curves, Figure 73, shows that in most cases the straight portion of the curve begins approximately at the load at which the washer became flat.

Thus for device EE, which is flat at loads corresponding to a stress in the bolt of less than 2,000 lb. per sq. in., the curve for screwing-on torque is straight above $5,000 \mathrm{lb}$. per sq. in., while for device DD, which is flat at $6,000 \mathrm{lb}$. per sq. in. stress, the curve is not straight until about $10,000 \mathrm{lb}$. per sq. in. 


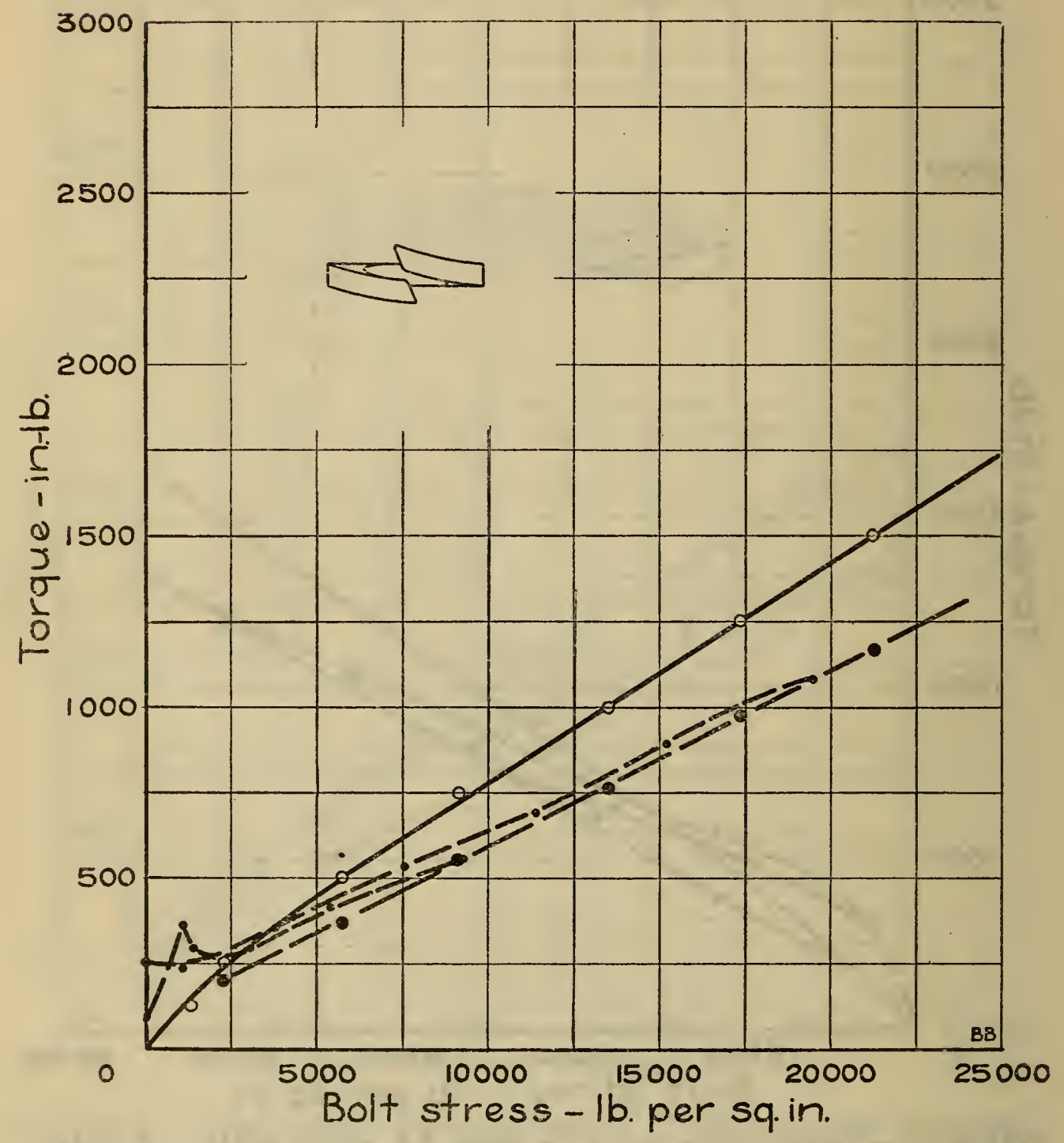

FIgure 64.-Torque-tension curves for device BB, spring washer. Five specimens were tested 


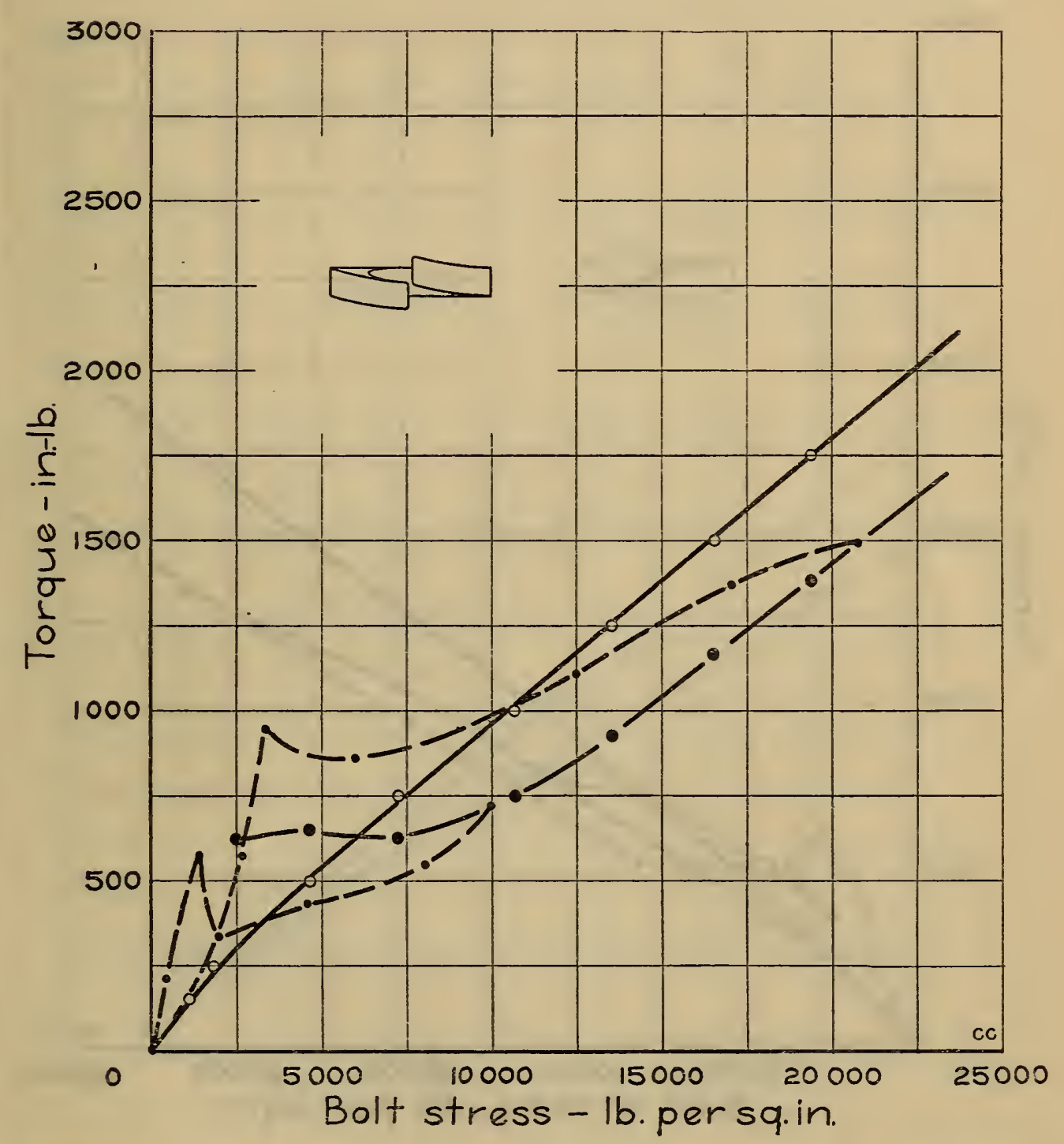

Frgure 65.-Torque-tension curves for device CC, spring washer. Five speci$79688-31-16$ mens were tested 


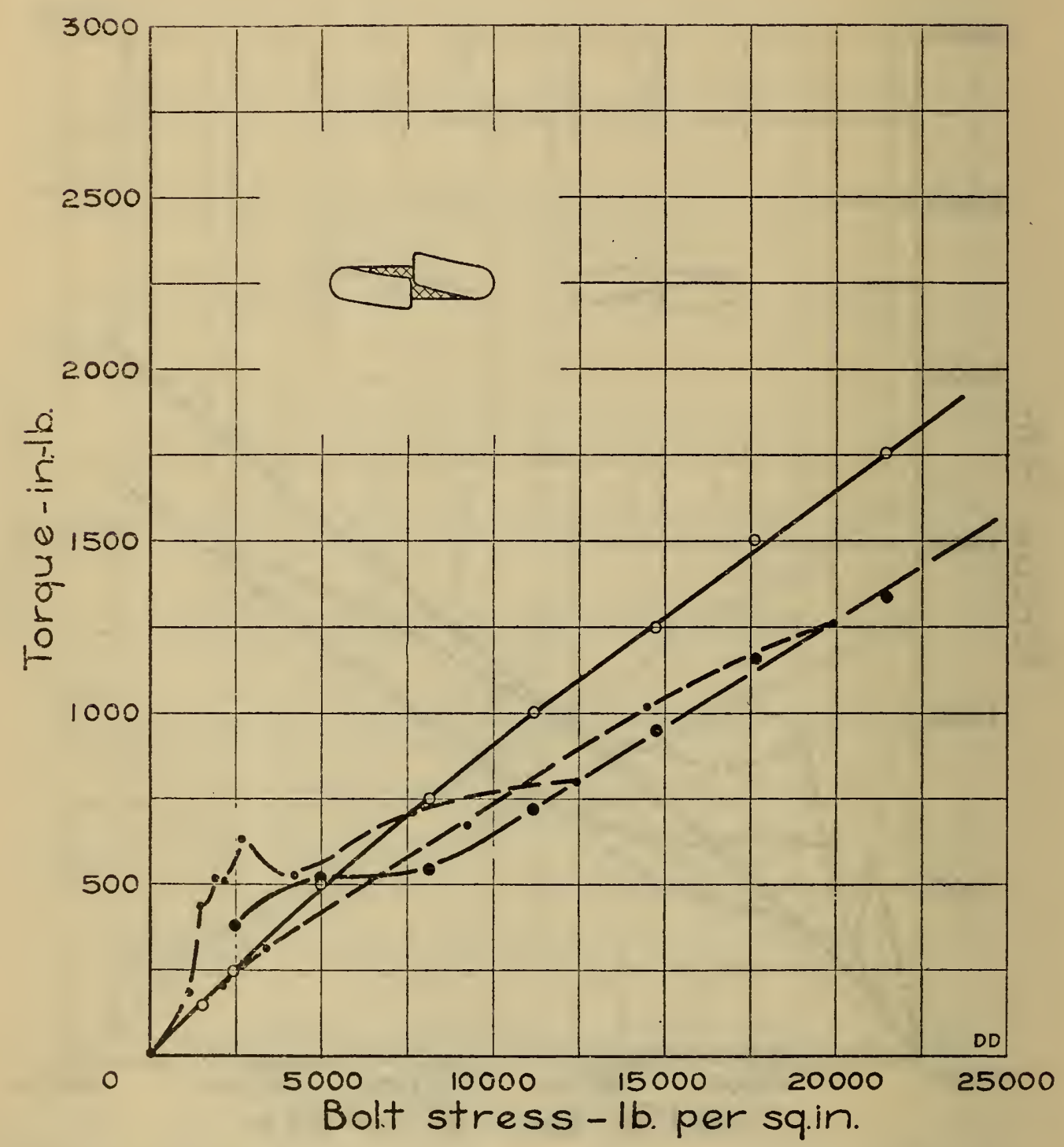

FIGURE 66.-Torque-tension curves for device DD, spring washer. Five specimens were tested 


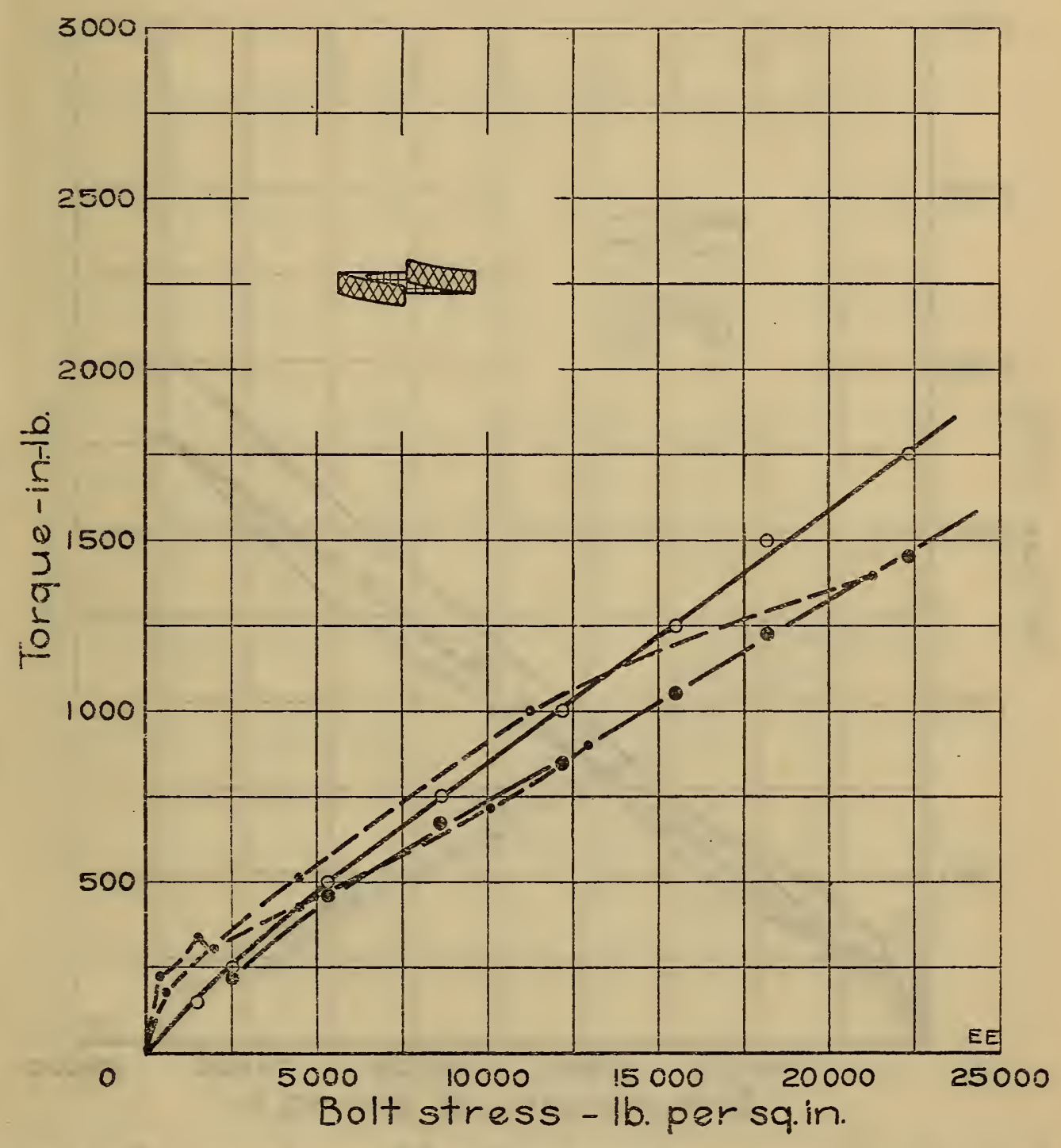

Figure 67.-Torque-tension curves for device EE, spring washer. Five specimens were tested 


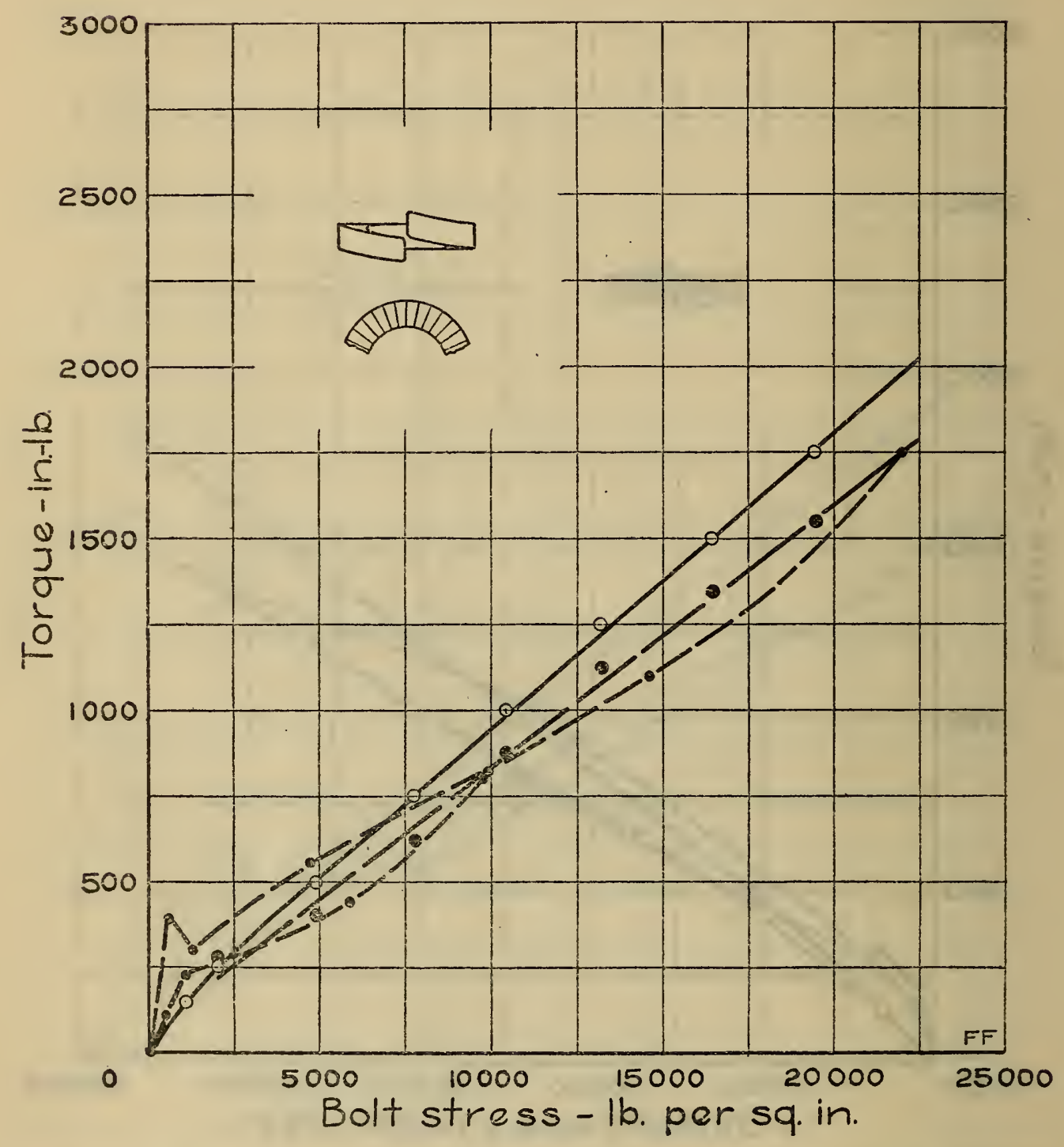

FIGURE 68.-Torque-tension curves for device FF, spring washer. Five specimens were tested 


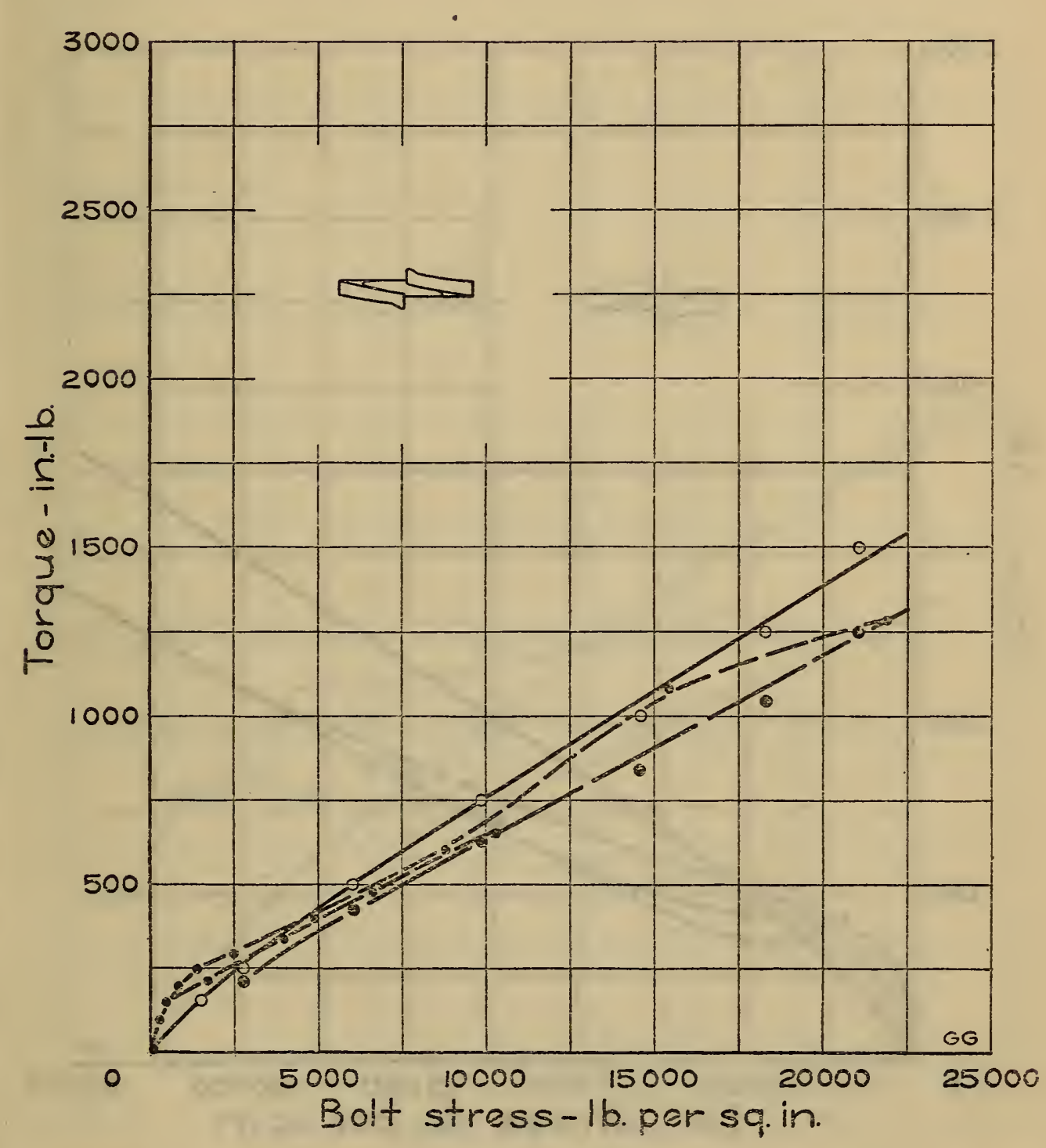

Figure 69.-Torque-tension curves for device GG, spring washer. Five specimens were tested 


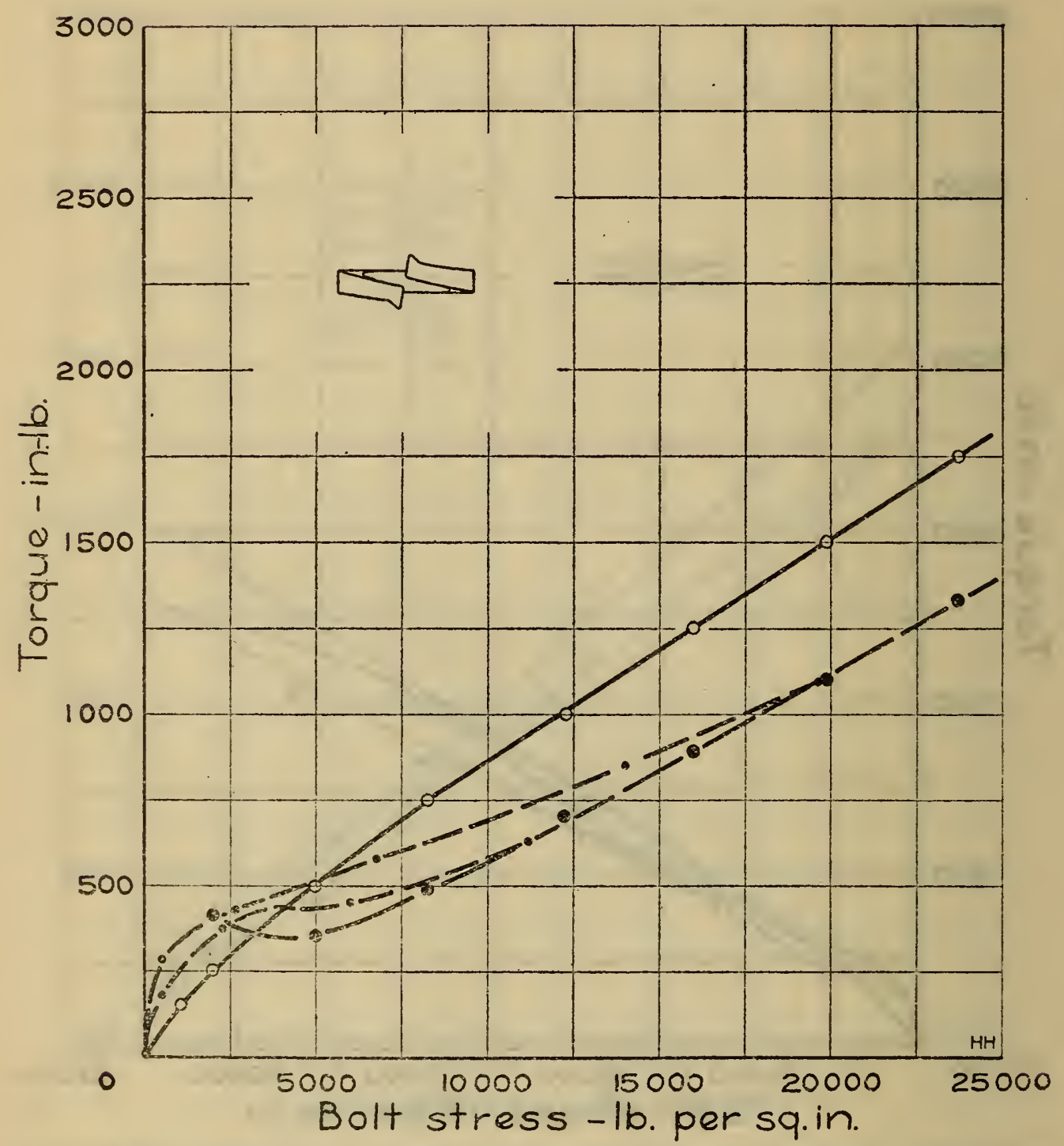

Figore 70.-Torque-tension curves for device HH, spring washer. Five spec imens were $e_{i}^{\mathrm{i}}$ tested 


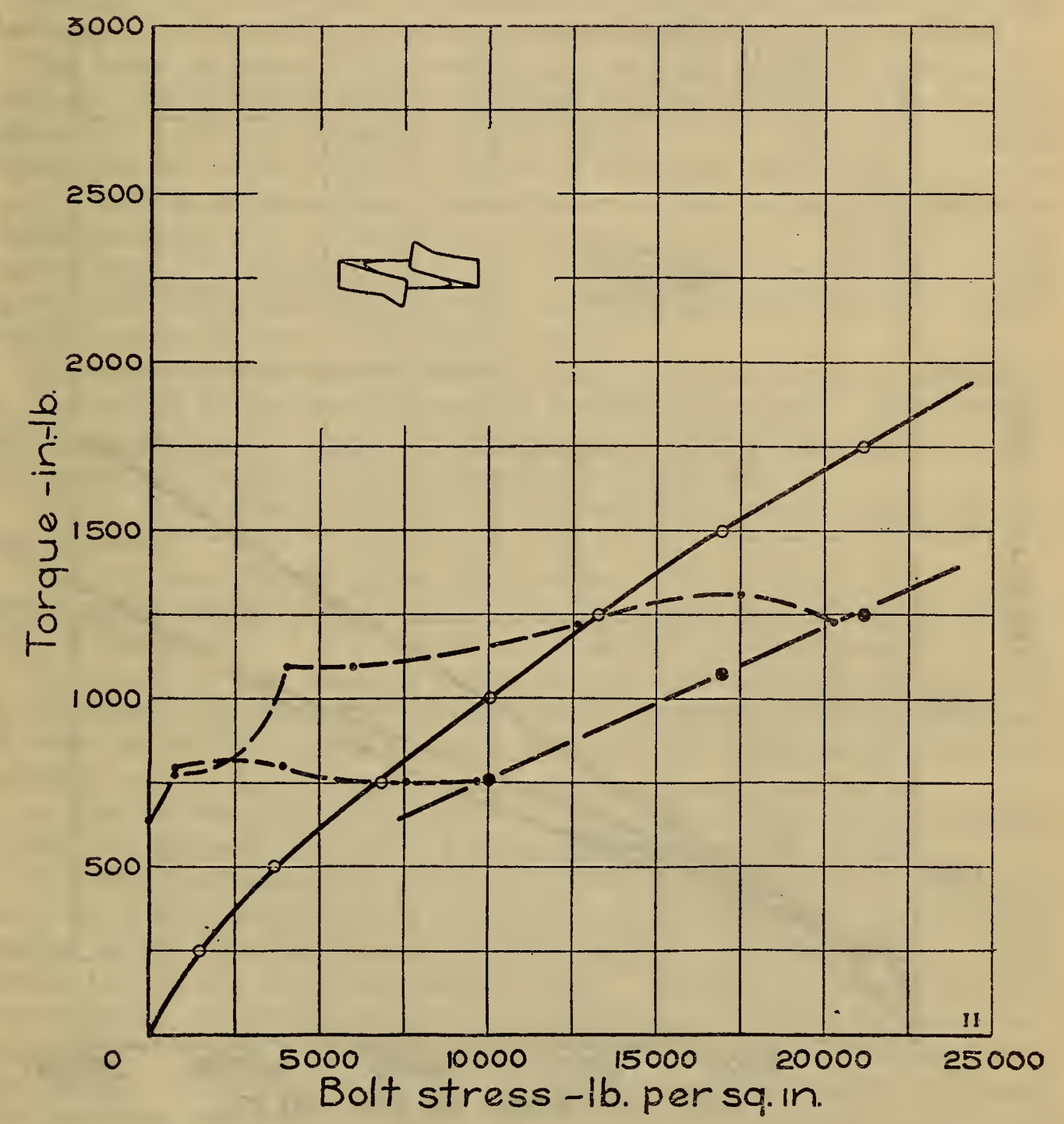

Frgure 71.-Torque-tension curves for device II, spring washer. Eleven specimens were tested 


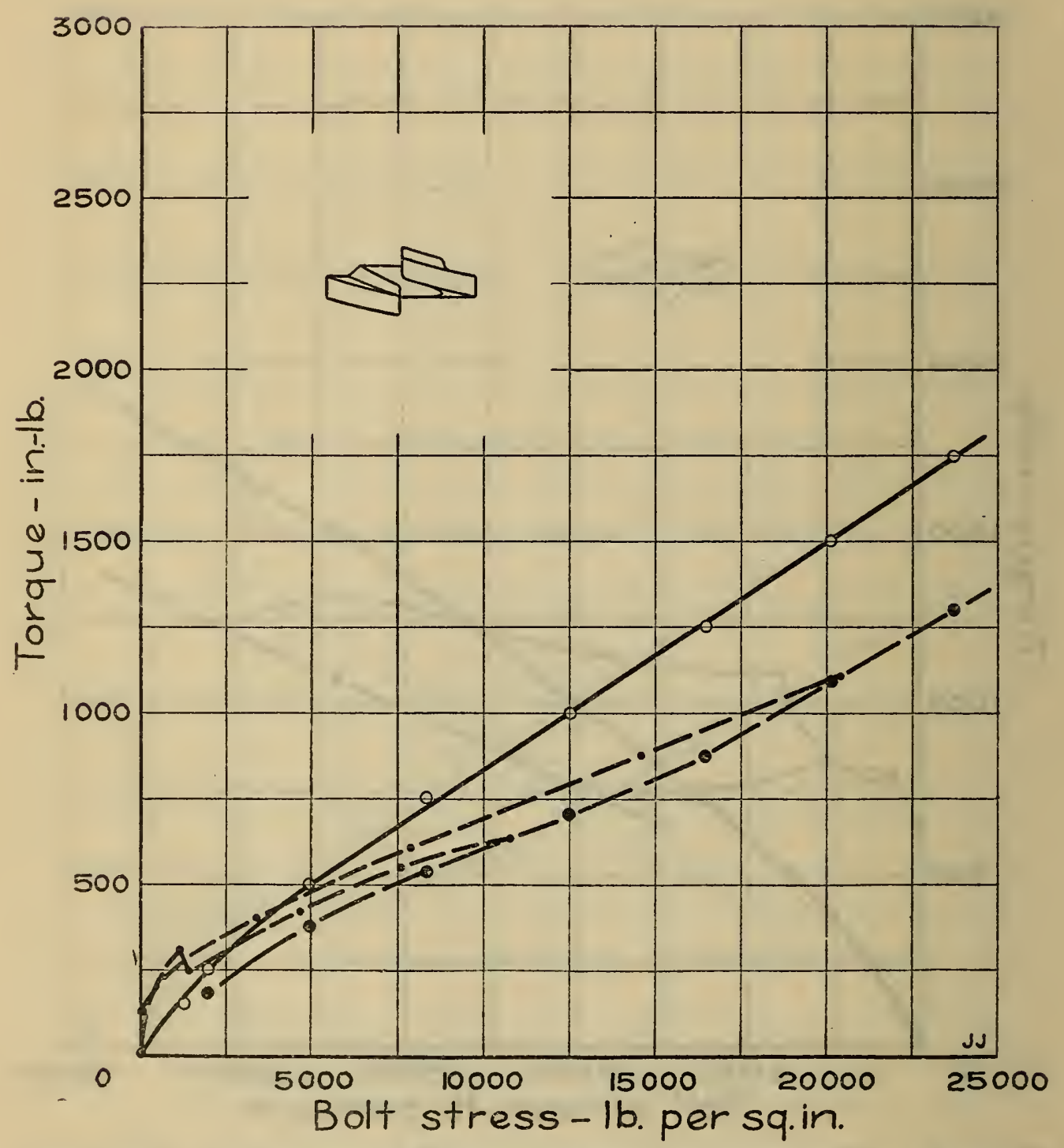

FIGURE 72.-Torque-tension curves for device JJ, spring washer. Five specimens were tested 
It seems reasonable to ascribe this to the higher friction of the washer edges before they are pressed flat. This is further confirmed by the different shape of the curves for devices HH and II, Figures 70 and 71. These have stiff bent-up bearing edges which can not be pressed flat even at the highest stresses. The screwing-on curve for II does not become straight. This curve for $\mathrm{HH}$ does not become approximately straight until over 7,000 lb. per sq. in., although this washer is "pressed flat" (see fig. 73) at a stress of less than 2,000 lb. per sq. in. Similar characteristics were noted on the screwing-on curves for devices J, O, P, and T, which may have a similar explanation.

The large difference in screwing-on torque at 20,000 lb. per sq. in. between the different spring washers, maximum 1,810 inch-pounds, minimum 1,400 inch-pounds, as contrasted with the much smaller differences $(1,580$ to 1,670$)$ found for the regular nuts is probably due to two causes; differences in the coefficient of friction and differences in the effective bearing radius of the washer on the nut. The two largest values are 1,810 inch-pounds for device $\mathrm{FF}$, which has knurled bearing faces, and 1,800 inch-pounds for device $\mathrm{CC}$, which has the largest outside radius of any of the spring washers.

Except for devices EE, FF, and GG, the difference between screwingon and initial screwing-off torque at $20,000 \mathrm{lb}$. per sq. in., is considerably greater than the theoretical difference $0.0141 \mathrm{~S}=282$ inch-pounds, the maximum being 470 inch-pounds for device II.

This is in marked contrast to the smaller values found for the regular nuts.

The only reasonable explanation seems to be a change in the effective bearing radius of the washer between screwing-on and screwingoff. A decrease of 0.2 in. would account for the discrepancy for II.

The faces of the bearing washers (EE and FF, fig. 75, and JJ, fig. 76) show after test that the radius of the scores made in screwing off were in several cases at least 0.2 inch less than those made in screwing on.

As can be seen from Figures 74 to 76 , all of the spring washers scored the bearing surface of the nut and the bearing washer.

In continuous screwing off the unscrewing stress at first decreased until the nut was sufficiently loosened to allow the edge of the spring washer to cut into the face of the nut and the bearing washer. The device II was the only exception to this. Its edges cut into the nut immediately, when the nut was unscrewed, so that the continuous unscrewing torque increased slightly over the initial value before decreasing. The cutting of the nut and the bearing washer increased the frictional resistance, causing the screwing-off torques in all cases finally to exceed the screwing-on torques for the same stress. In many cases the torque actually increased at times and then decreased suddenly, sometimes two or three times in succession. These irregularities were probably caused by breaking of the chip in the face of the nut. As the size of the chip increased, the torque increased. When the chip broke the torque decreased suddenly.

In Figures 77,78, and 79 and in Table 6, from which they are plotted, it must be remembered that for devices $I, I I$, and $I I I$ (regular nuts) in which the individual specimens gave more uniform results than 


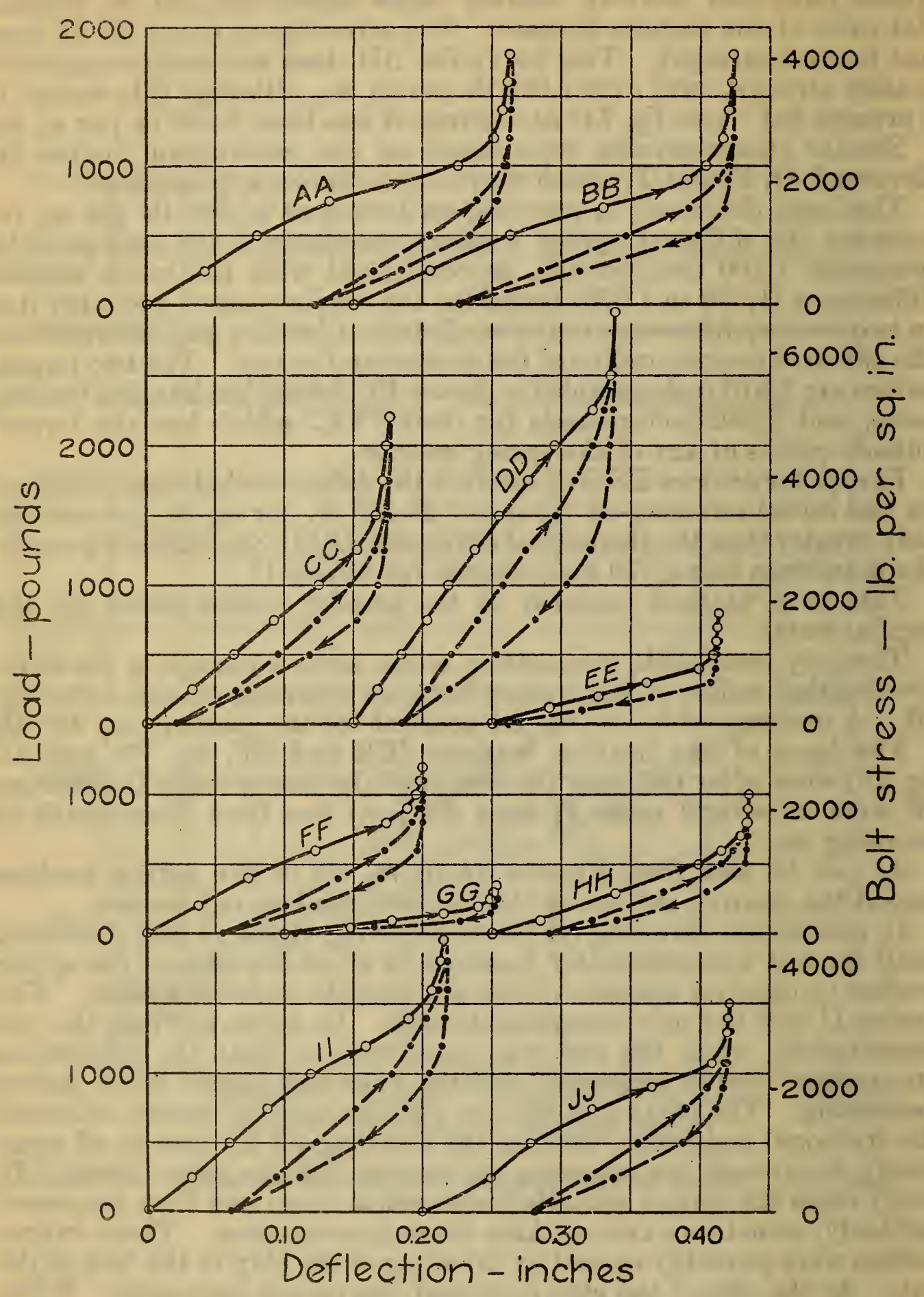

Figure 73.-Load-defleciion curves for devices $A A$ to JJ, spring washers 


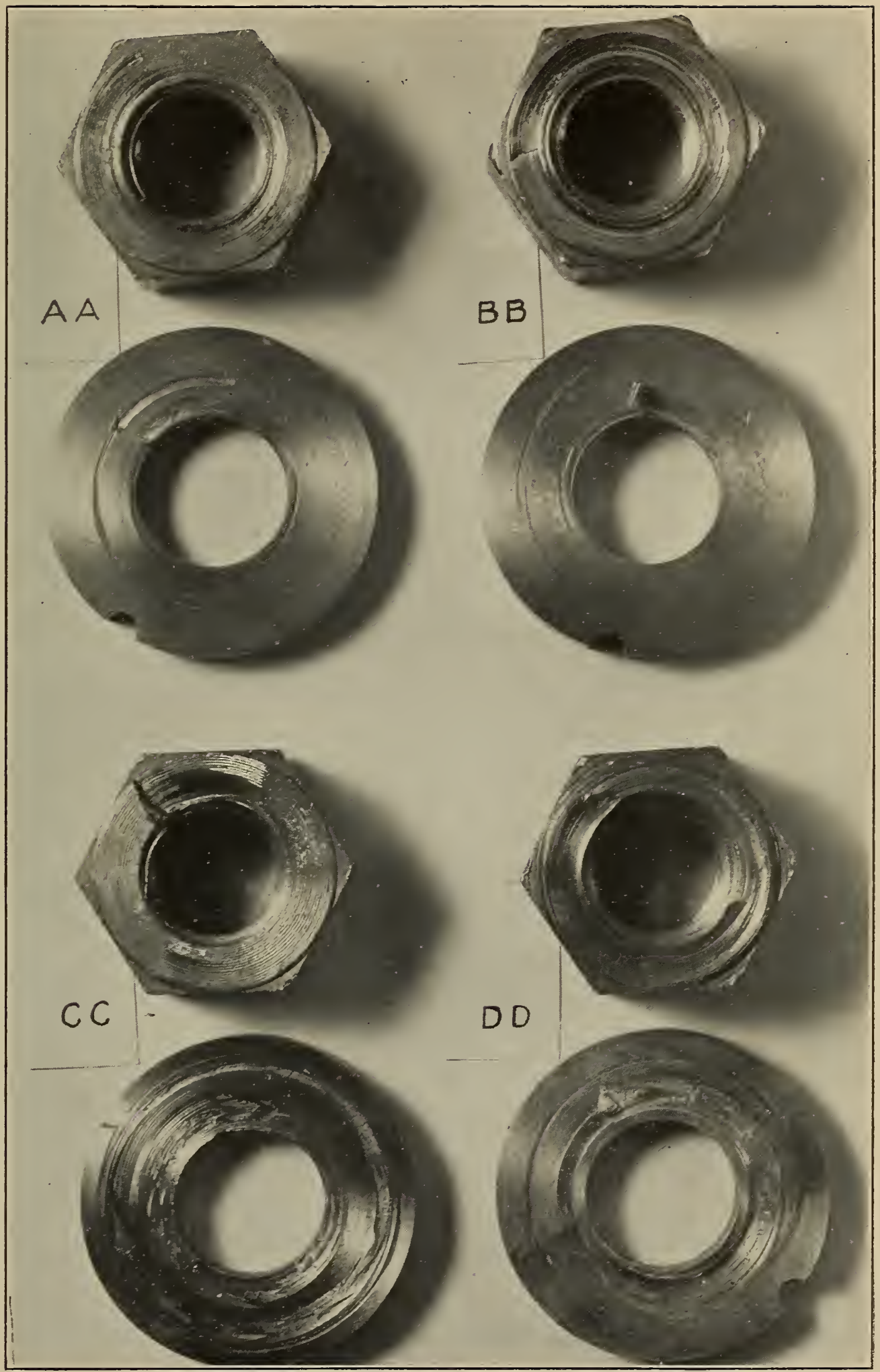

FIGURE 74.-Bearing washers and regular nuts after test for devices $A A$ to $D D$ spring washers 


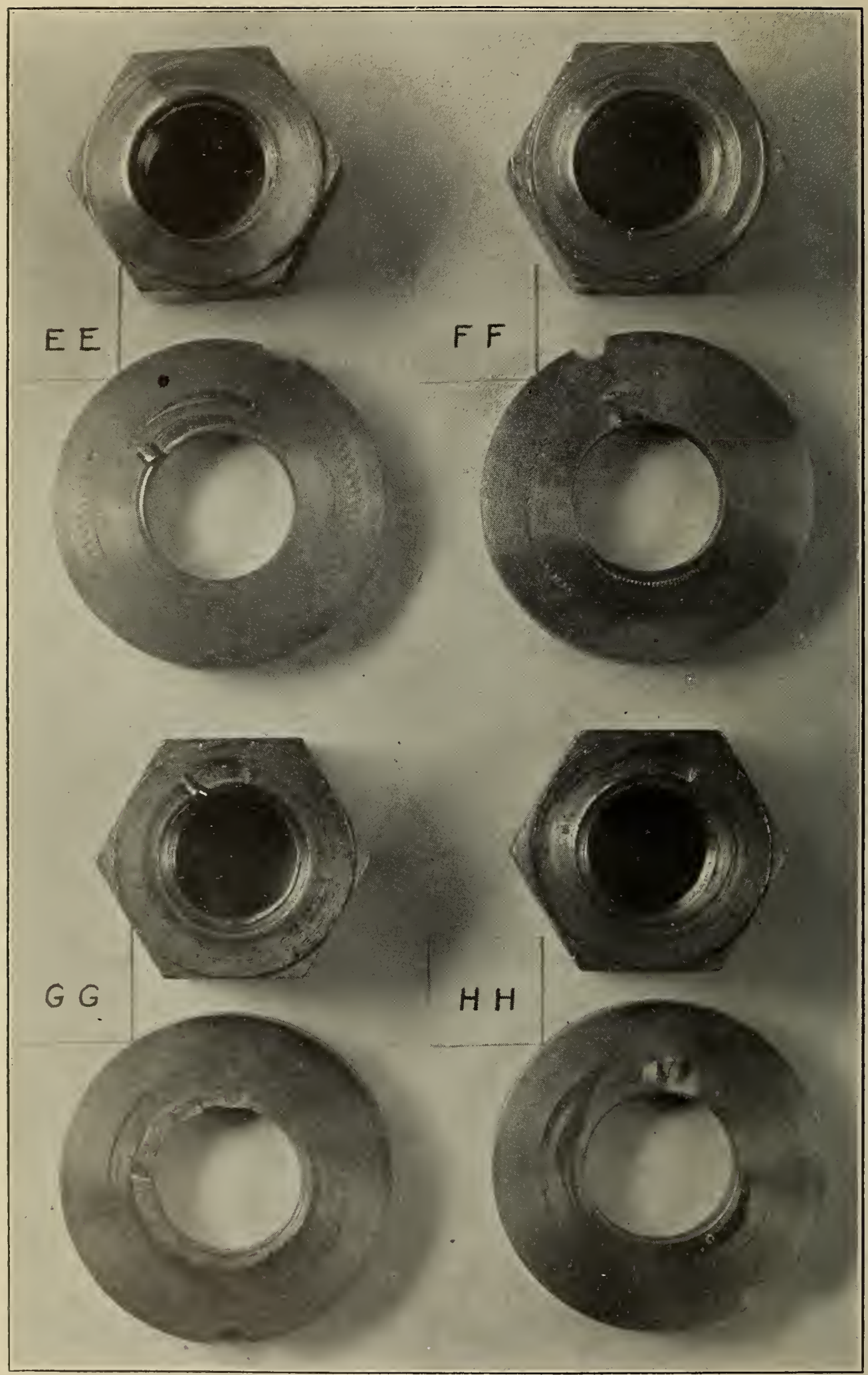

FIGURE 75.-Bearing washers and regular nuts after test for devices $E E$ to HH spring washers 
B. S. Journal of Research, RP386

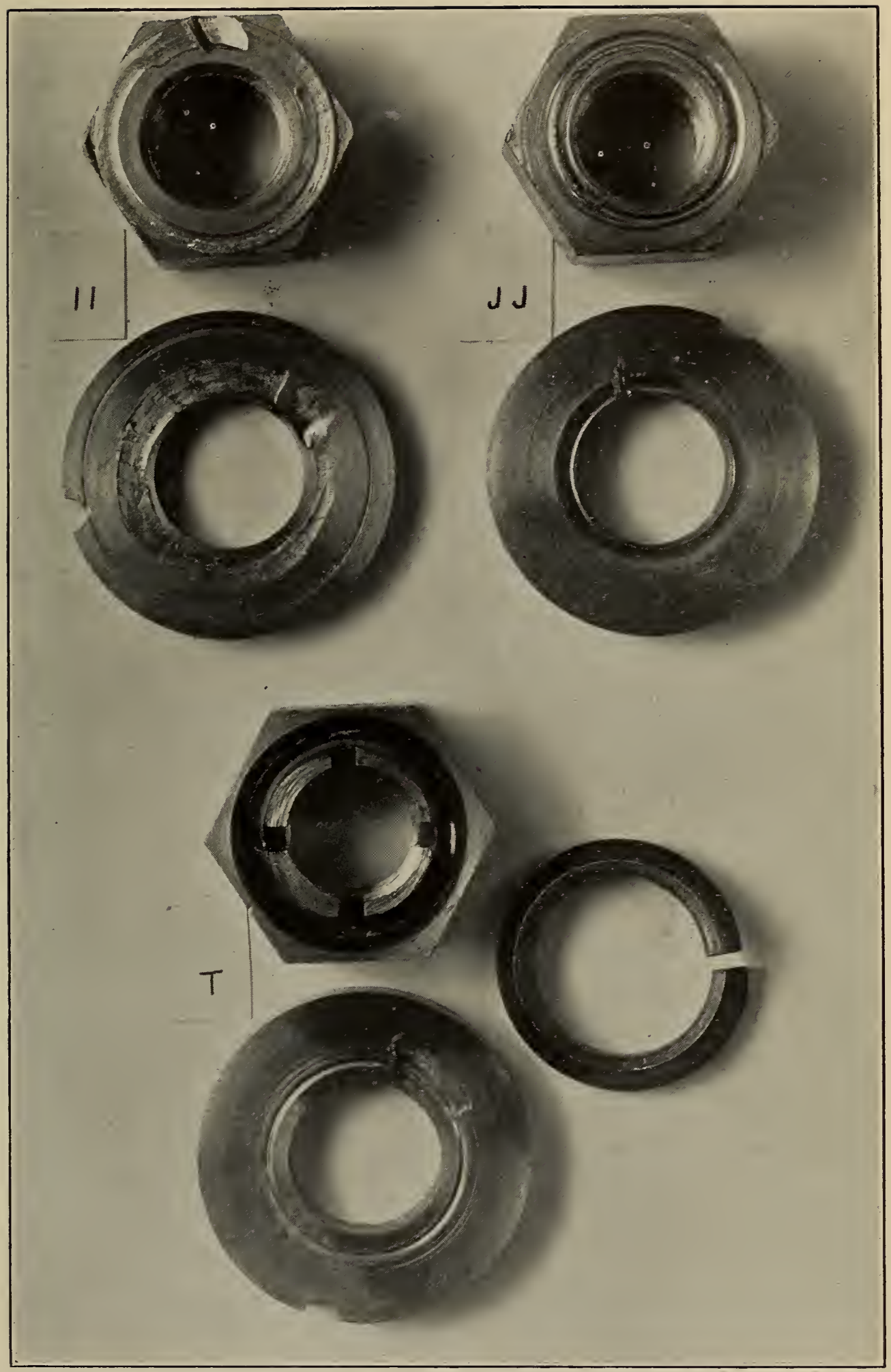

FIGURE 76.-Bearing washers and regular nuts after test for devices II and JJ spring washers; also bearing washer and nut for device $T$ 
for practically all the other devices, differences of over 6 per cent in torques were found between individual specimens and the mean of a group, and also between groups of nominally identical specimens under identical test conditions. Conclusions based upon differences of plus or minus 6 per cent or less are therefore not warranted. A retest of any one of the devices might place it in order above or below all of the devices whose initial unlocking torque did not differ from its value by more than 6 per cent in the present series of tests, at the stresses chosen for comparison. In addition, in many cases the initial screwing-off torques at 10,000 lb. per sq. in. are read from extrapolated curves. It is doubtful whether or not these values can be relied upon to within 10 per cent.

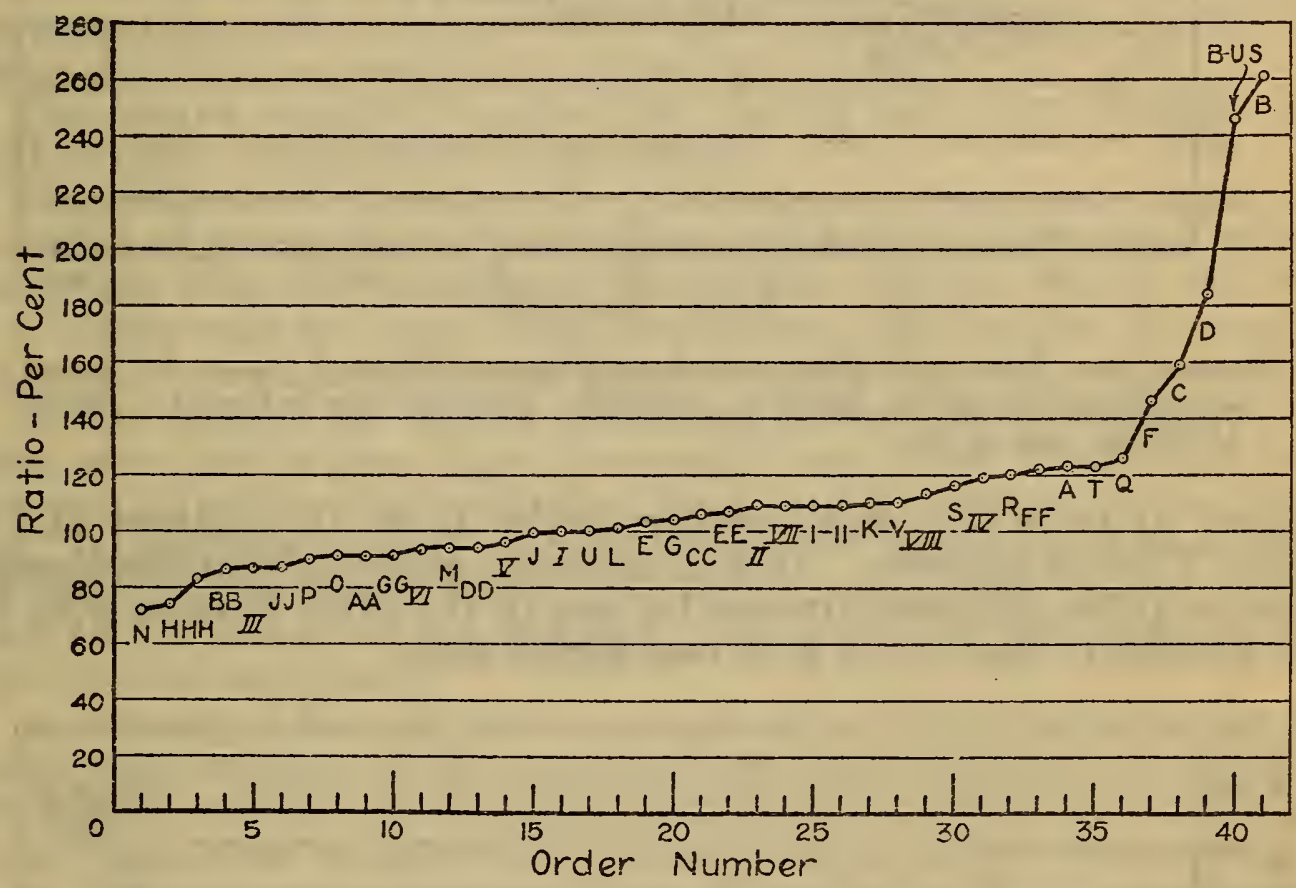

FIgURe 77.-Ratio of initial screwing-off torque for each device to initial screwing-off torque for device I, American National coarse thread. Stress 10,000 lb. per sq. in.

The curves of Figures 77, 78, and 79, may each be divided into two portions, the first portion containing the first 35 specimens in order and the second the last six specimens, B, B-U. S., C, D, F, and $Q$. The first portion in each case slopes upward, roughly following a straight line; for Figure 77, approximately 6 per cent for every five numbers; and for Figures 78 and 79, approximately 6 per cent for every seven numbers. A change of plus or minus 6 per cent in initial screwing-off torque for any device might shift it over a range of 10 to 14 numbers on this portion of the curves. That these ranges are rather too small than too large is shown by a comparison of the order numbers of devices $I V$ and $V$ at the three different stresses. These are both regular nuts with jam nuts, differing only in that one nut is slightly larger across the flats. Device $I V$ shifts from order number 31 to 19 , a decrease of 12 numbers, as the stress increases from 10,000 to $20,000 \mathrm{lb}$. per sq. in., while device $V$ shifts 
in order number from 14 to 29 , an increase of 15 numbers. Comparison of the order numbers of the different devices at the three different stresses shows that only two devices change their order

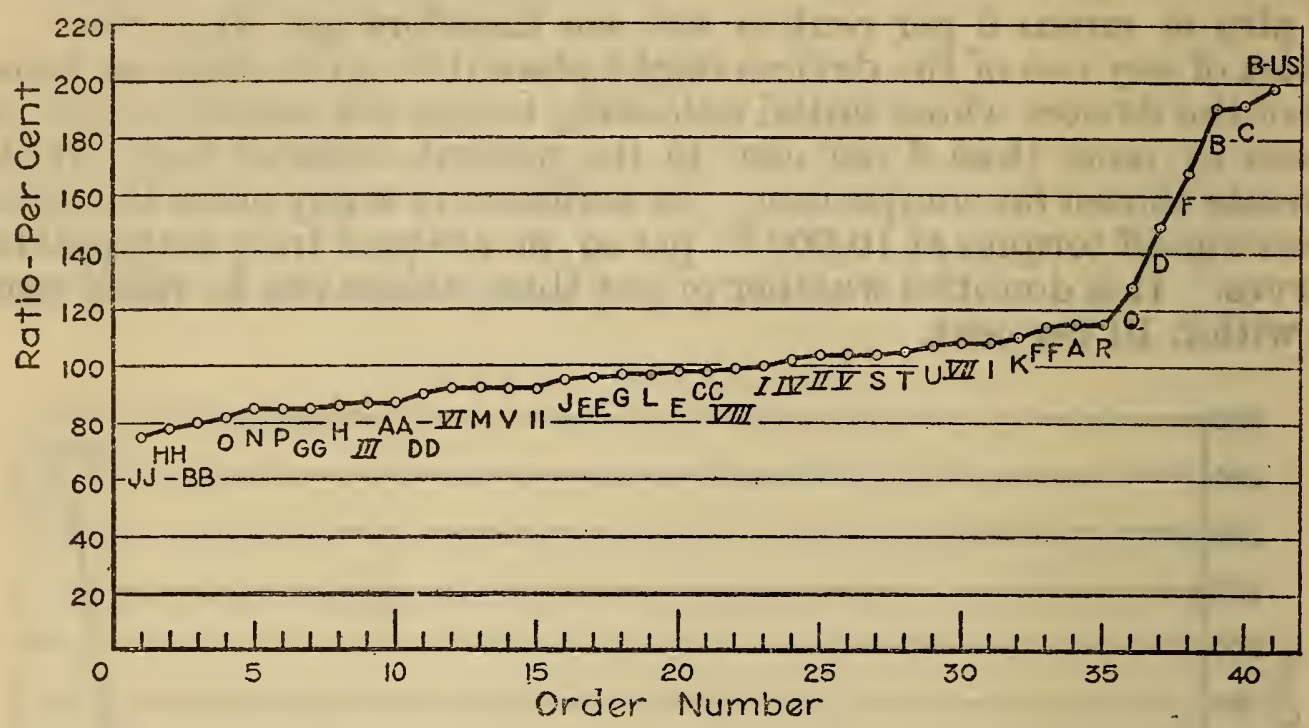

FIGURE 78.-Ratio of initial screwing-off torque for each device to initial screwing-off torque for device I, American National coarse thread. Stress 15,000 lb. per sq. in.

number by more than this amount; device II by 16 numbers and a device $\mathrm{V}$ by 20 numbers. It does not seem probable that the change of order at the different stresses for any of the other devices lying in this portion of the curves is of real significance.

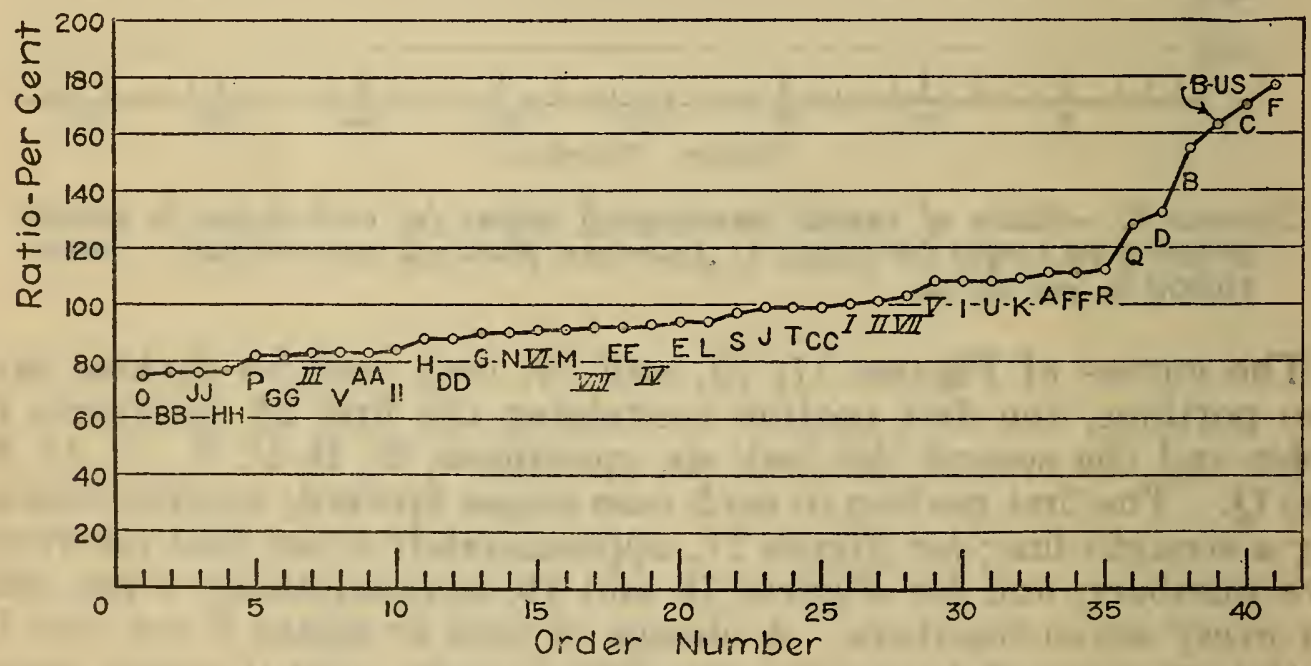

FIGURE 79.-Ratio of initial screwing-off torque for each device to initial screwing-off torque for device I, American National coarse thread. Stress 20,000 lb. per sq. in.

The five devices in the second portion of the curve show at all these stresses initial screwing-off torques over 25 per cent greater than the device $I$, American National coarse-thread regular nut. 


\section{CONCLUSIONS}

Tests were made on 41 devices, including regular nuts (American National coarse thread, American National fine thread, and U. S. standard) and commercial devices for preventing rotation of the nut on the bolt in service to determine the relation between static tensile stress in the bolt (diameter $3 / 4 \mathrm{in}$.) and the torque required to screw the nut on and to screw it off the bolt. The results lead to the following conclusions:

1. American National and U. S. standard nuts. The tests were in general agreement with Persy's theory. The torque required to screw on the nut was proportional to the stress in the bolt.

The torque required to screw on nominally identical nuts differed by more than plus or minus 6 per cent from the mean. Larger differences should be expected in engineering practice.

The torque required to screw the nut off was more irregular but still roughly proportional to the stress.

The differences between the screwing-on torque and the initial screwing-off torque were considerably less than the theoretical values, indicating that the condition of the surfaces changed during the test.

2. There was no great difference between the torques for regular nuts with jam nuts and the torques for regular nuts without jam nuts.

3 . The torques for slotted and castellated regular nuts with cotter pins were greater than those for regular nuts after the nut had been screwed off sufficiently to develop the shearing resistance of the cotter pin. Unless the pin was a snug fit in the slot, however, the screwingoff torque never exceeded the initial value, because the shearing resistance of the cotter pin was low and the stress in the bolt decreased as the nut was unscrewed.

4. For only a few (B, B-U. S., C, D, F, and Q) of the devices for preventing rotation of the nut in service were the initial screwing-off torques for stresses above $10,000 \mathrm{lb}$. per sq. in. much greater $(25$ per cent) than those for American National coarse-thread regular nuts.

5. For only one of these devices, F, were the initial screwing-off torques higher than the screwing-on torques.

6 . For all the other devices the ratio of the initial screwing-off torques to the initial screwing-off torques for American National coarse-thread regular nuts was distributed approximately uniformly between 72 per cent and 123 per cent at 10,000 , between 75 per cent and 115 per cent at 15,000 , and between 75 per cent and 112 per cent at $20,000 \mathrm{lb}$. per sq. in. stress in the bolt. The differences between individual specimens of any device were so large that it was possible to make only a rough arrangement of these devices in order, according to their initial unlocking torques.

Except for device V (and possibly II) there was no significant difference in their order of arrangement at the different stresses $(10,000,15,000$, and $20,000 \mathrm{lb}$. per sq. in.).

7. When screwing off was continued, several of the devices, VII and VIII, slotted and castellated nuts with cotter pins, B, B--U. S., C, D, F, Q, T, and CC, EE, and II, spring washers, maintained, over a range of stress, torques relatively much higher than regular nuts.

8. When screwing off was continued to zero stress, over half of the devices required an appreciable torque to rotate the nut when the stress in the bolt was zero, and several devices, C, D, F, I, K, P, Q, S, 
$\mathrm{V}$, and $\mathrm{AA}$ and II (spring washers), consistently required a relatively higher torque to rotate the nut.

9. All of the spring or lock washers roughened the bearing surface and the face of the nut. After closing flat they were all permanently deformed. As the nut was screwed off, the torques were at first about the same as those for regular nuts. When the nut had rotated sufficiently for the ends of the washer to cut in to the surfaces and offer considerable resistance to rotation, the stress in the bolt had, for many of the spring washers, been reduced to a low value.

Washington, September 30, 1931. 